\author{
Universidade de São Paulo \\ Instituto de Física
}

\title{
Estudo espectral das instabilidades MHD no tokamak TCABR
}

\author{
Victor Cominato Theodoro
}

Orientador: Prof. Dr. José Helder F. Severo

Dissertação de mestrado apresentada ao Instituto de Física para a obtenção do título de Mestre em Ciências

\section{Banca Examinadora:}

Prof. Dr. José Helder F. Severo (Orientador - IFUSP)

Prof. Dr. Zwinglio de O. Guimarães Filho (IFUSP)

Prof. Dr. Munemasa Machida (UNICAMP)

São Paulo 
FICHA CATALOGRÁFICA

Preparada pelo Serviço de Biblioteca e Informação do Instituto de Física da Universidade de São Paulo

Theodoro, Victor Cominato

Estudo espectral das instabilidades MHD no tokamak TCABR. São Paulo, 2013.

Dissertação (Mestrado) - Universidade de São Paulo.

Instituto de Física, Depto. de Física Aplicado

Orientador: Prof. Dr. José Helder Facundo Severo

Área de Concentração: Física de plasmas

Unitermos: 1.Física de plasmas; 2.Tokamaks;

3.Magnetohidrodinâmica; 4.Instabilidades MHD; 5.Bolometria.

USP/IF/SBI-086/2013 


\section{Agradecimentos}

Gostaria de agradecer ao professor Dr. José Helder Facundo Severo pela oportunidade de estudar e desenvolver este trabalho amparado por sua orientação, amizade e dedicação por todos esses anos.

Agradeço ao professor Dr. Zwinglio de Oliveira Guimarães Filho pelo auxílio e por todas as sujestões que colaboraram expressivamente pela qualidade da pesquisa desenvolvida.

Expresso meus especiais agradecimentos ao professor Dr. Valdemar Bellintani Jr. e a Társis Mendes Germano, que deram início e durante todo o tempo prestaram auxílio para tornar possível a implementação deste projeto.

Agradeço a todos os professores e técnicos que trabalham no Laboratório de Física de Plasmas que, de uma forma ou de outra, ajudaram na confecção de equipamentos ou na compreensão de conceitos relacionados a este trabalho.

Quero agradecer também às secretárias do Departamento de Física Aplicada, Sra. Maria Mavilia Vara e Sra. Ellen Pedroso e do Laboratório, Sra. Eleonora Lo Duca.

Agradeço também a todos os colegas que caminharam durante todos esses anos ao meu lado e sempre ajudaram a compreender novas ideias e desenvolver novos pensamentos.

Não poderia deixar de fazer um agradecimento especial para toda a minha família, por toda a paciência, compreensão e amor que tiveram para comigo durante o tempo em que mais precisei em toda minha vida. Agradeço também à Juliana Meale, por ter me apoiado não apenas durante o desenvolvimento deste trabalho mas em todo o tempo em que estivemos juntos.

Gostaria de deixar meus agradecimentos à FAPESP, pelo apoio financeiro que tornou possível o desenvolvimento deste projeto.

Por fim, expresso minha eterna gratidão à Santa Sabedoria que, através da cautelosa partilha dos dons, possibilitou a alegria e a honra da realização deste trabalho. 


\section{Resumo}

Neste trabalho foram estudadas instabilidades magnetohidrodinâmicas (MHD) utilizando um novo sistema bolométrico que foi instalado no tokamak TCABR para medidas da evolução temporal da potência irradiada. Este novo sistema conta com 24 cordas verticais, capazes de mapear toda uma seção poloidal da coluna de plasma com resolução espacial de aproximadamente $2 \mathrm{~cm}$ e uma resolução temporal de $20 \mu s$.

Como se sabe, as instabilidades MHD degradam o confinamento do plasma e modificam a topologia das superfícies magnéticas, causando a perda da energia do plasma. Por conta disso, compreender essas instabilidades é fundamental para o sucesso dos futuros reatores de fusão nuclear.

As perturbações (oscilações) causadas pelas instabilidades MHD modulam diversos parâmetros macroscópicos do plasma como a densidade, a temperatura e a potência irradiada. Então, utilizando o diagnóstico bolométrico, é possível medir as oscilações no perfil de potência irradiada e, a partir deles, extrair informações importantes para determinar a origem e as características de tais instabilidades.

No tokamak TCABR, as instabilidades foram caracterizadas através da análise espectral dos 24 sinais provenientes do novo sistema bolométrico. Para auxiliar a caracterização das instabilidades, um programa foi desenvolvido em Matlab para simular as medidas das perturbações no perfil de potência irradiada. Através do mesmo procedimento de análise espectral, os resultados simulados foram comparados aos experimentais de forma que os parâmetros simulados, como largura e posição das ilhas magnéticas, fossem ajustados aos experimentais.

Através dessa metodologia de análise, que combina simulação e experimento, foi possível caracterizar diversas instabilidades como o precursor dos dentes de serra e ilhas magnéticas de modos $m=2$ e $m=3$. 


\section{Abstract}

In this dissertation, magnetohydrodynamic (MHD) instabilities were investigated using a new bolometric system that was installed in the TCABR tokamak for radiation power measurements. This diagnostic is composed by 24 vertical chords that provide a full view of the poloidal cross section of the plasma column and provides spatial and temporal profiles with approximately $2 \mathrm{~cm}$ space and $20 \mu \mathrm{s}$ time resolution.

As it is well known, the MHD instabilities degrade the plasma confinement and modify the magnetic topology, leading to energy loss from the plasma. Therefore, the understanding of these instabilities is essential for the success of the controlled thermonuclear fusion reactors.

The MHD instabilities also cause perturbations (oscillations) in various macroscopic parameters, such as plasma density, temperature, and radiated power. Therefore, the oscillations in the radiated power profile measured by the bolometric diagnostic system provide a possibility to investigate the origin and features of the instabilities.

In the TCABR tokamak, the instabilities were characterized by spectral analysis of the 24 vertical chords of the bolometric signals. In addition, a Matlab program was developed to simulate the integral characteristic of the oscillations in the radiated power measured by the bolometric system. The spectral analysis of the simulated signals is then compared with the spectral analysis of the bolometric signals. The simulated parameters, island width and radial position, were then adjusted to fit the experimental spectrum results.

Using this method of analysis, which combines experiment and simulation, it was possible to characterize various instabilities, such as sawtooth precursor and $m=2$ and $m=3$ magnetic islands. 


\section{Sumário}

Agradecimentos $\quad$ iii

Resumo $\quad$ v

Abstract vii

1 Introdução 1

1.1 O conceito de tokamak e o TCABR . . . . . . . . . . . . . . . . 4

1.2 Instabilidades e ilhas magnéticas . . . . . . . . . . . . . . . . . . . 6

2 Modelo magnetohidrodinâmico $\quad 11$

2.1 Fator de segurança . . . . . . . . . . . . . . . . . . . 11

2.2 Ilhas magnéticas . . . . . . . . . . . . . . . . . . . . . . 13

2.2.1 Descrição clássica das ilhas magnéticas . . . . . . . . . . . . . 13

2.2.2 Determinação da dimensão da ilha magnética . . . . . . . . . . . 16

2.3 Instabilidades dentes de serra . . . . . . . . . . . . . . . . . . . 19

2.3.1 Modelo de Kadomtsev . . . . . . . . . . . . . . . . . . . . . . . . 20

3 Arranjo experimental $\quad 25$

3.1 Bolômetro resistivo . . . . . . . . . . . . . . . . . . . . 26

3.2 Fotodiodo . . . . . . . . . . . . . . . . . . . . . . . . 29

3.3 Comparação entre os detectores . . . . . . . . . . . . . . . . . . . . . 33

3.4 Câmara bolométrica . . . . . . . . . . . . . . . . . . 35

3.5 Amplificadores e sistema de aquisição . . . . . . . . . . . . . . . . . . . 40

4 Simulação e método de análise $\quad 43$

4.1 Simulação das medidas bolométricas . . . . . . . . . . . . . . . . 43

4.1 .1 Perturbação gaussiana . . . . . . . . . . . . . . . . . . . 45

4.1 .2 Perturbação gaussiana dupla . . . . . . . . . . . . . . . . 47

4.2 Metodologia de análise . . . . . . . . . . . . . . . . . . 51

$5 \quad$ Análise e resultados $\quad 57$

5.1 Instabilidades dentes de serra $\ldots \ldots \ldots$. . . . . . . . . . . . . 59

5.2 Caracterização do precursor dos dentes de serra . . . . . . . . . . . 66

5.3 Caracterização de ilhas magnéticas . . . . . . . . . . . . . . . . . 69 
6 Conclusões $\quad 81$

6.1 Perspectivas e propostas futuras . . . . . . . . . . . . . 83

$\begin{array}{lll}\text { Apêndice A Sistema de coordenadas cilíndricas } & 87\end{array}$

$\begin{array}{lll}\text { Apêndice B Radiometria } & 89\end{array}$

B.1 Definições básicas . . . . . . . . . . . . . . . . . . . . . . . . . 89

B.2 Transferência de potência radiânte . . . . . . . . . . . . . . 91

B.3 Correção geométrica para o bolômetro . . . . . . . . . . . . . . 95

$\begin{array}{ll}\text { Referências Bibliográficas } & 99\end{array}$ 


\section{Introdução}

A energia desempenha um importante papel no processo de desenvolvimento da civilização humana, sendo hoje uma componente vital para sustentar os países industrializados, bem como para manter o processo de industrialização de nações menos desenvolvidas. O consumo de energia de uma nação reflete a atividade industrial, que está diretamente relacionado com a produção de alimentos, de bens de consumo, com o transporte e com outras atividades inseridas no escopo social e econômico da população.

Além da alta demanda de energia das áreas mais desenvolvidas, o crescente processo de industrialização do planeta promove gradualmente o esgotamento das fontes naturais de energia, ao passo que, manter o atual processo de industrialização dos países emergentes de maneira sustentável torna-se uma tarefa cada vez mais difícil.

Um dos fatores que impedem o desenvolvimento sustentável é a atual dependência das fontes fósseis de energia, como o carvão e o petróleo, que ao serem utilizados em usinas termoelétricas para produção de energia, lançam na atmosfera componentes tóxicos que afetam diretamente a saúde e ameaçam o clima global. Além disso, a própria exploração desses combustíveis causa a degradação do ambiente, se não for feita da maneira adequada.

Como mostra a figura (1.1), os combustíveis fósseis representam mais de $60 \%$ das fontes de energia do planeta. As previsões e discussões recentes sobre sustentabilidade levaram ao incentivo e criação de projetos que visam manter o desenvolvimento mundial sem comprometer o futuro das próximas gerações [1].

Atualmente muito esforço está sendo empregado em tecnologias que viabilizem a utilização das fontes energéticas renováveis, como a eólica e a solar. Entretanto, atualmente essas fontes não possuem o potencial necessário para abastecer nem um terço da necessidade mundial, o que inviabilizaria sua utilização em larga escala nos setores industriais [2].

A geração de energia por hidroelétrica também possui limitações, já que a construção de usinas está limitada a presença de rios com potencial de produção. Além disso, na maior parte dos casos, a produção de uma pequena parcela de energia não poderia repor os danos causados à sociedade e ao ambiente pela construção de barragens e pelo o represamento da água [3]. 


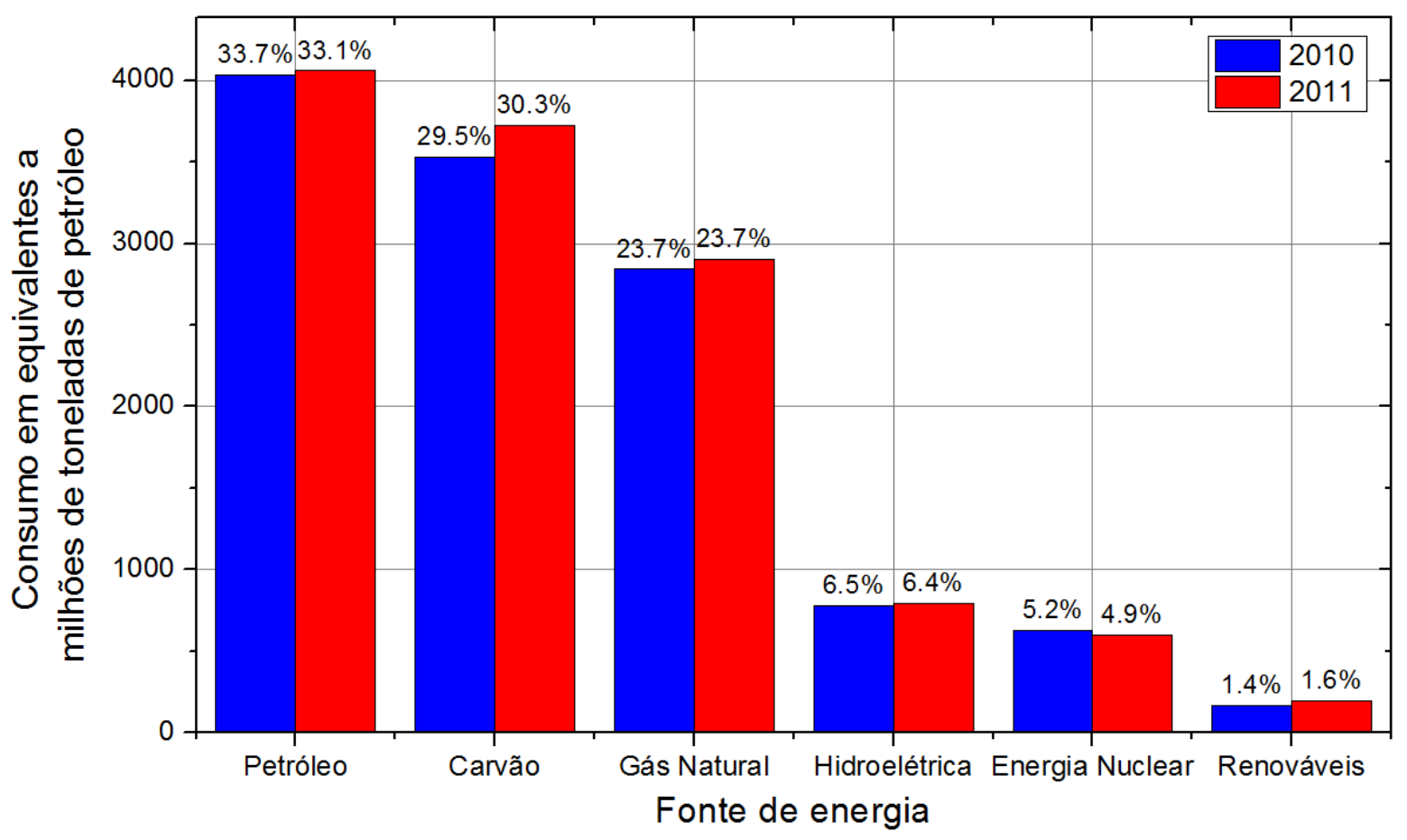

Figura 1.1: Principais fontes de energia primária em anos recentes. Os valores absolutos são dados em milhões de toneladas, para o petróleo e equivalentes de milhões de toneladas de petróleo para os outros. Os valores percentuais indicados são relativos ao total consumido naquele ano [4].

Neste sentido, a utilização da energia nuclear surge como uma alternativa para essa transição das fontes energéticas do planeta. A energia nuclear pode ser obtida através de dois processos: a fissão e a fusão.

Fissão nuclear corresponde à fragmentação de um núcleo pesado, normalmente de plutônio ou urânio, em núcleos mais leves (figura (1.2a)). Esse processo é acompanhado da liberação de uma elevada quantidade de energia que pode ser utilizada para gerar energia elétrica.

O elevado custo dos combustíveis da fissão nuclear, assim como a construção e manutenção das próprias instalações reduzem a atratividade desta fonte de energia quando comparada com as produzidas por combustíveis fósseis. Deve-se considerar ainda que existe muita resistência da sociedade e de grupos ambientalistas quanto a esse tipo de energia, tendo em vista os problemas da eliminação e estocagem dos subprodutos radioativos da reação e da má impressão causada por acidentes em reatores de fissão, como de Chernobyl, em 1986 e, mais recentemente, o ocorrido em Fukushima, em 2011 [5].

A fusão nuclear consiste na reação onde dois núcleos atômicos leves se combinam, formando núcleos mais pesados e, como ocorre na fissão, esse processo é acompanhado liberação de uma grande quantidade de energia (figura (1.2b)). Esse é o tipo de reação 
que dá origem à energia das estrelas.

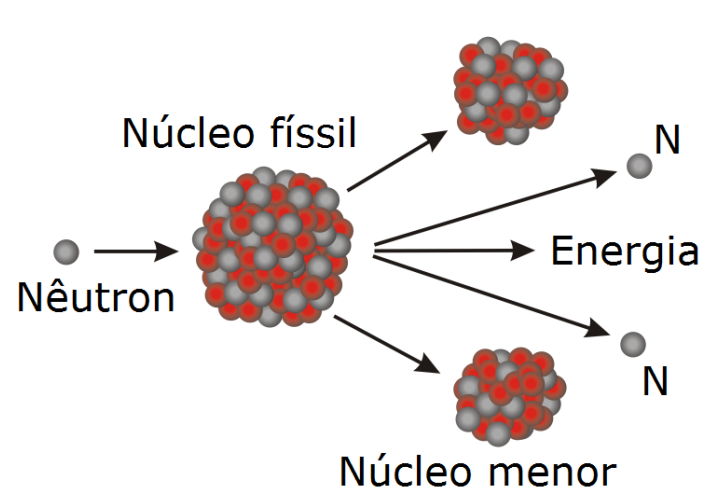

(a)

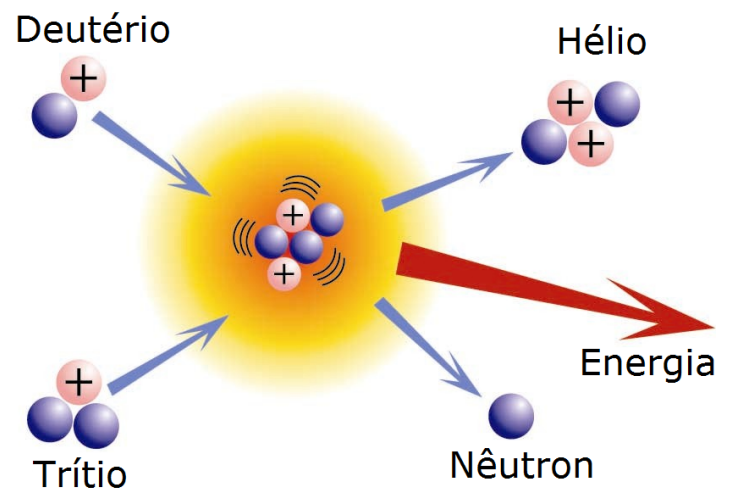

(b)

Figura 1.2: Em (a), está representado a reação de fissão nuclear de um elementos pela colisão com um nêutron de alta energia, em (b), é mostrado a reação de fusão nuclear dos elementos de deutério e trítio.

A reação de fusão apresenta um gigantesco potencial energético: uma reação de fusão libera quase quatro milhões de vez a energia liberada na reação química da queima de combustíveis fósseis. Enquanto que uma usina de carvão utiliza 2, 7 milhões de toneladas de carvão para produzir o equivalente a $1 G W . h$ em energia elétrica, um reator de fusão utilizaria apenas $250 \mathrm{~kg}$ de combustível [6].

O combustível da fusão é uma mistura de deutério e trítio [7]. O custo da extração e produção desses elementos é muito mais baixo que o custo do combustível da fissão nuclear, por exemplo.

A energia produzida pela fusão pode ser calculada através da diferença de massa $\Delta m$ entre os reagentes e os produtos da fusão nuclear. As principais reações de fusão nuclear são [8]:

$$
\begin{aligned}
\mathrm{D}+\mathrm{D} & \longrightarrow \mathrm{T}(1.01 \mathrm{MeV})+\mathrm{p}(3.03 \mathrm{MeV}) \\
\mathrm{D}+\mathrm{D} & \longrightarrow \mathrm{He}^{3}(0.82 \mathrm{MeV})+\mathrm{n}(2.45 \mathrm{MeV}) \\
\mathrm{D}+\mathrm{T} & \longrightarrow \mathrm{He}^{4}(3.52 \mathrm{MeV})+\mathrm{n}(14.06 \mathrm{MeV}) \\
\mathrm{D}+\mathrm{He}^{4} & \longrightarrow \mathrm{He}^{4}(3.67 \mathrm{MeV})+\mathrm{n}(14.67 \mathrm{MeV})
\end{aligned}
$$

Sendo que a reação de maior seção de choque é a que envolve $D+T$. Destas reações é possível notar que o único produto da reação de fusão é o hélio, um gás inerte que não apresenta riscos como o lixo produzido pelas usinas de fissão. Como os riscos de conta- 
minação radioativa, no caso de um acidente em uma usina de fusão, são extremamente baixos, o impacto ambiental desta fonte de energia é muito pequeno.

Para que a fusão nuclear ocorra, duas condições devem ser atingidas simultaneamente. A primeira delas diz respeito ao produto da densidade do plasma pelo tempo de confinamento da energia $\left(n_{e} t_{E}\right)$. Este produto deve ser de aproximadamente $3 \times 10^{14} \mathrm{~cm}^{-3} \mathrm{~s}$. A segunda condição para atingir a fusão é que a temperatura $T$ do plasma confinado magneticamente deve atingir a marca de $10 \mathrm{keV}$.

É possível condensar essas duas condições em um único critério, denominado critério de Lawson: $n_{e} T t_{E}>3 \times 10^{21} \mathrm{~m}^{-3} \mathrm{keVs}^{-1}[9]$.

Nas últimas décadas, o conceito de confinamento magnético de plasmas de fusões passou a ser estudado e diversos dispositivos foram desenvolvidos para atingir a tão sonhada fusão termonuclear controlada. As melhores propostas para futuras máquinas de fusão são o tokamak e o stellarator, sendo que o tokamak concentra hoje a maior parte dos esforços e investimentos em pesquisas.

Atualmente encontra-se em construção mediante grande esforço internacional um grande tokamak experimental denominado ITER (International Thermonuclear Experimental Reactor), cujo principal objetivo é demonstrar a viabilidade tecnológica de uma máquisa de fusão nuclear controlada [6].

Entretanto ainda existem muitas dificuldades a serem superadas quanto à fusão termonuclear controlada, principalmente no que diz respeito à eficiência e à qualidade do confinamento. Todos esses tópicos são estudados em diversos centros de pesquisas do mundo, proporcionando uma compreensão cada vez maior da física de plasmas e o aperfeiçoamento das tecnologias de modo que possibilitem a utilização da fusão nuclear como uma fonte de energia limpa para as futuras gerações.

\subsection{O conceito de tokamak e o TCABR}

Em um tokamak o plasma é formado em uma câmara de vácuo toroidal. Nesta câmara são injetados os gases que serão ionizados através de processos de ruptura dielétrica. O principio básico do confinamento magnético é a aplicação de um alto campo magnético toroidal $B_{\phi}$ na região da câmara de vácuo, induzido por um conjunto de bobinas externas à câmara.

O movimento de partículas ionizadas, quando submetidos a esse campo magnético, é irrestrito na direção paralela às linhas de campo, enquanto que qualquer movimento 
perpendicular resulta em um movimento circular ao redor das linhas de campo. Esse movimento circular é chamado de movimento ciclotrônico e possui frequência de rotação $\omega_{c}=e B / m$, chamada de frequência ciclotrônica e raio $\rho_{L}=v_{\perp} / \omega_{c}$, denominado raio de Larmor.

Com base nisso, o campo $B_{\phi}$ deve restringir o movimento das partículas a um toroide dentro da câmara de vácuo. Por efeito de indução eletromagnética é possível induzir uma corrente elétrica no gás, fazendo com que o plasma aqueça, além de dar origem a um campo magnético poloidal $B_{\theta}$, fundamental para manter a estabilidade da coluna de plasma.

Outro campo magnético importante neste sistema é o campo vertical $B_{V}$, que anula a expansão da coluna de plasma [10].

O TCABR é um tokamak de pequeno porte e alta razão de aspecto. Foi contruído no CRPP (Centre de Recherches em Physique des Plasmas) da École Polytecnique Fédérale de Lausanne Suisse, onde se chamava TCA (Tokamak Chauffage Alfvén) e era utilizado em pesquisas de aquecimento do plasma por ondas de Alfvén. Posteriormente esse tokamak foi trazido para o Instituto de Física da USP, onde realizou seu primeiro disparo em 1999 [11] sendo então rebatizado por TCABR. A figura (1.3) mostra a configuração dos principais dispositivos deste tokamak.

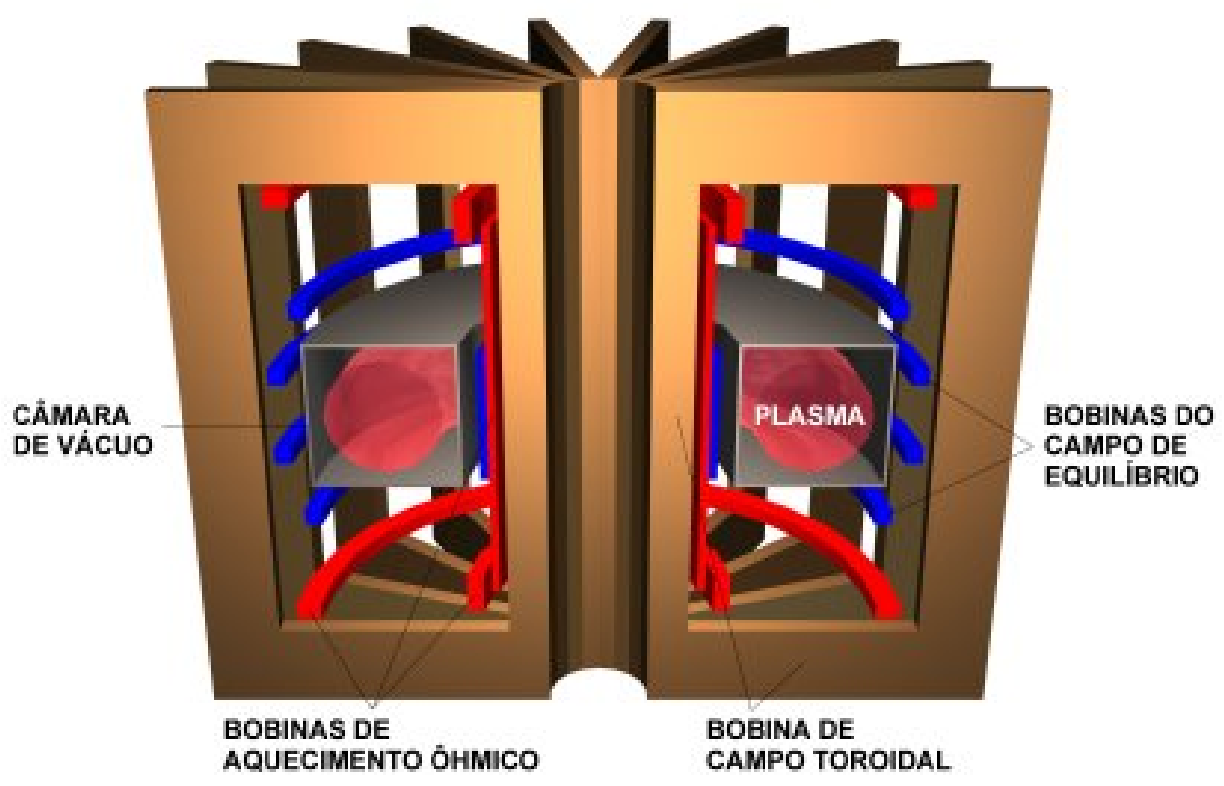

Figura 1.3: Esquema do tokamak TCABR [12].

Tokamaks como o TCABR são utilizados para pesquisar melhorias no confinamento, 
no aquecimento e no desenvolvimento de diagnósticos para que seja possível e viável a produção de energia em reatores de fusão. Os principais parâmetros do TCABR estão apresentados na tabela (1.1).

\begin{tabular}{|c|c|}
\hline Parâmetro & Valor \\
\hline \hline Raio maior $(R)$ & $615 \mathrm{~mm}$ \\
\hline Raio menor $(a)$ & $180 \mathrm{~mm}$ \\
\hline Campo magnético toroidal $\left(B_{\phi}\right)$ & $(\sim 1,1) \mathrm{T}$ \\
\hline Corrente de plasma $\left(I_{P}\right)$ & $(\sim 100) k A$ \\
\hline Densidade eletrônica $\left(n_{e}\right)$ & $(1,0 \sim 2,4) \times 10^{-19} \mathrm{~m}^{-3}$ \\
\hline
\end{tabular}

Tabela 1.1: Parâmetros gerais do tokamak TCABR.

As principais linhas de pesquisa desenvolvidas no tokamak TCABR são:

- Estudo da interação de ondas de Alfvén com o plasma: aquecimento, indução de corrente por radiofrequência, modo $\mathrm{H}$ e desenvolvimento de diagnósticos;

- Estudos da física da borda do plasma: transporte anômalo, turbulência, oscilações MHD (magnetohidrodinamicas) e confinamento melhorado.

- Rotação do plasma: rotação poloidal, toroidal e comportamento da rotação durante a aplicação de pulsos de RF e polarização da borda.

\subsection{Instabilidades e ilhas magnéticas}

Em um tokamak, as linhas de campo magnético possuem trajetórias helicoidais, formando superfícies de fluxo concêntricas com simetria toroidal (figura(1.4a)). Isso possibilita um bom confinamento do plasma, tendo em vista que, em primeira ordem, a trajetória das partículas carregadas será helicoidal em torno das linhas de campo [13].

Entretanto existem diversas instabilidades no plasma que causam a degradação do confinamento magnético, que por sua vez, culminam com a perda de energia. Uma instabilidade particular é o chamado modo de ruptura. A presença dessa instabilidade faz com que o plasma adote um novo estado de equilíbrio assimétrico [14]. Neste novo estado de equilíbrio as linhas de campo migram na direção radial dando origem as chamadas ilhas magnéticas (figura(1.4b)).

Como resultado, o fluxo radial (para fora) de partículas e energia aumenta na região onde essas ilhas estão localizadas, provocando a degradação do confinamento do plasma como um todo. 
Em tokamaks a presenças destas ilhas magnéticas é um fator limitante na eficiência de operação, inviabilizando assim a sua utilização como fonte de energia.

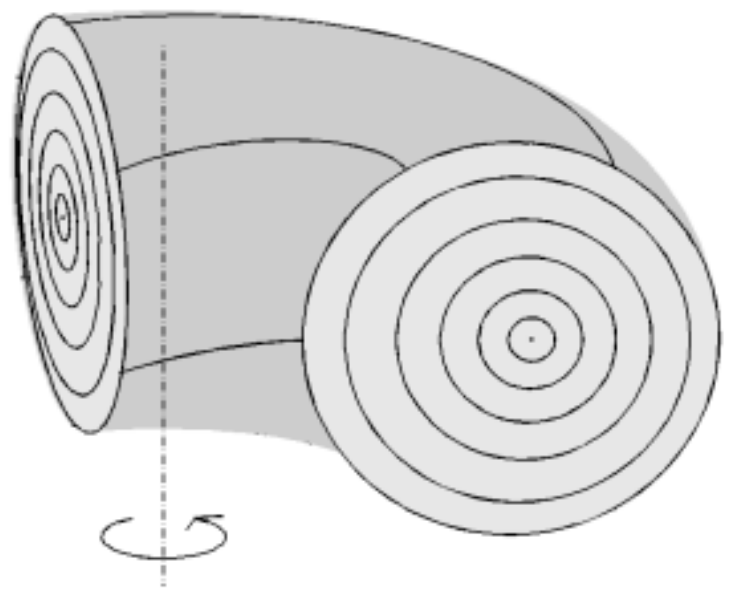

(a)

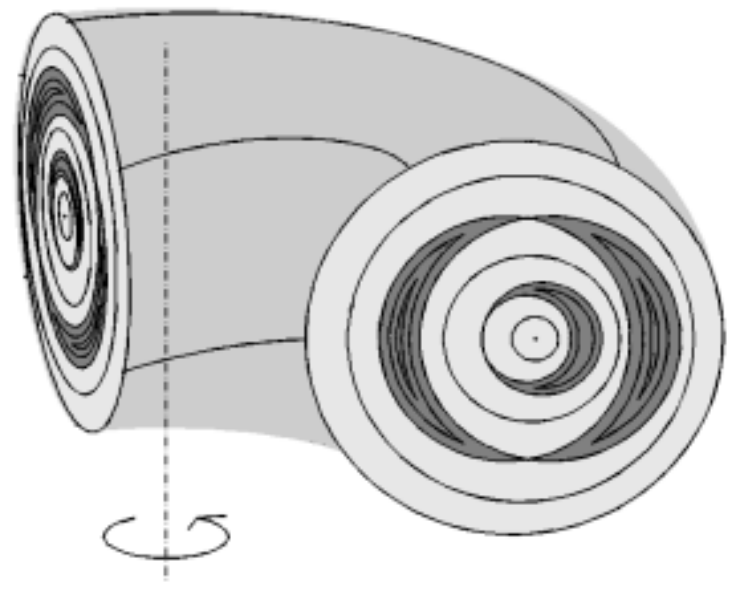

(b)

Figura 1.4: A figura (a) é uma representação das superfícies magnéticas do plasma em um tokamak. A organização concêntrica das superfícies favorece o confinamento. Em (b) estão respresentadas as superfícies magnéticas com a presença de ilhas magnéticas correspondentes aos modos $m=1$ e $m=2$ [15].

Além disso, quando os modos de ruptura são mais violentos podem provocar a perda total do plasma em uma disrupção. Entre outras causas, as disrupções acontecem quando o modo $m=2$, antes ausente ou inexpressivo, torna-se significativo na topologia magnética e sua amplitude cresce exponencialmente, modificando drasticamente a forma do plasma. Essas mudanças fazem com que o plasma se choque com o limitador, interrompendo instantaneamente a descarga [16].

Em máquinas grandes, as forças resultantes da rápida interrupção da corrente de plasma são muito altas e acabam sendo transferidas para as estruturas da máquina. Além disso, uma enorme quantidade de plasma de alta energia é atirada contra a parede provocando sérios danos à câmara de vácuo.

Resumindo, a presença de ilhas magnéticas deteriora o confinamento e ainda tornam o plasma susceptível a disrupções. Por essas razões, o estudo e a compreensão das ilhas magnéticas são necessários para desenvolver ferramentas que sejam capazes de suprimilas do plasma. Esse procedimento é essencial para o bom funcionamento dos tokamaks de hoje, e principalmente para os futuros reatores de fusão.

Algumas técnicas podem ser utilizadas para atenuar as deteriorações causadas pelas ilhas magnéticas, entre elas [17]:

- reduzir ou eliminar os ruídos produzidos por outras instabilidades; 
- criar um campo helicoidal externo de modo a inibir as correntes perturbativas;

- aplicar um pulso de radiofrequência na região da ilha, de modo a criar uma corrente que provocará a redução ou eliminação da ilha magnética.

No entanto, essas técnicas só podem ser utilizadas quando se sabe a posição radial das ilhas, dessa forma, um diagnóstico capaz de dar informações sobre a localização das ilhas é de grande interesse nas atuais pesquisas em fusão nuclear.

O principal objetivo deste trabalho é construir um diagnóstico não apenas capaz de determinar a localização espacial das ilhas magnéticas, como também de fornecer informações que as caracterizem como, por exemplo, seu tamanho.

O diagnóstico em questão trata-se de um sistema bolométrico de 24 canais, que fornece sinais de tensão proporcionais à potência radiativa emitida pelo plasma. $\mathrm{O}$ objeto de interesse nestes sinais são as oscilações características das instabilidades MHD que, no caso das ilhas magnéticas são denominadas oscilações de Mirnov [18].

Para auxiliar a técnica de identificação e análise dos modos foi desenvolvido um programa em MatLab para simular as medidas dos sinais bolométricos. Este programa apresentou excelentes resultados para estudos de perturbações no plasma e será aproveitado em futuros projetos desenvolvido no TCABR.

Além de determinar a posição radial e a dimensão das ilhas magnéticas, o sistema bolométrico também possibilitou a determinação da superfície ressonante $q=1$, caracterizada pelo limiar radial da instabilidade dente de serra. Também foi possível observar e caracterizar o modo precursor desta instabilidade, que pode ser identificado como a rotação da porção de plasma interna à superfície $q=1$ ao redor de seu eixo magnético.

Abaixo segue uma breve descrição do conteúdo dessa dissertação.

No capítulo 2 será apresentada uma breve introdução teórica sobre a descrição magnetohidrodinâmica do plasma, destacando principalmente os pontos referentes a superfícies ressonantes e caracterização de ilhas magnéticas para posterior verificação dos resultados experimentais.

O capítulo 3 apresenta uma explicação dos princípios de funcionamento de um bolômetro, fazendo uma comparação do bolômetro metálico com o construído a partir de fotodiodos. Neste capítulo também são apresentados todos os detalhes do diagnóstico bolométrico instalado no tokamak TCABR.

No capítulo 4 é descrito os processos e o programa de simulação de perturbações e de medidas desenvolvido em MATLAB para auxiliar na compreensão dos resultados 
experimentais e na caracterização das ilhas magnéticas detectadas no tokamak TCABR. Ainda nesse capítulo são apresentadas as técnicas de análise espectral utilizadas para estudar as instabilidades MHD através das oscilações medidas nos 24 canais bolométricos.

No capítulo 5 são apresentados os resultados obtidos da análise de diversos disparos em modo tokamak, onde foi possível identificar e caracterizar ilhas magnéticas utilizando os métodos apresentados neste trabalho. Em disparos onde é possível identificar a presença de instabilidades do tipo dente de serra, é possível estipular a posição da superfície $q=1$ e a largura média do precursor dos dentes de serra.

O capítulo 6 apresenta as conclusões mais importantes obtidas nesta dissertação, assim como as perspectivas e possíveis projetos futuros que podem ser desenvolvidos a partir desse trabalho. 


\section{Modelo magnetohidrodinâmico}

Para descrever os fenômenos macroscópicos em plasmas é muito comum utilizar o modelo magnetohidrodinâmico (MHD), que trata o plasma como um fluido condutor e permite estudar quantitativamente muitos fenômenos.

Neste capítulo pretende-se introduzir alguns conceitos da teoria MHD que permitam estudar de maneira simplificada as instabilidades abordadas neste trabalho, fazendo algumas previsões para que sejam comparadas com os resultados experimentais. O sistema de coordenadas utilizado nos cálculos a seguir é o sistema cilíndrico (Apêndice A), que permite descrever bem o plasma de um tokamak de grande razão de aspecto.

\subsection{Fator de segurança}

Um parâmetro muito importante do modelo MHD para plasmas de tokamak é o chamado fator de segurança q, que é muito importante em estudos de instabilidades e equilíbrio do plasma. Esse parâmetro é definido como sendo a razão entre caminhos infinitesimais percorridos ao longo de uma linha de força nas direções toroidal e poloidal. Para um tokamak de grande razão de aspecto e seção circular as linhas do campo magnético satisfazem a seguinte relação:

$$
\frac{R d \phi}{B_{\phi}}=\frac{r d \theta}{B_{\theta}}=\frac{d l}{B}
$$

então, a razão entre os caminhos na direção toroidal e poloidal define o fator de segurança:

$$
\frac{d \phi}{d \theta}=q(r)=\frac{r B_{\phi}}{R_{0} B_{\theta}(r)}
$$

Observa-se que, se uma linha magnética for seguida ao redor do toróide, esta se fecha sobre si mesma após um número inteiro de voltas ou continua indefinidamente, cobrindo ergodicamente uma superfície toroidal [19]. As linhas de campo que se fecham sobre si mesmas formam as chamadas superfícies magnéticas ressonantes, ou apenas superfícies ressonantes.

Essas superfícies ressonantes possuem fator de segurança dado por $q=m / n$, onde $m$ e $n$ são números inteiros que representam o número de voltas na direção poloidal $(m)$ e toroidal $(n)$ necessários para que a linha do campo volte ao ponto de partida. São nessas superfícies ressonantes que se formam as ilhas magnéticas. 
Na equação $(2.2), B_{\theta}(r)$ é o campo magnético poloidal:

$$
B_{\theta}(r)=\frac{\mu_{0} I(r)}{2 \pi r}
$$

onde $I(r)$ é o perfil radial de corrente na coluna de plasma. Substituindo:

$$
q(r)=\frac{2 \pi r^{2} B_{\phi}}{\mu_{0} R_{0} I(r)}
$$

Para determinar a corrente $I(r)$ é necessário saber o perfil de densidade de corrente para o plasma. Em uma abordagem simples, é comum adotar um perfil parabólico:

$$
\vec{J}(r)=J_{0}\left[1-\left(\frac{r}{a}\right)^{2}\right]^{\nu} \hat{\phi}
$$

onde $\nu$ é um parâmetro obtido experimentalmente. Com isso, é possível escrever a corrente em função da posição radial:

$$
I(r)=\frac{\pi a^{2} J_{0}}{\nu+1}\left[1-\left(1-\left(\frac{r}{a}\right)^{2}\right)^{\nu+1}\right]
$$

A corrente na borda $I(a)=I_{P}$ é a chamada corrente de plasma e pode ser determinada experimentalmente:

$$
I(a)=I_{P}=\frac{\pi a^{2} J_{0}}{\nu+1}
$$

portanto:

$$
I(r)=I_{P}\left[1-\left(1-\left(\frac{r}{a}\right)^{2}\right)^{\nu+1}\right]
$$

Substituindo esse resultado na equação (2.4):

$$
q(r)=\frac{2 \pi r^{2} B_{\phi}}{\mu_{0} R_{0} I_{P}} \frac{1}{\left[1-\left(1-\left(\frac{r}{a}\right)^{2}\right)^{\nu+1}\right]}
$$

Com isso, é possível determinar o fator de segurança na borda, calculando $q(r)$ para $r=a:$

$$
q(a)=\frac{2 \pi a^{2} B_{\phi}}{\mu_{0} R_{0} I_{P}}=\frac{a B_{\phi}}{R B_{\theta}(a)}
$$

que é equivalente a substituir $r=a$ na equação (2.2). O fator de segunça, então, pode 
ser escrito da seguinte forma:

$$
q(r)=q(a) \frac{\left(\frac{r}{a}\right)^{2}}{\left[1-\left(1-\left(\frac{r}{a}\right)^{2}\right)^{\nu+1}\right]}
$$

\subsection{Ilhas magnéticas}

Um efeito muito importante que acontece em plasmas sujeitos à instabilidades MHD é a mudança na topologia dos campos magnéticos devido aos efeitos não lineares provenientes das instabilidades de ruptura. As ilhas magnéticas são estruturas que surgem a partir destas mudanças topológicas para estabilizar o plasma em um novo estado de equilíbrio que, geralmente, tende a degradar a qualidade de seu confinamento.

As instabilidades de ruptura, em tokamaks, são causadas pelo gradiente de densidade de corrente toroidal de equilíbrio. O nome é devido ao efeito de ruptura e reconexão das linhas de campo magnético que ocorrem durante as instabilidades como consequência de sua resistividade [16].

Na maior parte do plasma, essas instabilidades possuem uma taxa de crescimento muito pequena. Nas chamadas superfícies ressonantes, onde $q=q\left(r_{s}\right)=\frac{m}{n}$, os efeitos da resistividade tornam-se importantes e os processos de reconexão magnética acabam modificando a topologia das linhas de campo. Os processos de reconexão magnética são muito complicados e não serão tratados neste trabalho, mas podem ser encontrados em literatura específica [20].

\subsubsection{Descrição clássica das ilhas magnéticas}

Para descrever as ilhas magnéticas é comum utilizar as coordenadas angulares. Um campo magnético helicoidal cilíndrico pode ser descrito por um sistema de duas variáveis $r$ e $\tau$ onde $\tau=m \theta+k z[21]$.

No caso de um tokamak, a variável $z$ deve ser substituida por uma váriável toroidal $\phi$, neste caso é possível utilizar a variável radial $r$ e a helicoidal $\chi$, onde:

$$
\chi=m \theta+n \phi
$$

Os modos de ruptura surgem quando existe cisalhamento no campo magnético. Para modelar esse sistema normalmente utiliza-se o chamado campo auxiliar em uma apro- 
ximação para um tokamak de grande razão de aspecto. O campo auxiliar é um campo de equilíbrio próximo à superfície ressonante e que possui amplitude perpendicular à coordenada $\chi[22]$ :

$$
B *=B_{\theta}\left(1-\frac{n}{m} q(r)\right)
$$

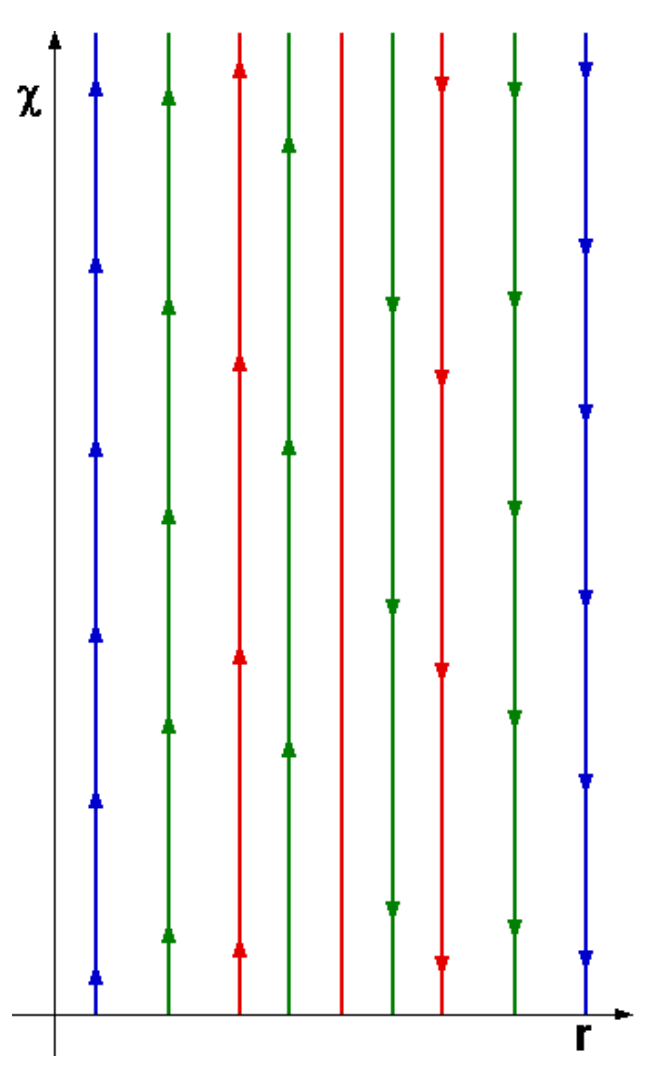

(a)

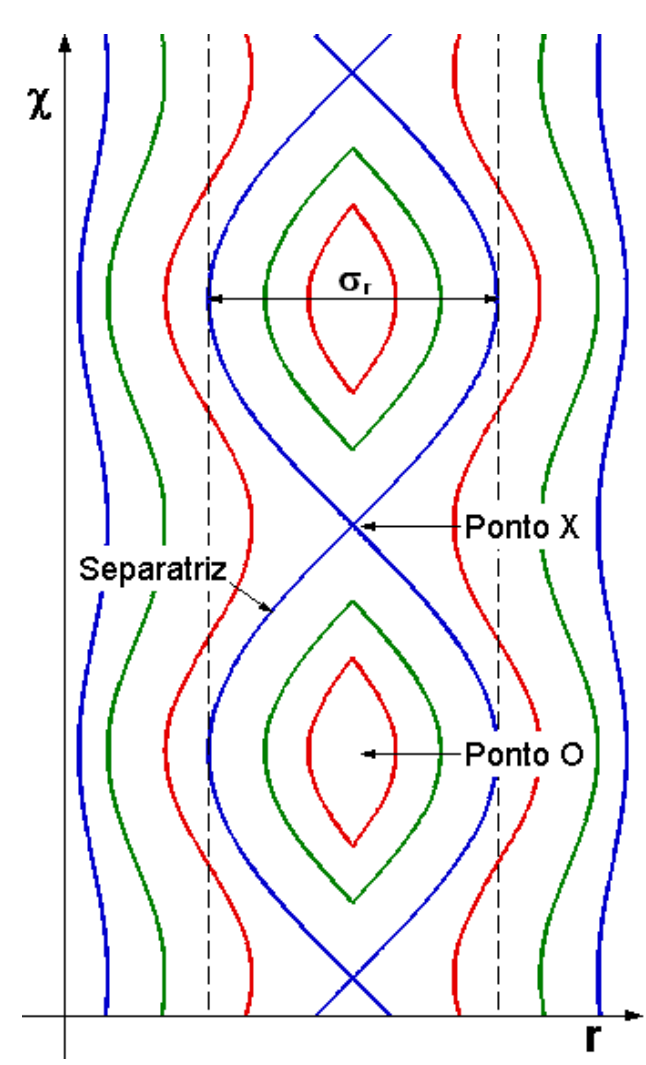

(b)

Figura 2.1: Em (a), configuração inicial das linhas de campo magnético próximas à superfície ressonante. Em (b) são mostradas as linhas de campo reconectadas formando as ilhas magnéticas. Nesta figura também estão apresentadas algumas definições importantes da geometria da ilha magnética.

A figura (2.1a) mostra uma representação dessas linhas de campo próximas de uma superfície ressonante. Na equação (2.13) é possível substituir $q\left(r_{s}\right)=m / n$ e aproximar o valor de $q(r)$ através de uma expansão em primeira ordem, já que se tratam de regiões próximas à superfície ressonante [16]:

$$
B *=B_{\theta}\left[1-\frac{1}{q\left(r_{s}\right)}\left(q\left(r_{s}\right)+\frac{d q}{d r}\left(r_{s}\right)\left(r-r_{s}\right)\right)\right]
$$

Uma substituição conveniente aqui é $x=\left(r-r_{s}\right)$ : 


$$
B *=-B_{\theta} \frac{q^{\prime}\left(r_{s}\right)}{q\left(r_{s}\right)} x
$$

Uma perturbação próxima à superfície ressonante $r=r_{s}$ provoca o surgimento das instabilidades de ruptura, que por sua vez, vão desencadear o surgimento de estruturas magnéticas topologicamente fechadas, as chamadas ilhas magnéticas, como estão representadas na figura (2.1b). As componentes perturbativas de campo radial podem ser denotadas por:

$$
B_{r}=\widetilde{B}_{r} \operatorname{sen}(m \chi)
$$

Sendo que $B * \gg \widetilde{B}_{r}$. Determinando a trajetória das linhas de campo é possível determinar a geometria da ilha magnética. A equação da trajetória é dada pela seguinte equação:

$$
\frac{d r}{r_{s} \widetilde{B}_{r}}=\frac{d \chi}{B *}
$$

ou:

$$
\frac{d x}{r_{s} B r}=\frac{d \chi}{B *}
$$

Para entender os efeitos da superfície ressonante, basta substituir as equações (2.13) e (2.16) na relação (2.17):

$$
\frac{d r}{r_{s} d \chi}=\frac{\widetilde{B}_{r} \operatorname{sen}(m \chi)}{B_{\theta}\left(1-\frac{n}{m} q(r)\right)}
$$

Observando essa equação é fácil notar que as variações radiais são negligenciáveis uma vez que $B * \gg \widetilde{B}_{r}$. Entretanto, quando $q(r) \rightarrow q\left(r_{s}\right)=m / n$, o campo auxiliar tende a zero, fazendo com que as oscilações do campo radial tornem-se importantes e, por conta disso, as variações radiais das linhas de campo tendem a crescer muito. Isso implica que as ilhas magnéticas tendem a se formar nas superfícies racionais $\left(r=r_{s}\right)$ onde $q\left(r_{s}\right)=m / n[14]$.

Agora, para determinar a geometria da ilha, é necessário substituir as equações (2.15) e (2.16) na equação (2.18):

$$
\frac{d x}{r_{s} d \chi}=-\frac{\widetilde{B}_{r} \operatorname{sen}(m \chi) q\left(r_{s}\right)}{B_{\theta} q^{\prime}\left(r_{s}\right) x}
$$


integrando esta equação:

$$
x^{2}=2 \frac{r_{s} \widetilde{B}_{r} q\left(r_{s}\right)}{m B_{\theta} q^{\prime}\left(r_{s}\right)}\left[\cos (m \chi)+\cos \left(m \chi_{0}\right)\right]
$$

Essa equação descreve as linhas de campo de uma ilha magnética. Aqui, $x$ é a distância da superfície ressonante $r_{s}$ até o ponto $r$. A constante de integração $\chi_{0}$ é um parâmetro que determina a superfície de fluxo que está sendo descrita.

O interesse aqui é na separatriz (figura (2.1b)) da ilha magnética, ou seja, para o valor mínimo de $\cos (m \chi)$, que é $\cos (m \chi)=-1, x$ deve ser igual a zero e, para isso, $\chi_{0}$ deve ser tal que $\cos \left(m \chi_{0}\right)=1$. Com isso:

$$
x_{\text {separatriz }}^{2}=2 \frac{r_{s} \widetilde{B}_{r} q\left(r_{s}\right)}{m B_{\theta} q^{\prime}\left(r_{s}\right)}[\cos (m \chi)+1]
$$

Nesta equação, a amplitude máxima de x é metade da largura $\sigma_{r}$ da ilha magnética, e essa amplitude máxima ocorre em $\cos (m \chi)=1$, portanto:

$$
\sigma_{r}=4\left(\frac{r_{s} \widetilde{B}_{r} q\left(r_{s}\right)}{m B_{\theta} q^{\prime}\left(r_{s}\right)}\right)^{\frac{1}{2}}
$$

Essa equação teórica, obtida a partir de conceitos de uma teoria clássica de instabilidades de ruptura é suficiente para estimar as dimensões de uma ilha magnética em um plasma de tokamak. Para obter esse valor para uma ilha específica, baseando-se em medidas experimentais, é necessário trabalhar um pouco mais essa equação.

\subsubsection{Determinação da dimensão da ilha magnética}

Na equação (2.23), o termo $\widetilde{B}_{r}\left(r_{s}\right)$ representa fisicamente o efeito perturbativo que a ilha causa no plasma, e pode ser obtido através do diagnóstico denominado bobinas de Mirnov, que são sondas magnéticas posicionadas ao redor da coluna de plasma a fim de medir variações do campo magnético poloidal [23].

Uma perturbação magnética causada por uma ilha pode ser modelada a partir da densidade de corrente perturbativa que, em uma aproximação para um tokamak de grande razão de aspecto, pode ser escrita como [24]:

$$
\widetilde{j}(r, \theta, \phi)=j_{m, n} e^{i\left(m \theta+n \phi-\omega_{m, n} t\right)} \delta\left(r-r_{m, n}\right)
$$

onde $r_{m, n}$ é a posição radial da superfície ressonante e os índices $m$ e $n$ são os modos 
poloidal e toroidal, respectivamente, da ilha magnética. Desta expressão é possível obter o campo magnético poloidal perturbado para uma dada posição $r$ tal que $r>r_{m, n}[25]$ :

$$
\widetilde{B}_{\theta}(r, \theta, \phi)=\mu_{0} j_{m, n} r_{m, n}\left(\frac{r_{m, n}}{r}\right)^{m+1} e^{i\left(m \theta+n \phi-\omega_{m, n} t\right)}
$$

sendo $r$ o raio onde $B_{\theta}$ foi medido. Considerando o caso onde $n=1\left(r_{m, 1}=r_{s}\right)$, o campo magnético poloidal perturbado na posição da superfície ressonante é:

$$
\widetilde{B}_{\theta}\left(r_{s}\right)=\mu_{0} j_{m, 1} r_{s} e^{i(m \theta-\omega t)}
$$

Calculando a equação (2.25) para $r=r_{b}$, onde $r_{b}$ é a posição radial de uma bobina de Mirnov, se obtém:

$$
\widetilde{B}_{\theta}\left(r_{b}\right)=\mu_{0} j_{m, 1} r_{s}\left(\frac{r_{s}}{r_{b}}\right)^{m+1} e^{i(m \theta-\omega t)}
$$

Com isso, é possível determinar uma relação para o campo magnético $B_{\theta}\left(r_{s}\right)$ a partir do valor do campo magnético $B_{\theta}\left(r_{b}\right)$, que pode ser medido por uma bobina de Mirnov. Essa relação é obtida fazendo a razão entre as equações (2.27) e (2.26):

$$
\frac{\widetilde{B}_{\theta}\left(r_{b}\right)}{\widetilde{B}_{\theta}\left(r_{s}\right)}=\left(\frac{r_{s}}{r_{b}}\right)^{m+1}
$$

e, na superfície ressonante, o campo magnético radial perturbado $\widetilde{B}_{r}$ é aproximadamente igual ao campo magnético poloidal perturbado $\widetilde{B}_{\theta}[26]$ :

$$
\widetilde{B}_{r}\left(r_{s}\right) \approx \widetilde{B}_{\theta}\left(r_{s}\right)=\widetilde{B}_{\theta}\left(r_{b}\right)\left(\frac{r_{b}}{r_{s}}\right)^{m+1}
$$

Outro termo necessário para determinar a largura da ilha magnética é $q^{\prime}(r)$ :

$$
\frac{d q(r)}{d r}=\frac{4 \pi B_{\phi}}{\mu_{0} R_{0} I_{p}} \frac{r\left[1-\left(1+\nu\left(\frac{r}{a}\right)^{2}\right)\left(1-\left(\frac{r}{a}\right)^{2}\right)^{\nu}\right]}{\left[1-\left(1-\left(\frac{r}{a}\right)^{2}\right)^{\nu+1}\right]^{2}}
$$

Tendo assumido um perfil de corrente parabólica para o plasma, é possível determinar o perfil do campo magnético poloidal substituindo a equação (2.6) na equação (2.3):

$$
B_{\theta}(r)=\frac{\mu_{0} I_{P}}{2 \pi r}\left[1-\left(1-\left(\frac{r}{a}\right)^{2}\right)^{\nu+1}\right]
$$

Agora, substituindo as equações para o campo magnético poloidal (2.31), do termo 
$q^{\prime}(r)$ (2.30) e para o campo magnético radial perturbado (2.29) na equação para a largura da ilha (2.23), é possível obter uma equação para computar a largura da ilha magnética a partir de parâmetros experimentais:

$$
\sigma_{r}=4\left(\frac{r_{s}^{2-m} r_{b}^{m+1} \tilde{B}_{\theta}\left(r_{b}\right)}{2 a m B_{\theta}(a)\left[1-\left(1+\nu\left(\frac{r_{s}}{a}\right)^{2}\right)\left(1-\left(\frac{r_{s}}{a}\right)^{2}\right)^{\nu}\right]}\right)^{1 / 2}
$$

Existe uma diferença na largura da ilha quando se observa a região mais interna e a mais externa do plasma. A causa dessa diferença está associada à diferença do campo magnético toroidal nas duas regiões. O campo toroidal é maior na região mais interna e, por isso, essa região é denominada de região de campo alto (High Field Side ou HF) e o lado oposto é denominado região de campo baixo (Low Field Side ou LF). É possível estimar essa diferença utilizando a equação (2.23).

Em termos gerais, o campo magnético toroidal possui um perfil que varia com o inverso da posição radial [16]:

$$
B_{\phi} \propto \frac{1}{R}
$$

onde $R$ é o raio partindo do centro do toroide. O valor de $R$ para as superfícies ressonantes é dado por: $R_{H F}=R_{0}-r_{s}$ e $R_{L F}=R_{0}+r_{s}$, onde $R_{0}$ é o raio maior do tokamak, portanto:

$$
\frac{B_{\phi}(H F)}{B_{\phi}(L F)}=\frac{R_{0}+r_{s}}{R_{0}-r_{s}}
$$

Utilizando a equação (2.2), calculada em $r=r_{s}$, na equação (2.23) é possível determinar a largura da ilha em função do campo toroidal:

$$
\sigma_{r}=4\left(\frac{R_{0} \widetilde{B}_{r} q^{2}\left(r_{s}\right)}{m q^{\prime}\left(r_{s}\right) B_{\phi}}\right)^{\frac{1}{2}}
$$

e, utilizando a definição de $q=\frac{m}{n}$ :

$$
\sigma_{r}=4\left(\frac{R_{0} \widetilde{B}_{r}}{n} \frac{q\left(r_{s}\right)}{q^{\prime}\left(r_{s}\right)} \frac{1}{B_{\phi}}\right)^{\frac{1}{2}}
$$

Assumindo que, o campo $\widetilde{B}_{r}$ seja igual para uma mesma superfície magnética e que apenas o campo $B_{\phi}$ seja diferente entre o HF e o LF, a razão da entre as larguras para cada uma dessas regiões pode ser escrita como: 


$$
\frac{\sigma_{r}(H F)}{\sigma_{r}(L F)}=\left(\frac{q(H F) q^{\prime}(L F)}{q(L F) q^{\prime}(H F)} \cdot \frac{B_{\phi}(L F)}{B_{\phi}(H F)}\right)^{\frac{1}{2}}
$$

A equação (2.9), para o fator de segurança $q(r)$ pode ser escrita em dois termos: um que é constante para toda uma superfície magnética e outro que depende do campo toroidal $B_{\phi}$ :

$$
q(r)=\frac{2 \pi r^{2} B_{\phi}}{\mu_{0} R_{0} I_{P}} \frac{1}{\left[1-\left(1-\left(\frac{r}{a}\right)^{2}\right)^{\nu+1}\right]}=C(r) B_{\phi}
$$

E o mesmo pode ser feito para a equação (2.30):

$$
q^{\prime}(r)=\frac{4 \pi B_{\phi}}{\mu_{0} R_{0} I_{p}} \frac{r\left[1-\left(1+\nu\left(\frac{r}{a}\right)^{2}\right)\left(1-\left(\frac{r}{a}\right)^{2}\right)^{\nu}\right]}{\left[1-\left(1-\left(\frac{r}{a}\right)^{2}\right)^{\nu+1}\right]^{2}}=K(r) B_{\phi}
$$

Substituindo esses resultados calculados para $r=r_{s}$ na equação (2.37):

$$
\frac{\sigma_{r}(H F)}{\sigma_{r}(L F)}=\left(\frac{C\left(r_{s}\right) B_{\phi}(H F) K\left(r_{s}\right) B_{\phi}(L F)}{C\left(r_{s}\right) B_{\phi}(L F) K\left(r_{s}\right) B_{\phi}(H F)} \cdot \frac{B_{\phi}(L F)}{B_{\phi}(H F)}\right)^{\frac{1}{2}}=\left(\frac{B_{\phi}(L F)}{B_{\phi}(H F)}\right)^{\frac{1}{2}}
$$

Por fim, substituindo a razão para os campos apresentada na equação (2.34):

$$
\frac{\sigma_{r}(H F)}{\sigma_{r}(L F)}=\left(\frac{R_{0}-r_{s}}{R_{0}+r_{s}}\right)^{\frac{1}{2}}
$$

é possível calcular teoricamente o quanto maior deve ser a largura da ilha magnética no HF quando comparada com a região LF.

\subsection{Instabilidades dentes de serra}

A emissão de radiação na frequência de raios X mole (entre 0, $1 \mathrm{keV}$ e $10 \mathrm{keV}$ ) depende da temperatura, da densidade do plasma e da concentração de impurezas. Através das medidas de emissão de raios X moles é possível estudar fenômenos que ocorrem no centro da coluna de plasma [27].

Em observações da evolução temporal dessas medidas é possível observar a presença de oscilações características, que recebem o nome de oscilações dentes de serra (figura (2.2)), que são associadas a disrupturas da região interna à superfície $q=1$ [28]. 
No que segue será apresentado uma pequena introdução ao modelo de Kadomtsev que, através do processo de reconexão das superfícies magnéticas, explica a inversão de fase das oscilações dentes de serra e a rotação de um aparente modo $m=1$, ambos observados por diagnósticos como raios X mole, ECE e outros.

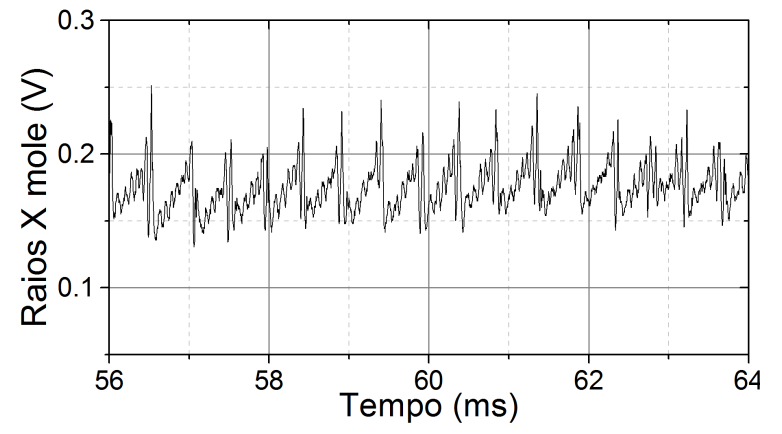

Figura 2.2: Exemplo de sinal da evolução da emissão de raios-X mole onde ocorrem instabilidades do tipo dentes de serra.

\subsubsection{Modelo de Kadomtsev}

Para explicar o colapso característico das instabilidades dentes-de-serra, Kadomtsev propôs um modelo de reconexões magnéticas rápidas [29]. De acordo com esse modelo, as reconexões estão relacionadas com os mesmos modos de ruptura que provocam a formação de ilhas magnéticas. Essas reconexões são características das instabilidades resistivas.

O modelo será ilustrado considerando um tokamak de grande razão de aspecto. A indução de uma corrente no plasma provoca o seu aquecimento. Como a condutividade do plasma é proporcional à $T_{e}^{3 / 2}$, onde $T_{e}$ é a temperatura eletrônica [30], existe uma tendência da corrente se concentrar no centro e, como resultado, a densidade radial de corrente no eixo magnético $J_{0}$ aumenta por efeito joule.

A equação para o fator de segurança no eixo magnético é dada por [27]:

$$
q(r=0)=q_{0}=\frac{B_{\phi}}{R_{0}} \frac{1}{\frac{d B_{\theta}}{d r}(0)}=\frac{2 B_{\phi}}{R_{0} J_{0}}
$$

Então, conforme a temperatura no centro aumenta, a corrente também aumenta e, para uma densidade de corrente central $J_{0}$ suficientemente alta, $q_{0}$ cai para um valor menor que a unidade, fazendo com que a superfície ressonante $q=1$ apareça no plasma.

Utilizando a teoria MHD ideal, Rosenbluth mostrou que as superfícies internas a $q=1$ são ligeiramente forçadas a ficarem mais próximas entre si em um plasma confinado toroidalmente [31] sendo que, no instante inicial, a configuração das superfícies de $\psi$ constante é como a representada na figura (2.3a) enquanto que a configuração do fluxo no instante final aparece como na figura $(2.3 \mathrm{~b})$.

No caso da descrição MHD ideal do processo as superfícies de fluxo não devem mudar sua topologia, portanto as linhas de fluxo podem se aproximar uma das outras tanto 
quanto se queria, mantendo-se levemente deslocadas do centro sem nunca se sobrepor.

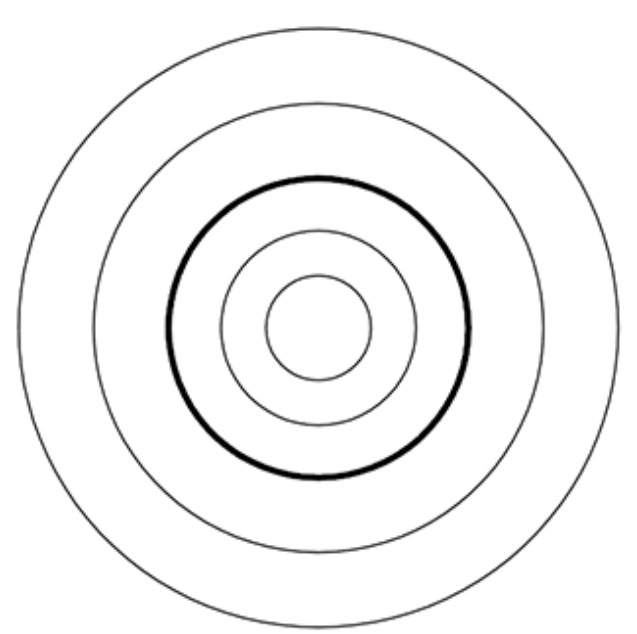

(a)

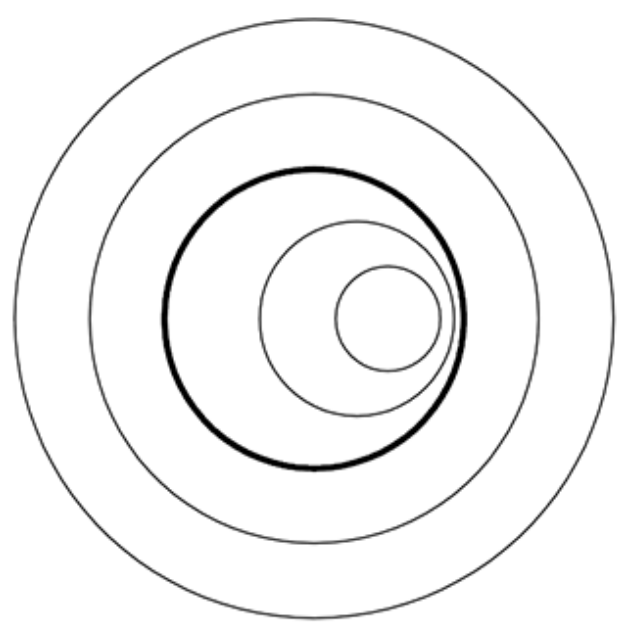

(b)

Figura 2.3: Configuração inicial (a) e final (b) das superfícies de fluxo desenvolvida por Rosenbluth utilizando a teoria MHD ideal [31]. A linha mais escura representa $q=1$.

Em casos onde os processos de reconexão são permitidos, por exemplo, quando efeitos de resistividade são levados em conta, o ponto onde as superfícies magnéticas são forçadas a se aproximar torna-se uma região propícia para que as linhas de campo se quebrem e rapidamente se reconectem com as linhas adjacentes, mudando a topologia das superfícies de fluxo magnético [32].

Para que ocorra essa reconexão Kadomtsev sugere que o campo magnético poloidal nas proximidades da superfície ressonante $q=1$ seja o mesmo campo auxiliar proposto para os modelos de ilhas magnéticas [22]:

$$
B *=B_{\theta}\left(1-\frac{n}{m} q(r)\right)
$$

onde, neste caso específico, $n=1$ e $m=1$, então é possível escrever a equação de duas maneiras:

$$
\begin{aligned}
B * & =B_{\theta}(1-q) \\
B * & =\frac{r B_{\phi}}{R}\left(\frac{1}{q}-1\right)
\end{aligned}
$$

Nas duas equações é fácil ver que $B *$ é zero na superfície ressonante e, em ambos os lados dessa superfície as linhas de campo tem sinais opostos, o que corresponde a uma 
inversão do campo poloidal no ponto ressonante $r=r_{s}$.

Nesse ponto as instabilidades de ruptura causam a reconexão das superfícies magnéticas próximas: primeiramente as duas camadas de fluxo 1 e 2 se conectam como mostra as figuras (2.4a) e (2.4b) onde também é possível ver uma ilha "A" formada a partir da reconexão das duas superfícies de fluxo. As linhas de campo dessa ilha possuem a mesma orientação das linhas onde $q>1$, no caso, o sentido horário e, portanto, esta ilha possui $q>1[29]$.

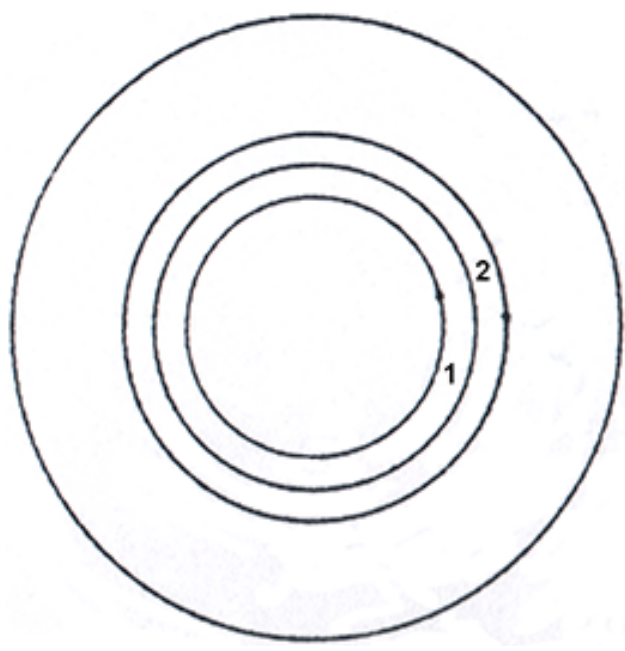

(a)

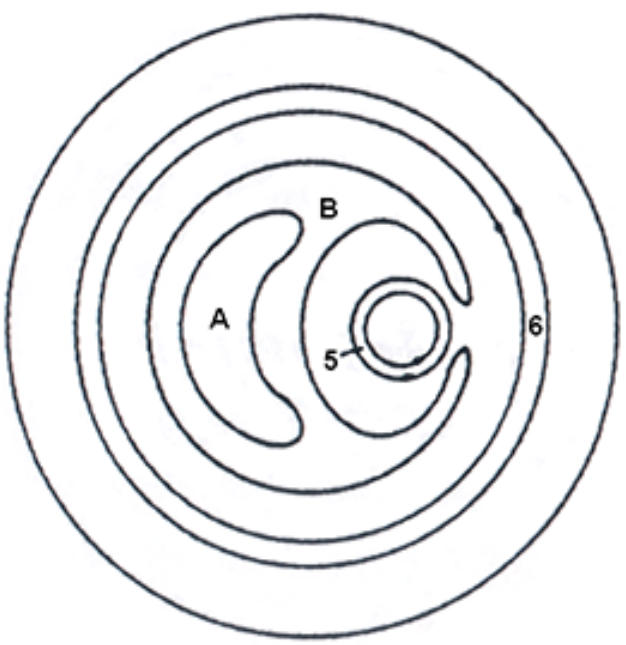

(c)

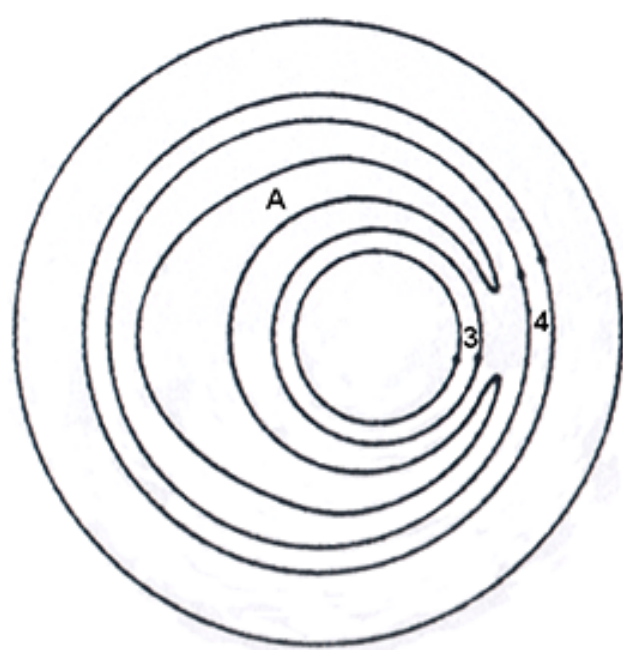

(b)

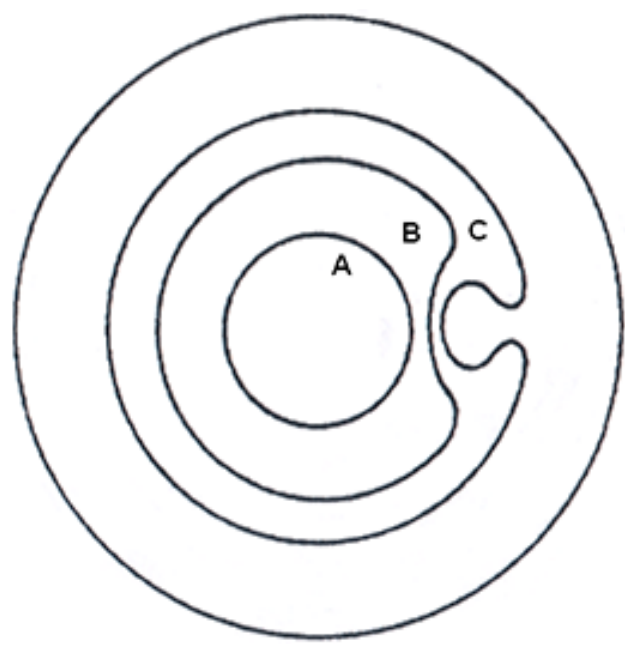

(d)

Figura 2.4: Processo de reconexão de acordo com o modelo de Kadomtsev [33].

Depois da reconexão das camadas 1 e 2 , as camadas 3 e 4 são forçadas a se aproximar e posteriormente sofrer uma reconexão, o que provoca a formação da ilha "B" externamente a ilha "A" como mostra a figura (2.4c). Esse processo se repete até as últimas linhas de campo com sentidos contrários se reconectarem como as camadas de fluxo 5 e 6 da figura 
(2.4d). Como agora todas as linhas de campo estão na mesma direção, $q>1$ em todos os lugares e, portanto, o plasma assume uma configuração estável.

Através do aquecimento ôhmico, muita energia térmica é acumulada no interior da superfície $q=1$ e, com o processo de reconexões descrito acima, uma nova estrutura magnética toma o lugar do antigo eixo magnético, e toda essa energia acumulada é transferida para regiões de posição radial maior [34]. Essa dinâmica explica as oscilações em forma de dentes de serra medidas através dos diagnósticos de raios-X moles para posições radiais menores que $q=1$, e também a mudança de fase das oscilações quando essa medida é feita para posições radiais maiores que $q=1$.

Outra oscilação, senoidal, de maior frequência e menor amplitude, também é observada nos sinais dos diagnósticos que registram os dentes de serra. Como essas oscilações precedem o "crash" dos dentes de serra, são normalmente atribuídos ao precurssor da instabilidade, entretanto, essas oscilações ocorrem devido ao próprio movimento natural de rotação do plasma: após algumas reconexões magnéticas a nova estrutura magnética começa a rodar ao lado do eixo magnético e conforme suas dimensões aumentam, a amplitude das oscilações também aumentam, como pode ser visto na figura (2.2).

Esses fenômenos foram observados também utilizando o diagnóstico de bolometria, que será apresentado no capítulo seguinte. As medidas e comparação entre os resultados obtidos com o diagnóstico de raios-X mole serão apresentados no capítulo 5. 


\section{Arranjo experimental}

Como em qualquer outra ciência, uma maneira de promover o avanço nas pesquisas em fusão nuclear é mediante o constante aperfeiçoamento das técnicas e instrumentos de medida, proporcionando melhoras nos resultados experimentais, permitindo o desenvolvimento de uma teoria cada vez mais precisa da física de plasmas confinados magneticamente.

É inevitável, entretanto, que os diagnósticos de plasmas se deparem com problemas causados pela natureza agressora do plasma termonuclear, como por exemplo, as altas temperaturas, que impossibilitam a utilização de diagnósticos invasivos, como sondas eletrostáticas, em posições próximas ao centro do plasma.

A espectroscopia de plasma pertence à classe não perturbativa que, através da medição da radiação eletromagnética emitida, extrai informações importantes sobre diversos parâmetros do plasma.

O bolômetro é um tipo de detector utilizado para medir a potência da radiação eletromagnética emitida pelo plasma. Seu princípio de funcionamento baseia-se no aquecimento de um material de capacidade térmica conhecida. Isso define o chamado "bolômetro resistivo" que, apesar de ter uma resposta temporal relativamente baixa, possui excelente precisão em medidas absolutas da potência radiante.

Quando o interesse é medir, não o valor absoluto da potência irradiada, mas as oscilações desta emissão no tempo, faz-se o uso de sensores semicondutores, como por exemplo, fotodiodos, que são relativamente rápidos quando comparados aos bolômetros resistivos, embora possuam uma sensibilidade fortemente dependente do comprimento de onda.

Neste capítulo será feita uma breve introdução sobre o princípio de funcionamento do bolômetro resistivo e uma comparação com os sensores do tipo semicondutor. Também são apresentados os detalhes da câmara de fotodiodos e amplificadores de sinais utilizados neste experimento.

Ao longo do capítulo serão utilizadas definições e nomenclaturas específicas de radiometria. Essas definições e conceitos são apresentados no apêndice B, que é uma pequena introdução à radiometria. 


\subsection{Bolômetro resistivo}

Em princípio, o bolômetro consiste de um elemento de absorção de capacidade térmica $C$ e resistência elétrica $R_{b}$, podendo ser um metal ou um semicondutor, montado em uma das arestas de uma ponte de Wheatstone, como é mostrado na figura (3.1a). Quando o elemento de absorção é atingido por uma radiação eletromagnética, sua temperatura sofre uma variação $\Delta T$, portanto, quanto maior for a energia da radiação eletromagnética, tanto maior será essa variação de temperatura. Essa variação provoca uma mudança $\Delta R_{b}$ na resistência do elemento de absorção que pode ser medida utilizando um galvanômetro.

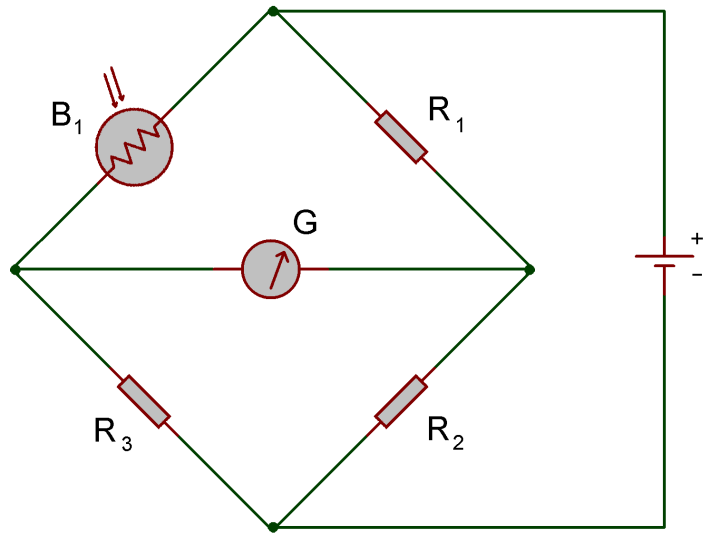

(a)

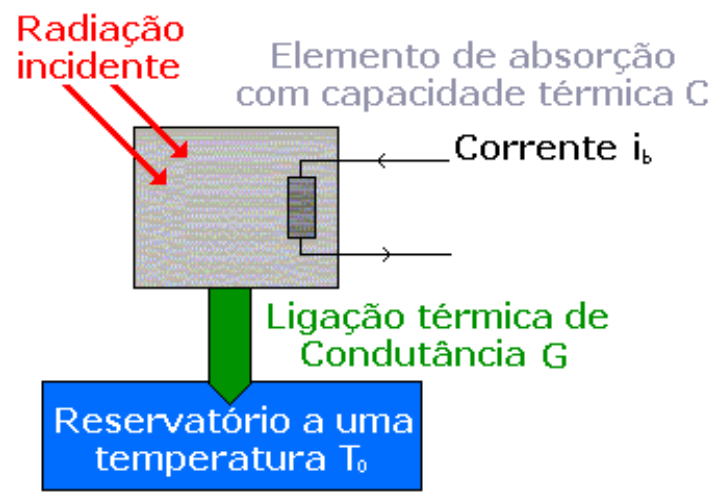

(b)

Figura 3.1: Em (a) é apresentado um circuito de um bolômetro e, em (b), está representando um modelo do funcionamento do bolômetro.

A variação relativa da resistência se relaciona com a variação da temperatura do elemento de absorção através da seguinte relação:

$$
\frac{\Delta R_{b}}{R_{b}}=\alpha \Delta T
$$

sendo que $\alpha$ é o coeficiente térmico da resistência. Esse coeficiente depende do tipo de material. Normalmente os bolômetros são confeccionados de ouro, platina, níquel ou bismuto.

Esse coeficiente é positivo se o material do bolômetro for um metal, e é negativo se o material for um semicondutor. Uma definição utilizada é que para $\alpha>0$ o bolômetro é positivo e, para $\alpha<0$, o bolômetro é negativo [35].

No diagrama da figura (3.1a), $B_{1}$ representa a termorresistência de resistência $R_{b}$ sobre a qual se incide o fluxo luminoso, $R_{3}$ é um elemento que possui a mesma resistência 
que o elemento $B_{1}$, e tem o objetivo de compensar a variação de temperatura daquele elemento.

As resistências $R_{1}$ e $R_{2}$ são escolhidas de forma que a corrente medida pelo galvanômetro seja zero quando a radiação incidente no elemento $B_{1}$ for nula. Então, se a resistência do bolômetro varia de $\Delta R_{b}$ pelo galvanômetro circulará uma corrente:

$$
\Delta i=i_{b} \frac{\Delta R_{b}}{R_{b}} L
$$

onde $i_{b}$ é a corrente que passa pelo elemento termorresistivo do sistema e $L$ é um coeficiente que depende da razão das resistências da ponte de Wheatstone. Substituindo a equação (3.1) na equação (3.2), esta pode ser escrita como:

$$
\Delta i=i_{b} \alpha \Delta L
$$

Por outro lado, a variação de temperatura $\Delta T$ está conectada com o fluxo de potência radiante incidente no bolômetro da seguinte forma:

$$
\Delta T=K \frac{\Phi}{G}
$$

onde $K$ é o coeficiente de absorção da radiação e $G$ é o coeficiente de condução térmica. Substituindo isso na equação (3.3):

$$
\Delta i=i_{b} \alpha L K \frac{\Phi}{G}
$$

Portanto, para uma corrente $i_{b}$ constante, a variação de corrente no galvanômetro é proporcional ao fluxo de potência radiante $\Phi$ incidente.

O bolômetro, como qualquer outro termoelemento, possui uma constante de tempo alta, o que significa uma baixa resposta em frequência. Depois que a radiação deixa de incidir sobre a parte sensível do detector, a temperatura $\Delta T$ começa a cair. Utilizando o modelo simples apresentado na figura (3.1b), essa variação de temperatura excede a de um reservatório térmico de temperatura $T_{0}$, e é transferida através da ligação de condutividade térmica $G$. Se $C$ é a capacidade térmica do bolômetro, então a velocidade com que a temperatura vai cair $\left(\frac{d \Delta T}{d t}\right)$ deve obedecer a seguinte equação diferencial:

$$
C \frac{d \Delta T}{d t}+G \Delta T=0
$$

cuja solução é dada por: 


$$
\Delta T=\Delta T_{0} e^{-t / \tau}
$$

onde:

$$
\tau=\frac{C}{G}
$$

Daí é possível concluir que a transferência de temperatura tem um decaimento exponencial.

Resolvendo agora o caso particular da mesma equação diferencial, que representa o sistema quando é atingido por um fluxo de potência radiante constante $\Phi_{0}$. Neste caso, a equação diferencial pode ser escrita como:

$$
C \frac{d \Delta T}{d t}+G \Delta T=K \Phi_{0}
$$

e a solução é dada por:

$$
\Delta T=\frac{K \Phi_{0}}{G}\left[1-e^{-t / \tau}\right]
$$

O que significa que no limite $t / \tau \rightarrow \infty, \Delta T \rightarrow \frac{K \Phi_{0}}{G}$. Esse limite será atingido tão rapidamente quanto menor for a constante de tempo $\tau$. Essa constante varia da ordem de $(1 \sim 300) m s$ para bolômetros metálicos. Isso faz com que o uso desses detectores seja restrito a estudos de processos que variam lentamente com o tempo.

Para averiguar a resposta do detector, é necessário considerar um fluxo de potência radiante que varie no tempo. Para um caso oscilatório geral, a parte oscilatória desse fluxo pode ser descrita através da seguinte equação:

$$
\Phi=\Phi_{0} e^{-2 \pi i f t}
$$

onde $f$ é a frequência do sinal. Com isso, a equação diferencial da transferência de temperatura fica:

$$
C \frac{d \Delta T}{d t}+G \Delta T=K \Phi_{0} e^{-2 \pi i f t}
$$

A solução para essa equação é:

$$
\Delta T=\frac{K \Phi_{0}}{G-2 \pi C i f} e^{-2 \pi i f t}
$$


Desta forma $\Delta T$ oscila com a mesma frequência do fluxo incidente. A parte real da amplitude da oscilação é:

$$
|\Delta T|=\frac{K \Phi_{0}}{\sqrt{G^{2}+4 \pi^{2} C^{2} f^{2}}}=\frac{K \Phi_{0}}{G \sqrt{1+(2 \pi f \tau)^{2}}}
$$

Então, se $f \tau \ll 1$ então:

$$
|\Delta T|=\frac{K \Phi_{0}}{G}
$$

ou seja, a amplitude das oscilações medidas não depende da frequência $f$. Entretanto, se $f \tau \gg 1$, o valor medido de $\Delta T$ será:

$$
|\Delta T|=\frac{K \Phi_{0}}{2 \pi C f}
$$

O que significa que a variação da temperatura do elemento é inversamente proporcional à frequência da intensidade do fluxo de potência radiante incidente. Isso significa que o sistema não terá tempo de voltar à sua temperatura estacionária antes que um novo pulso de fluxo incida sobre o detector, resultando em uma medida que não é confiável.

A sensibilidade do detector pode ser determinada em função dos parâmetros elétricos do sistema e das propriedades da radiação incidente. Nesse modelo simples, a sensibilidade não depende do comprimento de onda da radiação incidente [36]:

$$
S_{e}=\frac{1}{2 i}\left(\frac{Z}{R}-1\right)
$$

onde Z e R são, respectivamente, a impedância e a resistência do elemento de absorção e $i$ é a corrente que percorre esse mesmo elemento.

Bolômetros resistivos podem ser tecnologicamente muito complicados, podendo utilizar desde ponte de Wheatstone para medir variações na termorresistência com maior precisão, até sofisticados sistemas ópticos, como os utilizados para medir a radiação de micro-ondas cósmica de fundo [37].

\subsection{Fotodiodo}

O fotodiodo é um tipo de fotodetector capaz de converter certas frequências da radiação eletromagnética incidente em um sinal de corrente elétrica. Fotodiodos são formados através da junção de semicondutores do tipo PN (ou PIN) sendo que um dos elementos 
semicondutores atua como foto-gerador de elétrons livres.

Um diodo é construído a partir da junção de materiais com dopagens opostas. O material do tipo $\mathrm{P}$ possui elementos com carência de elétrons em sua camada de valência (normalmente um composto trivalente) aumentando o número de portadores de cargas livres positivas, chamados de "lacunas", enquanto que o material do tipo N possui dopagem de elementos com elétrons excedentes (como um composto pentavalente) para aumentar assim o número de portadores de cargas livres negativas, os elétrons.

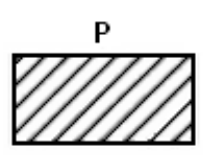

(a) antes do contato

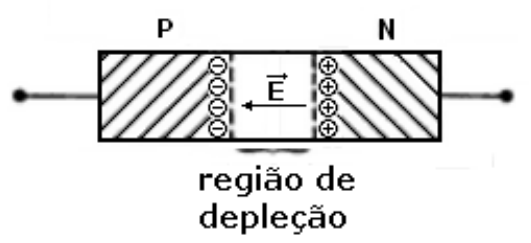

(b) depois do contato

Figura 3.2: Formação da região de depleção e do potencial de contato na junção PN.

Ao unir os elementos ocorre uma difusão dos elétrons do material N para o P. Os elétrons do material $\mathrm{N}$ começam a preencher as lacunas do material $\mathrm{P}$ gerando uma corrente entre os dois materiais. Essa corrente cessa quando o potencial elétrico for intenso o bastante para conter as forças de ionização dos compostos. O potencial de equilíbrio $V_{0}$ é chamado de potencial de contato. Essa região formada pela difusão dos elétrons é denominada região de depleção e está representada na figura (3.2).

A montagem e o funcionamento de um fotodiodo são semelhantes ao de um diodo. A região de depleção define boa parte das características do semicondutor. No caso do fotodiodo, deve ser mantida fina para reduzir o tempo de resposta, porém, para aumentar a eficiência quântica do detector, deve possuir camadas espessas o suficiente para permitir que uma grande fração de fótons incidentes possa ser devidamente absorvida. Existe então compromisso entre tempo de resposta e eficiência quântica [38].

Em um fotodiodo, entretanto, os portadores de carga são produzidos por fotoionização, como pode ser visto na figura (3.3). Os elétrons, produzidos pela fotoionização, são acelerados pelo campo elétrico até a camada $\mathrm{N}$, de onde podem percorre o circuito até o terminal positivo da fonte. Ao mesmo tempo as lacunas são coletadas pelo terminal negativo da fonte, ou seja, novos elétrons são inseridos nestas lacunas para que outros fótons possam produzi-los. Esse modo de operação é denominado modo fotocondutivo. Tal processo provoca uma pequena variação da corrente, que pode ser medida utilizando 
um amperímetro.

Ligando uma fonte de tensão reversamente polarizada, a barreira de potencial a ser vencida pelos elétrons é:

$$
\varepsilon=V_{0}+V
$$

onde $V_{0}$ é o potencial de contato característico do fotodiodo e $V$ é a tensão aplicada pela fonte.
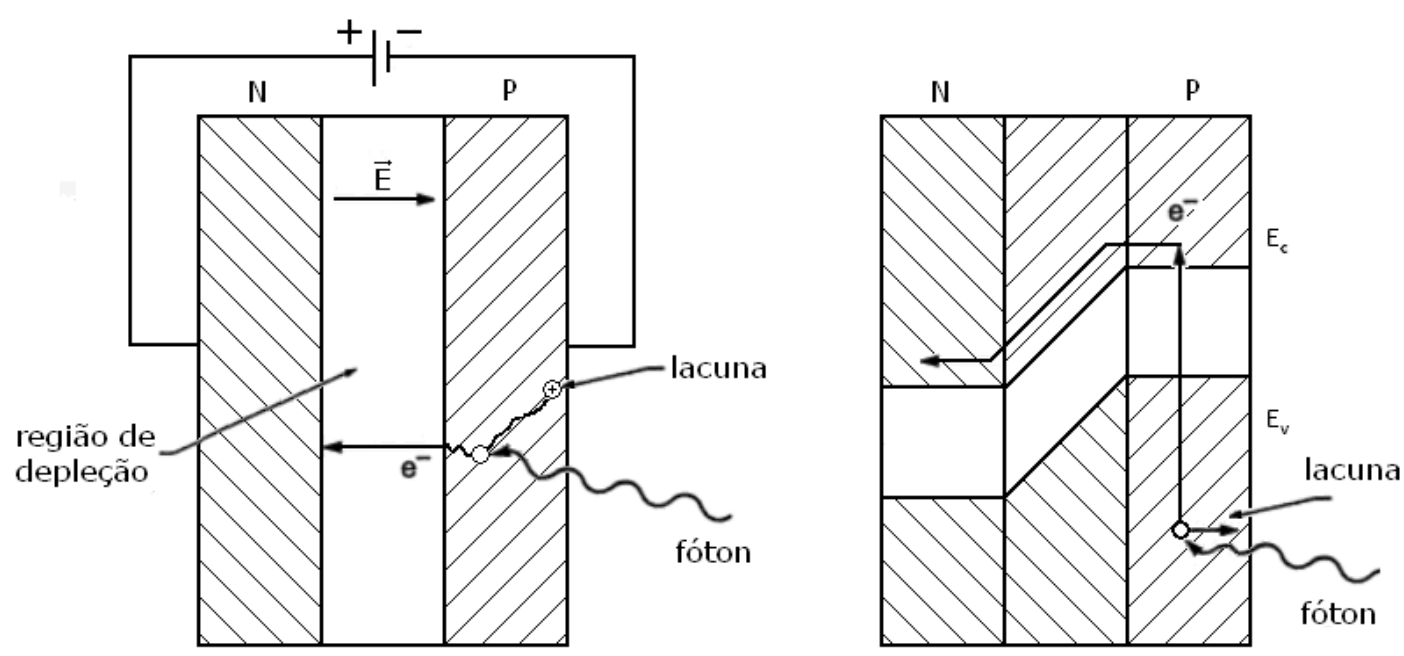

Figura 3.3: Processo de detecção em um fotodiodo. Os elétrons gerados por fotoionização são difundidos para a região de depleção, onde o campo os arrasta até a região $\mathrm{N}$

O tipo de operação mais sensível do fotodiodo é o modo fotovoltaico, que utiliza uma tensão $V$ nula. Assim, quando um elétron é produzido por um fóton ele tem que vencer apenas a barreira de potencial $V_{0}$, que pode ser escolhida de acordo com os elementos utilizados na confecção do fotodiodo.

A corrente gerada pelo fotodiodo $i_{f}$, chamada de fotocorrente, é definida pela taxa de fótons incidentes $N_{\phi}\left[s^{-1}\right]$, vezes a carga $(-q)$ do elétron vezes a eficiencia quantica $\eta$ do sistema, que é a razão entre o número de elétrons produzidos pelo número de fótons incidentes:

$$
i_{f}=-N_{\phi} q \eta
$$

A energia de um fóton é dada pela conhecida relação:

$$
E_{f}=h \nu=\frac{h c}{\lambda}
$$


Portando, a potência da radiação incidente é:

$$
P_{f}=N_{\phi} E_{f}=N_{\phi} \frac{h c}{\lambda}
$$

Relacionando essa potência incidente no fotodiodo com a fotocorrente definida na equação (3.19), é possível definir a sensibilidade do fotodiodo como a razão entre a fotocorrente e a potência incidente, ou seja:

$$
S_{f}=\frac{i_{f}}{P_{f}}=\frac{\eta \lambda q}{h c}
$$

Um importante aspecto deste tipo de detector é o fato de possuir comprimento de onda de corte $\lambda_{c}$, que é determinado pela "energia de bandgap" $\left(E_{g}\right)$ do elemento utilizado na confecção do semicondutor [36]:

$$
\lambda_{c}=\frac{h c}{E_{g}}=\frac{1,24 \mu m}{E_{g}(e V)}
$$

Determinar o tempo de resposta do fotodiodo não é uma tarefa simples. A constante que determina a resposta às variações de intensidade dependem, basicamente, de 3 constantes de tempo distintas [39]:

$\tau_{r c}:$ constante de tempo da combinação circuito-diodo, que está fortemente ligada a capacitância da região de depleção e do resistor de carga do fotodiodo;

$\tau_{d i}:$ tempo característico para os portadores de carga percorrerem as regiões dopadas;

$\tau_{d r}$ : tempo característico para os portadores de carga percorrerem a região de depleção;

e o tempo de resposta é dado por:

$$
\tau_{f o t}=\sqrt{\tau_{r s}^{2}+\tau_{d i}^{2}+\tau_{d r}^{2}}
$$

Com isso é possível definir uma frequência de corte para o fotodiodo, porém, o cálculo de cada um desses termos é muito complicado e requer conhecimentos muito específicos sobre a construção do semicondutor.

Contudo, essas informações são bem conhecidas pelo fabricante e, consultando o manual, é possível obter o tempo de resposta de um fotodiodo. 


\subsection{Comparação entre os detectores}

Com base nas definições acima, é possível comparar as principais características dos dois detectores. Um bolômetro metálico foi anteriormente utilizado no tokamak TCABR para medidas de potência média total irradiada pelo plasma [40]. As características específicas deste bolômetro resistivo podem ser utilizadas para determinar os principais parâmetros desse tipo de diagnóstico.

Fotodiodos também foram utilizados como bolômetros no tokamak TCABR, desta vez para determinar o perfil radial de potência média irradiada pelo plasma [41].

Um parâmetro importante a ser comparado é a dependência da sensibilidade de cada sensor com o comprimento de onda da radiação incidente. A equação (3.17) descreve a sensibilidade do bolômetro resistivo e mostra que a medida feita por esse detector não depende do comprimento de onda da radiação incidente, ao contrário do fotodiodo que, como pode ser visto na equação (3.22), possui uma dependência linear com o comprimento de onda.

Além disso, como também foi dito na seção (3.2), o dispositivo semicondutor possui um comprimento de onda de corte $\lambda_{c}$ devido a fatores quânticos, a partir do qual o sensor não é capaz de medir.

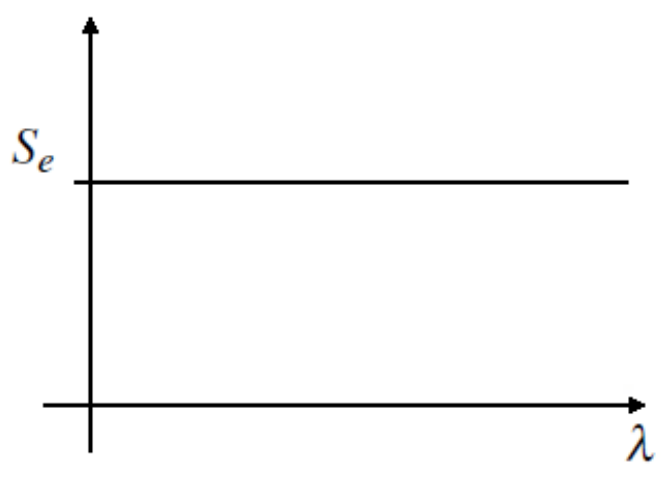

(a) Bolômetro resistivo

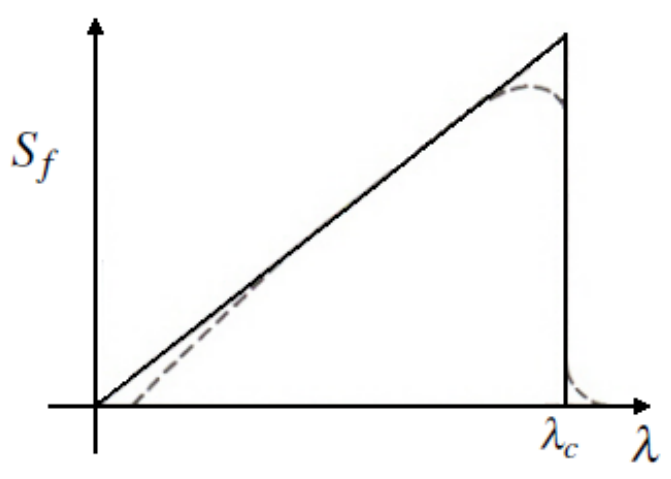

(b) Fotodiodo

Figura 3.4: Representação da dependência da sensibilidade com o comprimento de onda da radiação incidente para os sensores: (a) bolômetro resistivo e (b) fotodiodo. No caso do fotodiodo a linha contínua mostra a resposta ideal do sensor e a linha tracejada representa os desvios típicos [36].

A figura (3.4) mostra uma representação da dependência com o comprimento de onda no caso dos dois detectores descrita através dos modelos apresentados nas seções 
anteriores. As curvas mostradas nessa figura foram obtidas a partir de modelos simples, mas que fornecem boas diretrizes de comparação. Existem, entretanto, diversos fatores eletrônicos e quânticos da própria confecção que os tornam mais complexos, alterando a forma dessas curvas, como a apresentada na figura (3.8).

Utilizando os valores do bolômetro que operou no TCABR, disponíveis na tabela (3.1), é possível estimar o tempo de resposta $\tau$ utilizando a equação (3.8).

\begin{tabular}{|c|c|}
\hline \multicolumn{2}{|c|}{ Parametros do bolômetro metálico } \\
\hline Capacidade térmica $(C)$ & $2,2 \mathrm{~mJ} / \mathrm{K}$ \\
\hline Condutividade térmica $(G)$ & $11 \mathrm{~mW} / \mathrm{K}$ \\
\hline Coef. de temperatura da resistência $(\alpha)$ & $2,710^{-3} \mathrm{~K}^{-1}$ \\
\hline Resistência de corrente nula $\left(R_{0}\right)$ & $4,7 \mathrm{k} \Omega$ \\
\hline
\end{tabular}

Tabela 3.1: Principais parâmetros do bolômetro metálico utilizado no TCABR [40].

Usando esses valores no cálculo, o tempo de resposta será da ordem de: $\tau \approx 200 \mathrm{~ms}$. Portanto, a frequência de corte deste detector seria da ordem $f_{C b o l} \approx 5 \mathrm{~Hz}$. Para frequências de oscilações mais altas do que essa, a eficiência do detector é fortemente reduzida.

Os fotodiodos utilizados para fins de bolometria no tokamak TCABR, modelo AXUV16EL, possuem um tempo de resposta muito menor [41]. De acordo com o manual do fabricante, o fotodiodo modelo AXUV16EL, produzido pela International Radiation Detectors (IRD), possui um tempo de resposta de $\tau_{f o t}=0,5 \mu s$ [42]. Com esse tempo de resposta, a frequência de corte do fotodiodo é de aproximadamente $f_{C f o t}=2,0 \mathrm{MHz}$.

A banda de frequência de interesse no tokamak TCABR, nesta experiência, é a das oscilações MHD. Estas oscilações possuem frequências características em cada tokamak e, no TCABR, são da ordem de $f_{M H D}=10 k H z \sim 15 k H z$ [43]. A figura (3.5) mostra a curva de resposta em frequência para estes sensores.

A partir dessas análises é possível concluir que o bolômetro resistivo é um diagnóstico ideal para medidas de potência total irradiada em termos absolutos, por outro lado, a baixa resposta em frequência deste sensor não permite utiliza-lo para monitorar e estudar as instabilidades MHD, pois, como foi mostrado, a frequência característica das oscilações MHD $f_{M H D}$ é mais alta que sua frequência de corte $f_{C b o l}$.

Sobre o fotodiodo é possível afirmar exatamente o contrário: a não linearidade faz com que não seja um bom sensor para medidas absolutas da potência irradiada pelo plasma, quando comparado com o bolômetro resistivo, pois não detecta todo o tipo de radiação com o mesmo ganho. Entretanto, por possuir um tempo de resposta muito menor que 
aquele, é mais adequado para medidas de oscilações rápidas da potência radiante emitida pelo plasma.

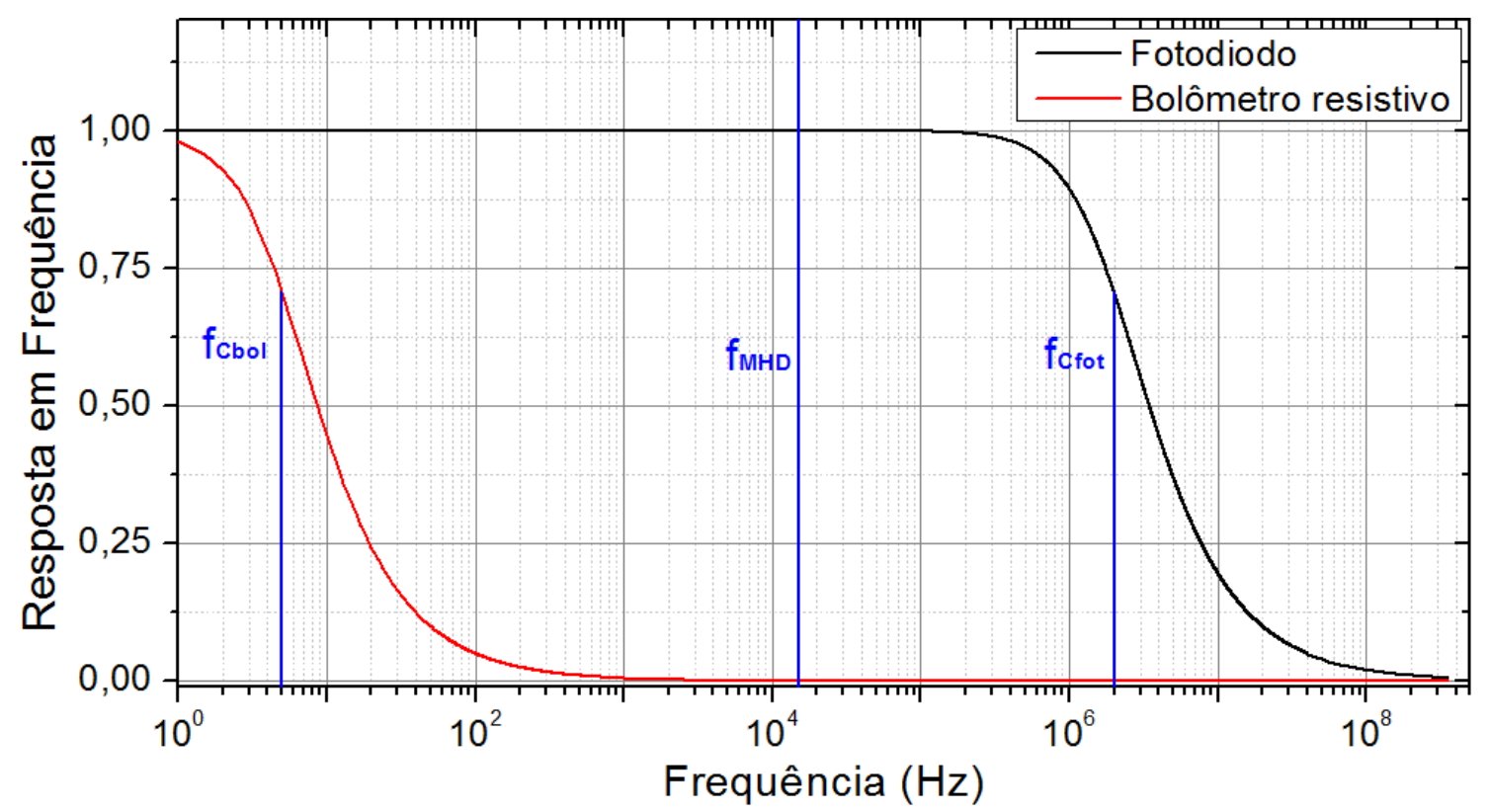

Figura 3.5: Representação da resposta em frequência do bolômetro resistivo e do fotodiodo. As linhas verticais azuis indicam as frequências de corte de cada sensor e a frequência de Mirnov para o tokamak TCABR.

Os dois tipos de detectores, então, são úteis em experimentos específicos. Os fotodiodos são capazes de medir as modulações na radiação provocadas pelas oscilações MHD, permitindo o estudo e o monitoramento das mesmas. O bolômetro resistivo, por outro lado, possui resposta uniforme em todas as frequências do espectro de radiação, mostrando-se um excelente diagnóstico para medir o potência total irradiada pelo plasma.

\subsection{Câmara bolométrica}

A fim de mapear as oscilações MHD através da potência radiante emitida pelo plasma, é necessário utilizar uma grande quantidade de fotodiodos posicionados de forma tal que toda a seção poloidal da coluna de plasma seja medida.

Para fazer isso foi montado um sistema bolométrico utilizando arrays de fotodiodos e fendas retangulares, a fim de colimar as cordas de visão de cada fotodiodo e, assim, monitorar toda uma secção poloidal da coluna de plasma.

Para que os fotodiodos pudessem ser instalados no interior da câmara de vácuo, foi construída uma câmara bolométrica especial onde foram instalados três arrays de 
detectores e três fendas, como é mostrado na figura (3.6).

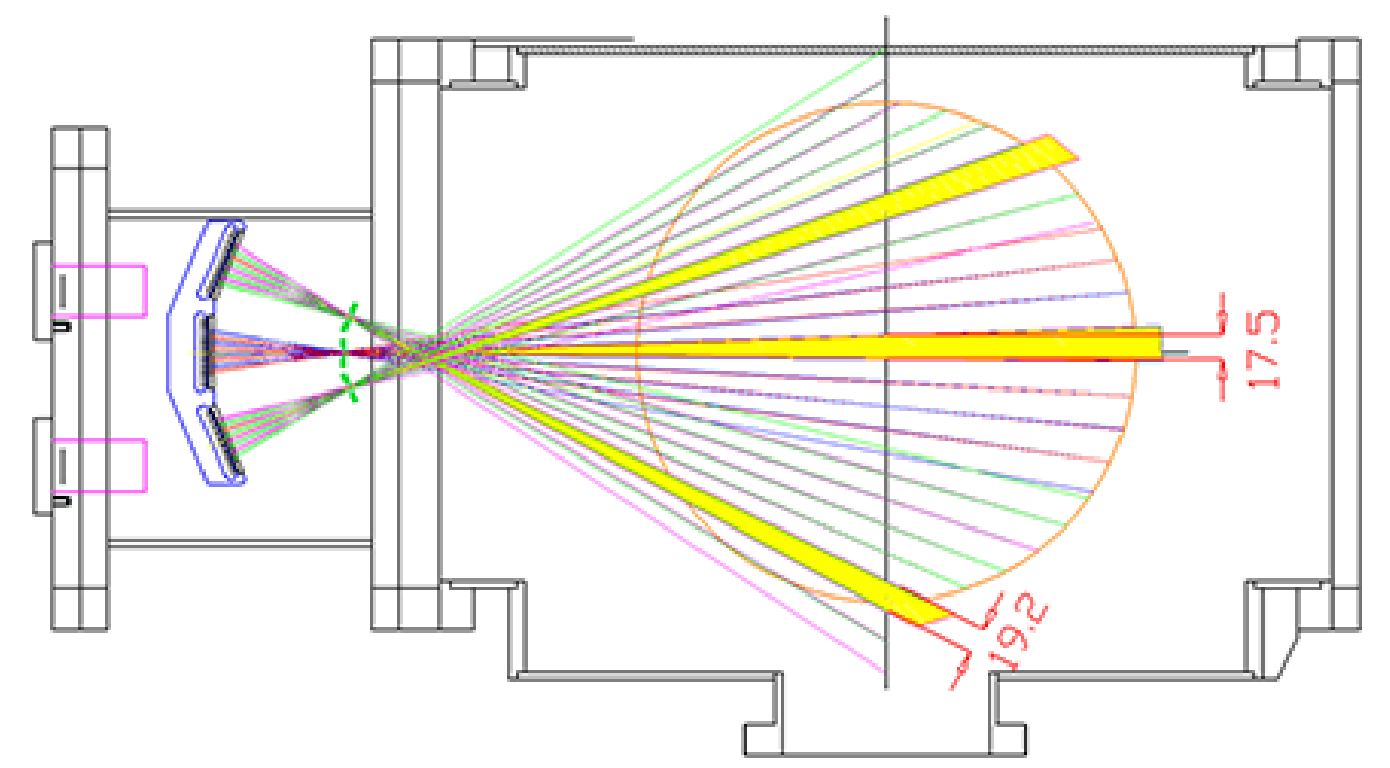

Figura 3.6: Esquema mostrando a abertura das cordas do bolômetro, dando detalhe a três delas. As dimensões das aberturas no eixo central estão mostradas em milímetros.

Os arrays utilizados neste experimento são do modelo AXUV16EL, que já haviam sido utilizados em experiências de bolometria do tokamak TCABR e em experiências de bolometria de alta resolução do tokamak Alcator C-Mod [44]. Esse dispositivo é um "vetor linear" contendo 16 fotodiodos de $10 \mathrm{~mm}^{2}$ de área ativa cada um. A figura (3.7) mostra um desenho deste detector com todas as cotas em milímetros.
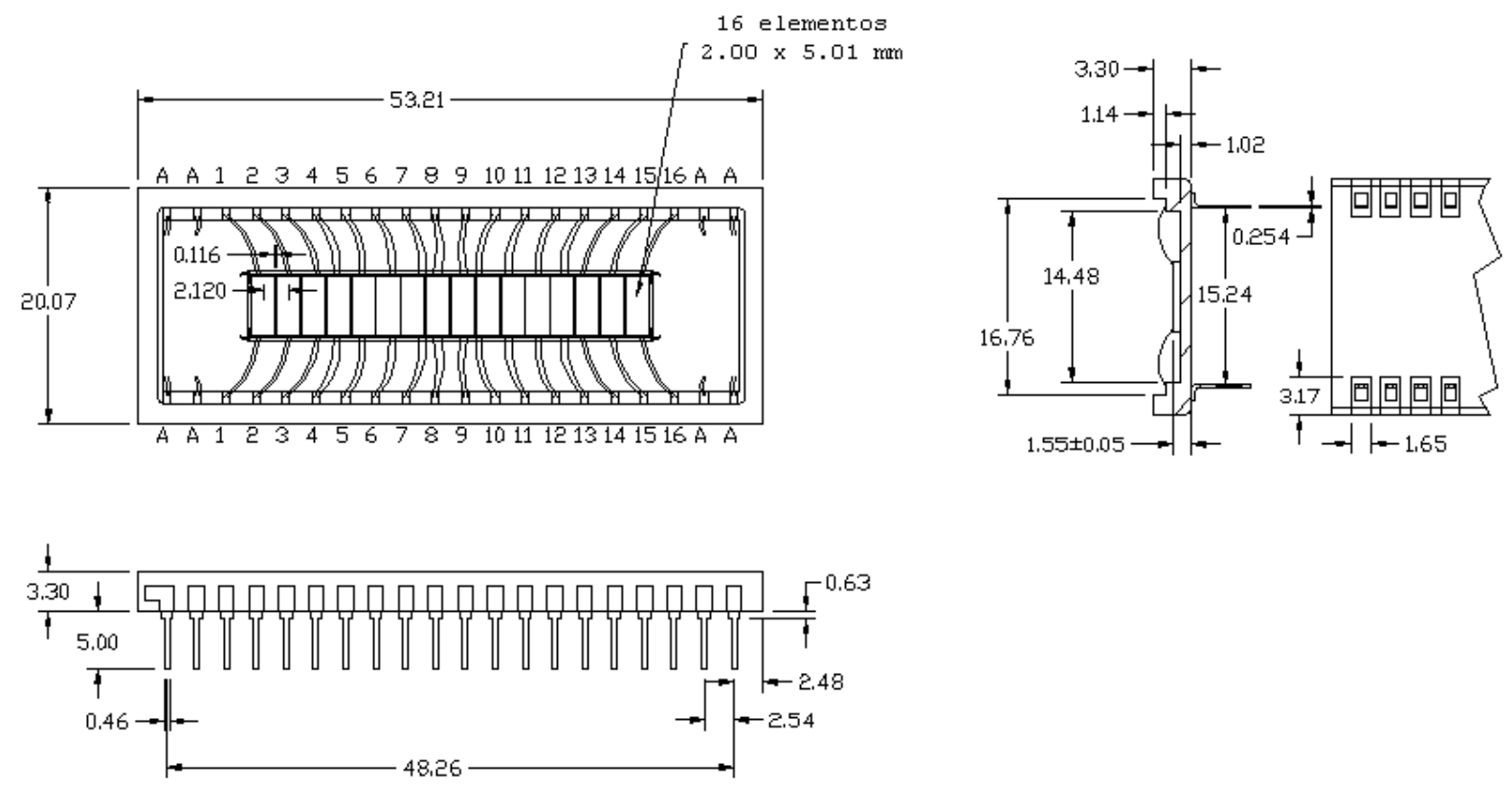

Figura 3.7: Esquema mostrando as dimensões do array de fotodiodos AXUV16ELO [42]. 
A vantagem de se utilizar esses arrays é que eles contêm um grande número de fotodiodos com posições bem estabelecidas, o que possibilita o monitoramento de toda a coluna de plasma com boa resolução, definida pela abertura da fenda utilizada para colimar a radiação incidente sobre cada elemento do array. O sistema para este experimento foi montado utilizando 24 fotodiodos.

O gráfico apresentado na figura (3.8) mostra a curva de sensibilidade deste detector em função do comprimento de onda. Embora esse detector apresente uma sensibilidade que dependa do comprimento de onda, como foi visto na seção (3.2), ele pode ser usado para o estudo das oscilações MHD.

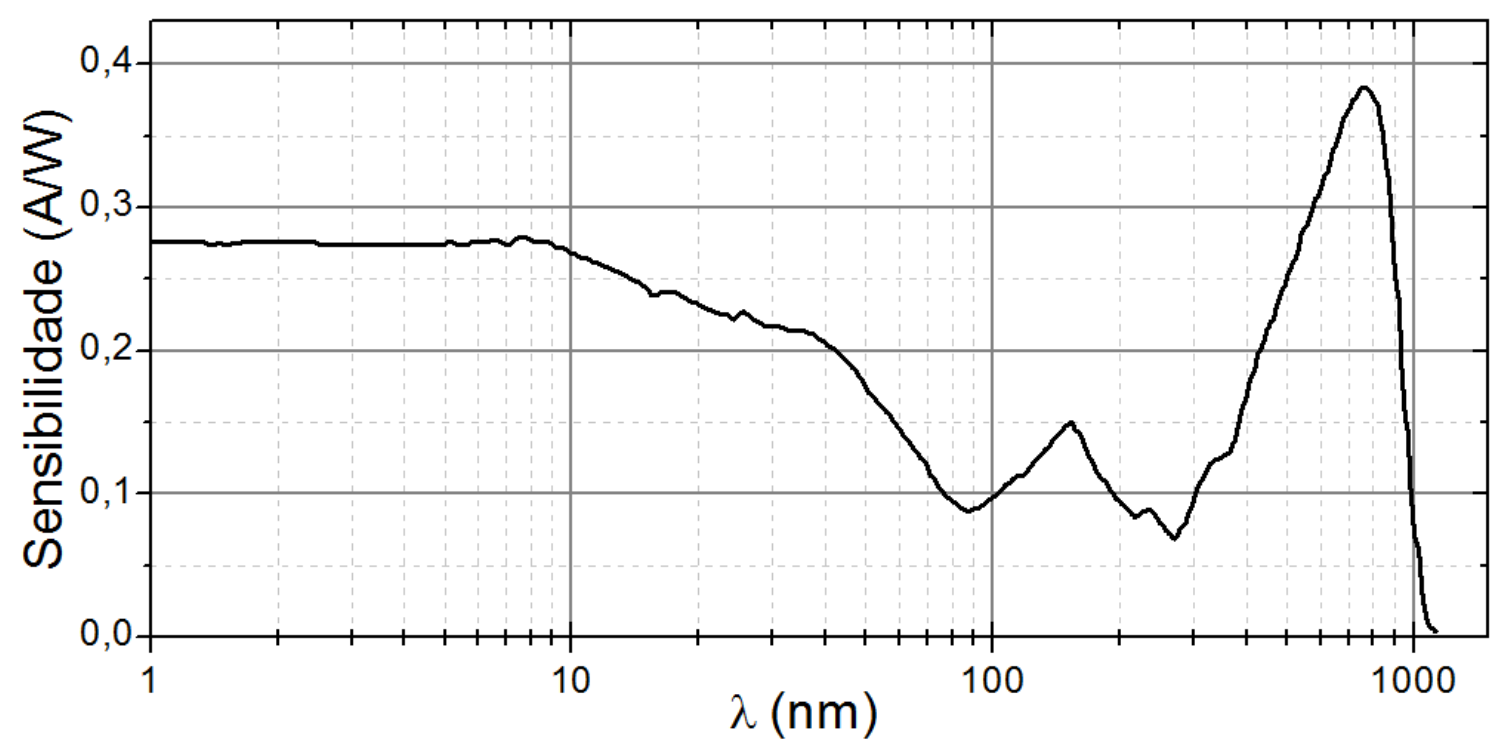

Figura 3.8: Gráfico da sensibilidade dos fotodiodos do array AXUV16ELO em função do comprimento de onda da radiação incidente [42].

As três fendas, que determinam as cordas de visão do bolômetro, foram cortadas a laser em chapas de aço inox com 1,90 $\mathrm{mm}$ de abertura na direção poloidal, 25, $85 \mathrm{~mm}$ de abertura na direção toroidal e 0,25 $\mathrm{mm}$ de espessura.

A câmara bolométrica, onde foram fixados os arrays de fotodiodos, foi fabricada em aço inox, de modo que possa ser fixada na parte superior da câmara do tokamak. As figuras (3.9a) e (3.9b) mostram detalhes dessa base de fixação da câmara bolométrica e do suporte para o fotodiodo, respectivamente.

A tampa da câmara bolométrica foi fixada ao corpo com parafusos e a vedação foi feita utilizando anéis de alumínio e um o-ring de borracha. Detalhes da montagem e da câmara bolométrica são mostrados nas figuras (3.10a) e (3.10b). 


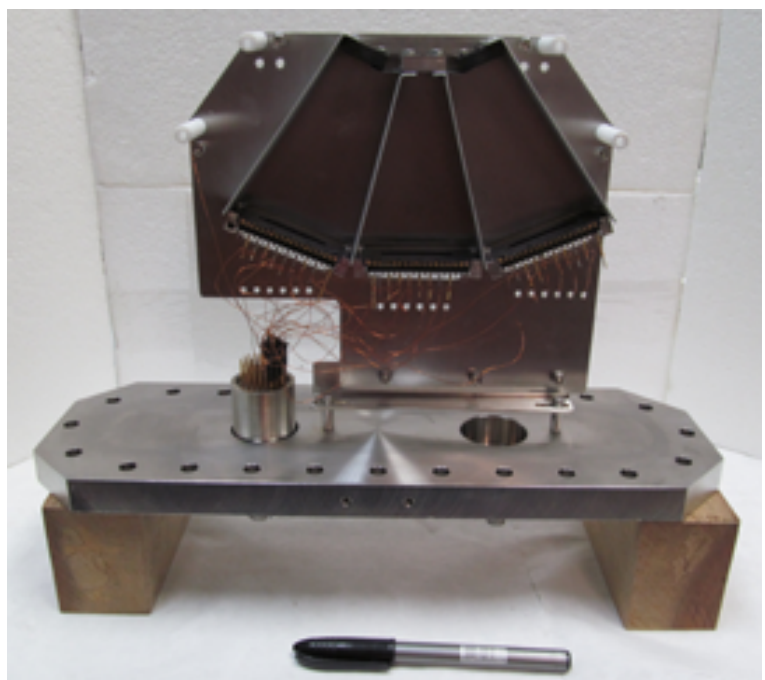

(a)

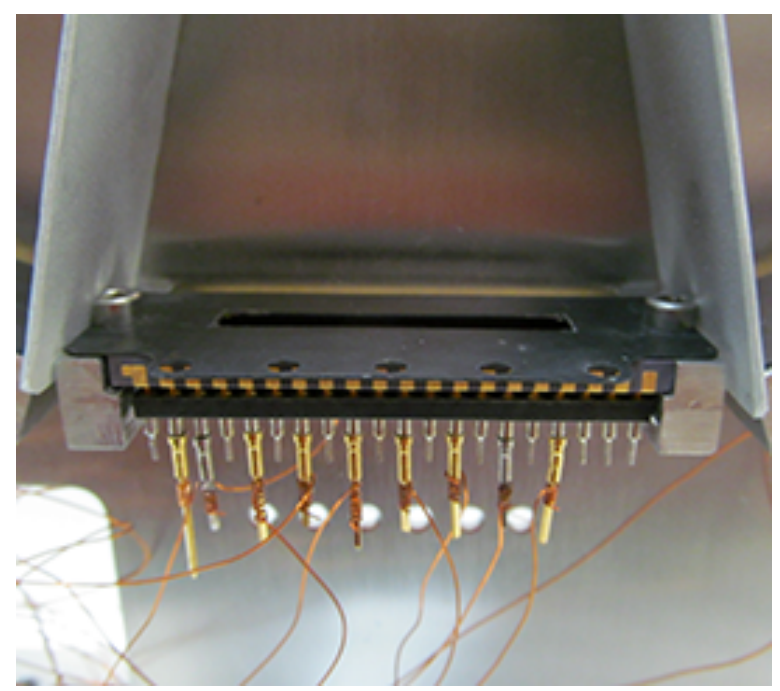

(b)

Figura 3.9: Em (a), detalhe da tampa superior da câmara bolométrica, onde são fixados os arrays de fotodiodos, suas respectivas fendas, o passador de fios e todas as conexões elétricas. Em (b), é mostrado um detalhe do suporte do array e os contatos elétricos dos fotodiodos.

O tokamak e todos os seus sistemas são uma grande fonte de ruídos e, para evitar que esse ruído possa interferir nos sinais do bolômetro o contato elétrico entre a câmara bolométrica e o tokamak foi impedido através da utilização de um isolante de teflon, como mostrado na figura (3.11b).

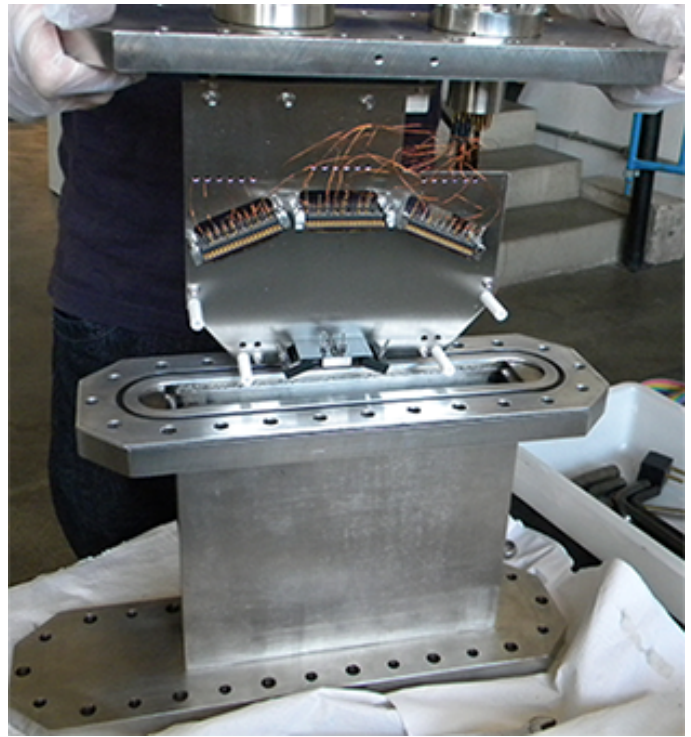

(a)

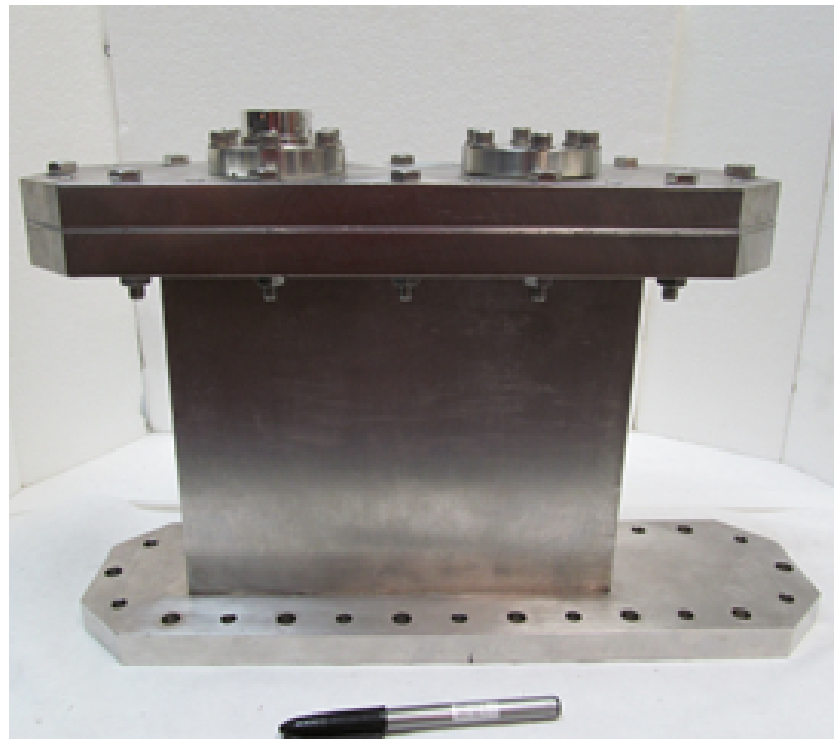

(b)

Figura 3.10: Em (a) é mostrada a montagem da câmara bolométrica e, em (b), a câmara bolométrica fechada e pronta para ser instalada no tokamak. 
Para evitar que partículas atinjam os detectores durante o modo limpeza do tokamak, foi instalado um shutter entre o plasma e as fendas. O acionamento do shutter é feito de através de um sistema pneumático. A figura (3.11a) mostra uma foto do shutter.

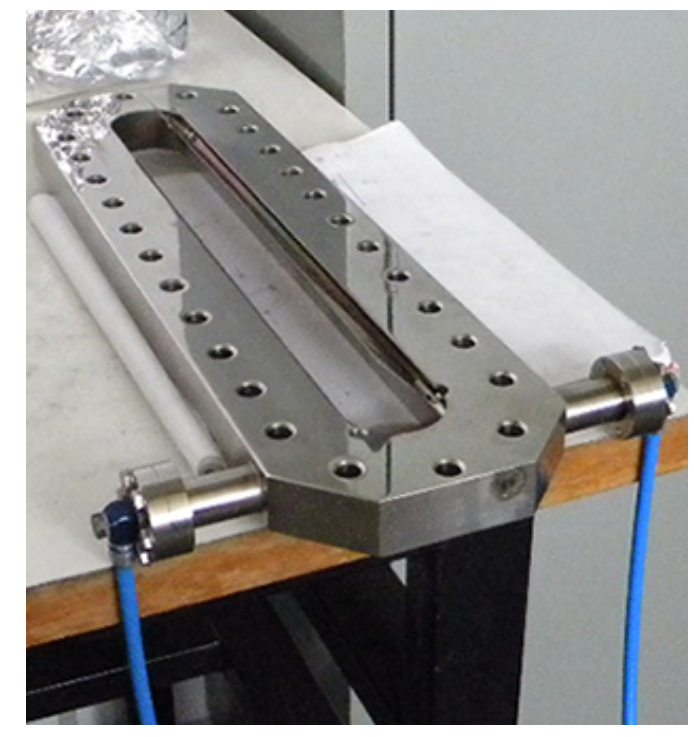

(a)

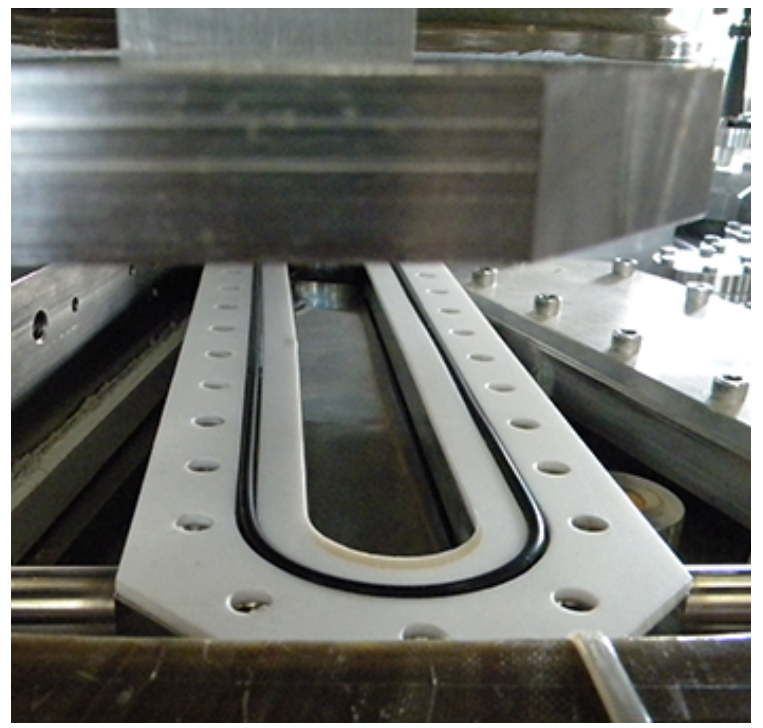

(b)

Figura 3.11: Em (a), shutter utilizado para proteção dos fotodiodos no modo de limpeza. Em (b) é apresentado um detalhe do shutter fechado, quando instalado no tokamak. nesta mesma figura é possivel ver os anéis de teflon que isolam eletricamente a câmara bolométrica do tokamak.

O fechamento do shutter é acionado automaticamente quando a máquina entra em modo de limpeza através de um sistema montado especificamente para o bolômetro. O circuito desse sistema está apresentado na figura (3.12).

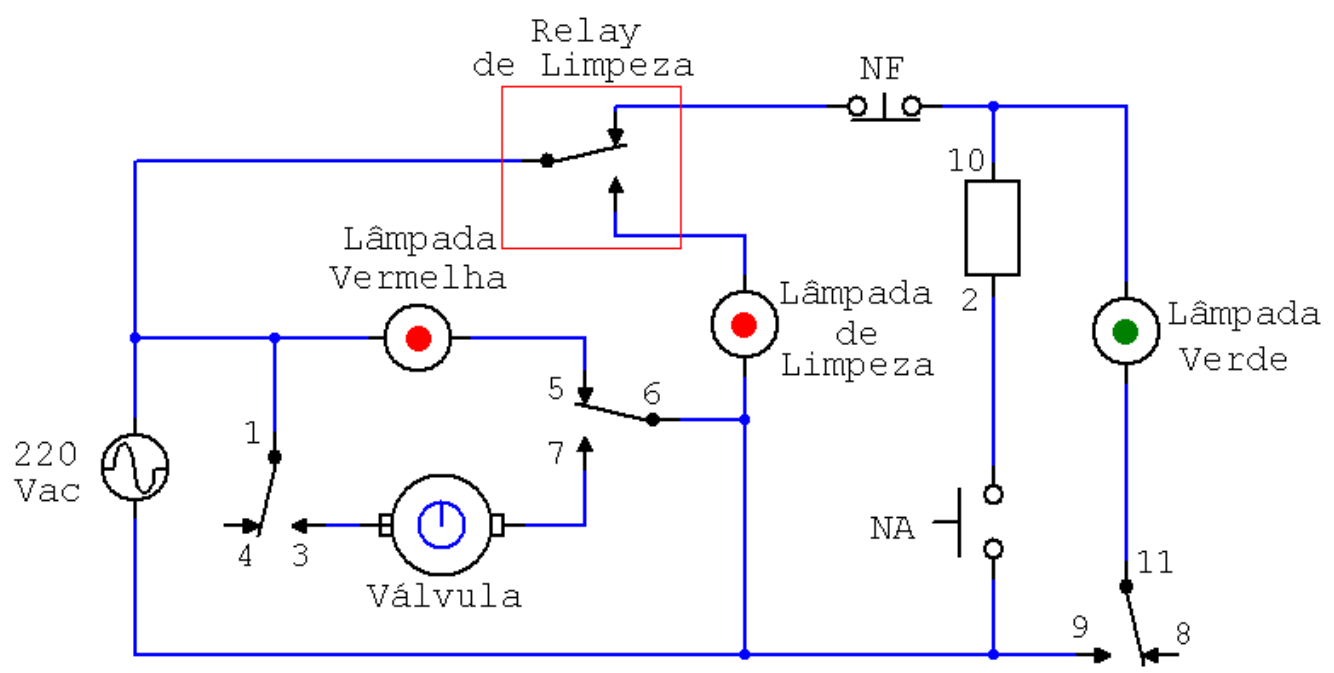

Figura 3.12: Circuito do sistema de fechamento automático do shutter do bolômetro. 
A figura (3.13) mostra um esquema com todos os detalhes e indicações do diagnóstico montado. Também é possível ver nessa figura as bissetrizes das cordas bolométricas, traçadas do centro de cada fotodiodo passando pelo meio de sua respectiva fenda.

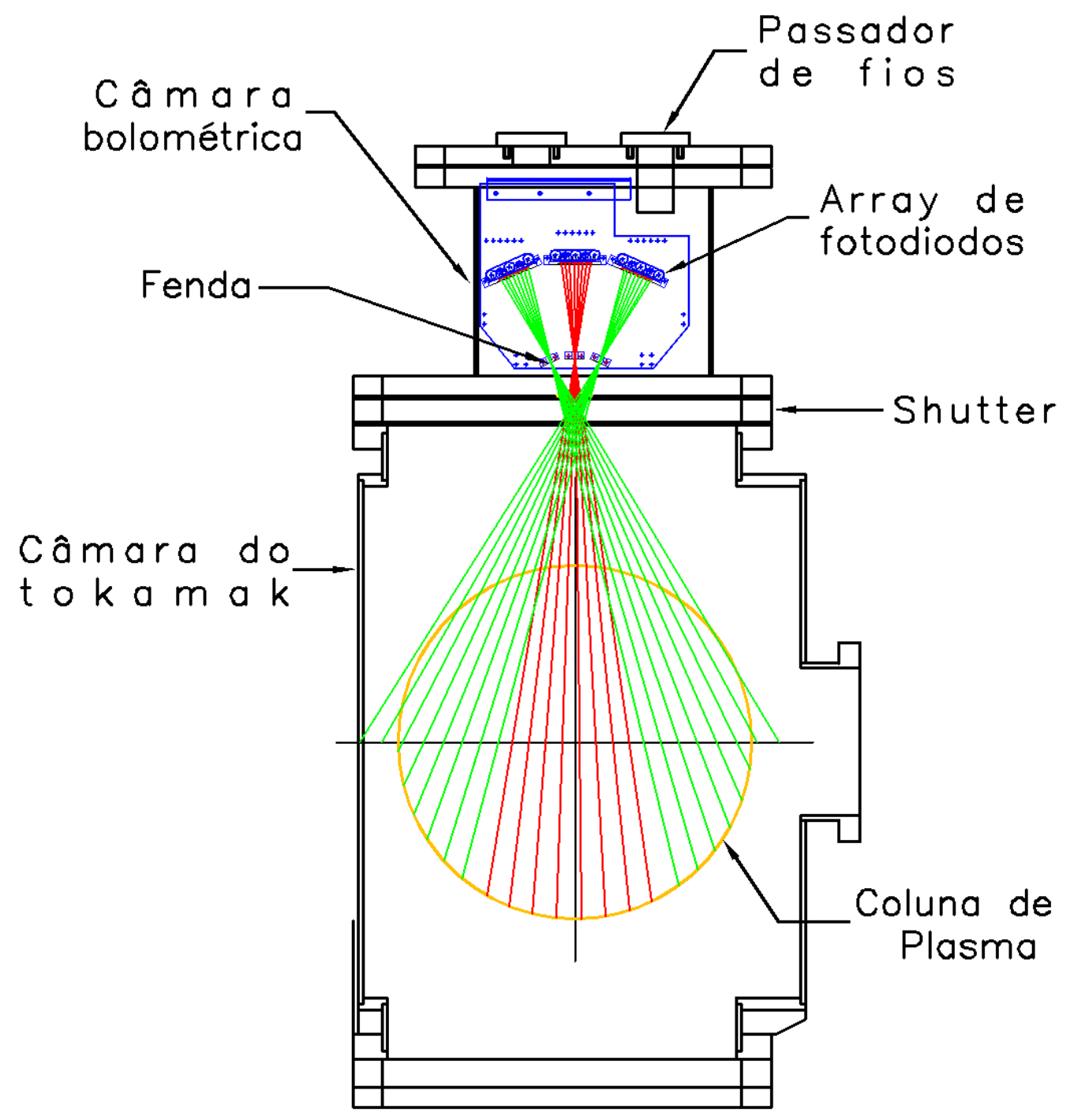

Figura 3.13: Esquema mostrando a montagem do bolômetro e do shutter na câmara de vácuo no tokamak TCABR. As cordas bolométricas, cujas bissetrizes estão representadas pelas linhas verdes e vermelhas, fazem um mapeamento completo da coluna de plasma.

\subsection{Amplificadores e sistema de aquisição}

O sinal de saída de um fotodiodo é basicamente uma corrente, produzida pela conversão da energia do fóton em energia cinética para os elétrons. Por si só, os fotodiodos podem produzir um sinal com voltagem suficiente para medidas grosseiras, entretanto, esse modo de operação produz um sinal de resposta não linear e possui uma banda 
passante muito restrita [39].

A utilização de um amplificador operacional como um conversor de corrente para tensão melhora drasticamente o desempenho do fotodiodo quando o objetivo é fazer medidas rápidas, precisas e com boa resolução. Um amplificador operacional é um amplificador (Amp Op) diferencial de alto ganho com alta impedância de entrada e baixa impedância de saída [45].

Entretanto, a utilização deste artifício requer um estudo detalhado dos componentes utilizados e dos resultados que se deseja obter, pois existe um importante compromisso entre ganho, banda de resposta em frequência, estabilidade, ruído e nível DC.

Neste experimento utilizou-se o mesmo circuito para os amplificadores que fora proposto pelo Dr. Bellintani em seu trabalho de doutorado [41]. Este circuito, que está apresentado na figura (3.14a), consiste de um amplificador operacional modelo LF365N, um capacitor de $0,33 p F$ e um resistor de $680 k \Omega$.

Para testar a resposta em frequência desse sistema montou-se um aparato utilizando um array de fotodiodos AXUV16EL ligado a um amplificador e um LED T-15522 de alta frequência ligado a um gerador de sinais.

Aplicando um sinal senoidal no LED e incidindo a luz produzida sobre os fotodiodos é possível medir o ganho do sistema em função da frequência aplicada. A figura (3.14b) mostra uma curva de ganho obtida através deste procedimento, que é uma informação importante do diagnóstico.

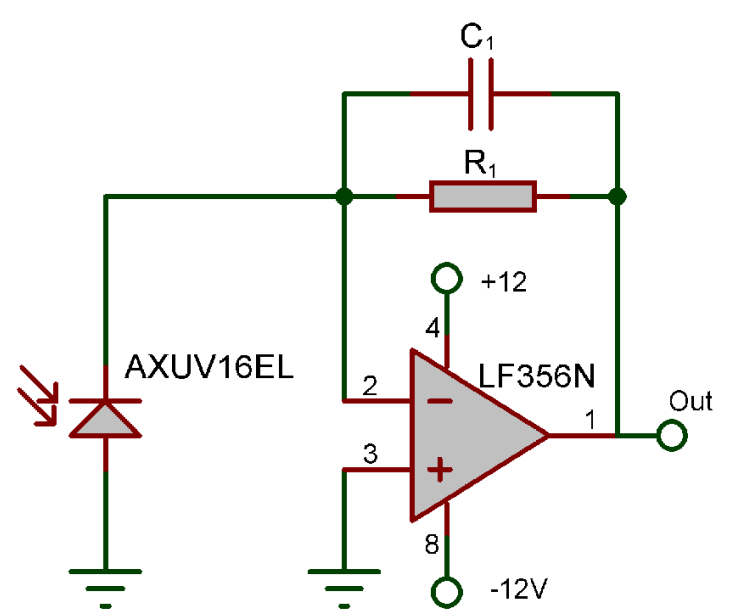

(a)

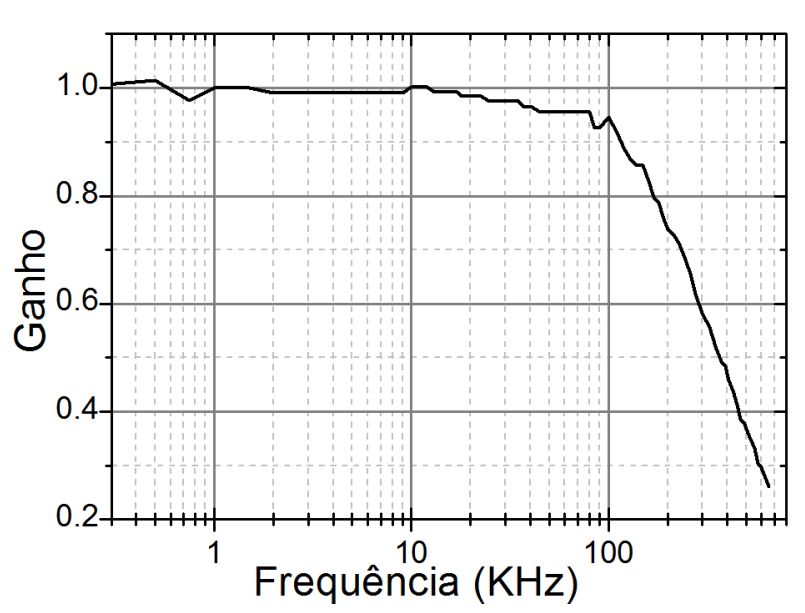

(b)

Figura 3.14: Esquema dos circuito de amplificação dos sinais bolométricos (a). Cada fotodiodo possui um circuito próprio. Em (b), está mostrado um gráfico do ganho do sistema de fotodiodos e amplificadores utilizados nesta experiência.

Os amplificadores foram montados e fixados dentro de uma caixa de alumínio aterrada 
para reduzir o ruído e proteger os componentes. Essa caixa de alumínio foi fixada logo na saída do passador de fios da câmara bolométrica para evitar perda do sinal proveniente dos fotodiodos.

Os sinais de saída dos amplificadores são conduzidos até o sistema de aquisição de dados utilizando cabos coaxiais. A malha destes cabos foi aterrada na caixa dos amplificadores e na câmara bolométrica.

A aquisição dos dados é feita através de uma interface VME a uma taxa de aquisição de $500 \mathrm{kSamples}$ por canal, que equivale a 100 mil pontos por canal, no intervalo de $200 \mathrm{~ms}$ que compreende a duração do plasma [46].

Os dados experimentais do tokamak TCABR são armazenados em um banco de dados gerenciados em MySQL. O acesso do usuário a este banco de dados é feito através do sistema MDSPlus, que permite exporta-los diretamente para outros programas de tratamento de dados, como OCTAVE, IDL e MATLAB [47]. 


\section{Simulação e método de análise}

A análise dos modos MHD é feita através do estudo detalhado do perfil espacial e temporal do espectro dos sinais obtidos com os diagnósticos de bolometria, raios-X mole e bobinas de Mirnov. No entanto, a interpretação do espectro não é uma tarefa muito simples.

Tanto os sinais ópticos quanto os magnéticos são características integrais do plasma e dependem fortemente dos perfis espaciais dos parâmetros macroscópicos, tais como temperatura, densidade e corrente. Estes sinais, por sua vez, ainda são dependentes do tempo, o que dificulta muito sua comparação com modelos teóricos.

Uma maneira de sanar este problema é utilizar artifícios de simulações computacionais para prever e comparar os resultados. Através da simulação de uma perturbação conhecida é possível gerar sinais simulados provenientes de um sistema com características geométricas iguais as dos diagnósticos usados no tokamak, possibilitando a comparação com os resultados experimentais.

Para analisar os dados experimentais foram utilizadas diversas técnicas de análise espectral que, por si só, não dão informação suficiente para discriminar o tipo e determinar os parâmetros de um modo perturbativo presente no plasma. A aplicação destes métodos aos resultados simulados fornecem informações que permitem compreender melhor o resultado experimental.

A simulação e a análise de seus resultados fornecem um bom modelo para determinar os parâmetros das perturbações medidas experimentalmente no tokamak TCABR. A seguir serão descritos a simulação de dados para o diagnóstico bolométrico e os processos de análise dos sinais simulados e experimentais.

\subsection{Simulação das medidas bolométricas}

Para realizar a simulação, um programa foi desenvolvido em MatLab. Este programa cria uma grade mapeada com unidades métricas reais e a cada pixel é atribuído um valor de emissividade. Para simular as medidas do bolômetro, são traçadas cordas ao longo dessa grade de acordo com as posições reais das fendas e dos fotodiodos, então, os valores de emissividade são somados ao longo destas cordas.

A ideia é de que cada pixel represente um elemento de volume do plasma, ao qual corresponde um valor de emitância. O resultado da soma da emitância ao longo de uma 
corda é a potência instantânea irradiada por todo esse volume de plasma.

Variando a distribuição de emitância na grade, por exemplo, de acordo com as modulações causadas pela atividade MHD, e refazendo a soma sobre os elementos de cada corda é possível obter outro resultado para a potência instantânea irradiada em um instante posterior. Repetindo esse procedimento até formar um intervalo de tempo suficientemente grande é possível fazer uma análise espectral destes sinais simulados.

Um modelo simples para essa simulação é utilizar um perfil radial cúbico para a emitância natural do plasma [48]:

$$
\epsilon(r)=\epsilon_{0}\left(1-\left(\frac{r}{a}\right)^{3}\right)
$$

onde $a$ é o raio do plasma e $\epsilon_{0}$ a emitância no centro da coluna. Na figura (4.1a) são mostradas os ângulos de visada visto por cada fotodiodo, e a figura (4.1b), mostra um exemplo da grade com perfil de emitância descrito pela equação (4.1).

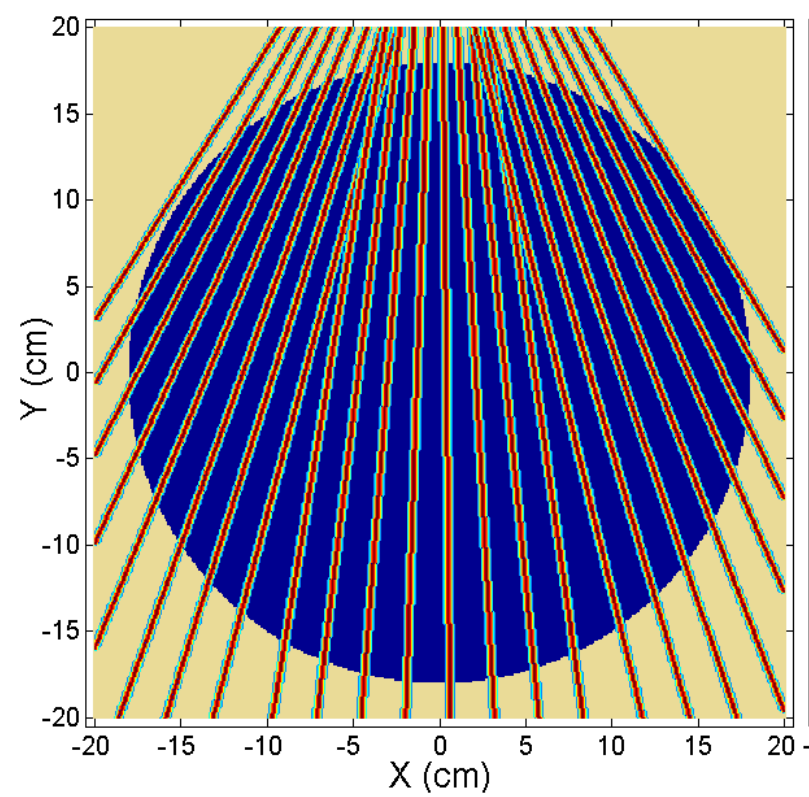

(a)

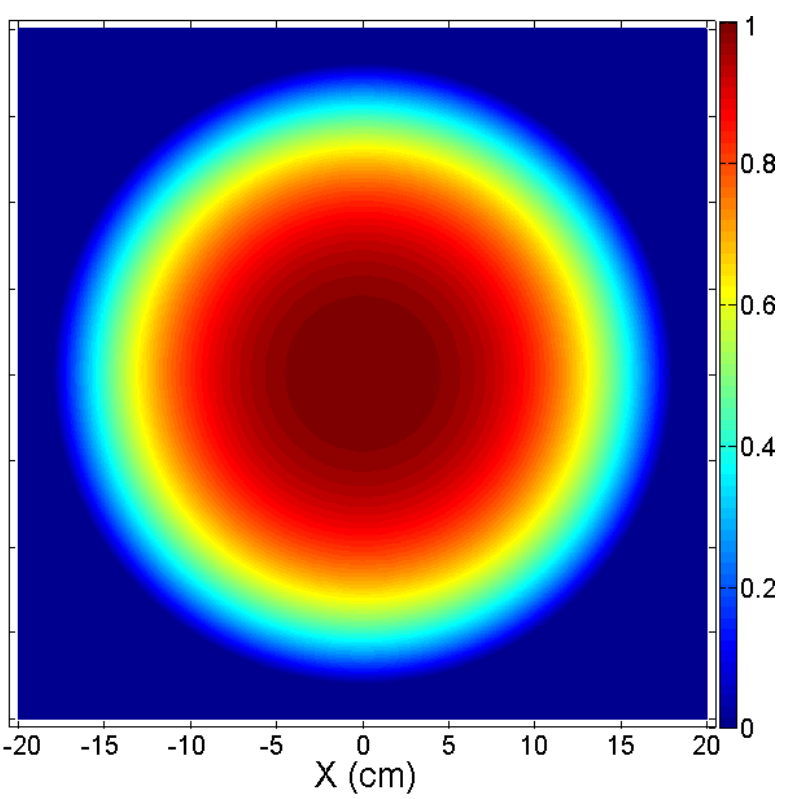

(b)

Figura 4.1: A figura (a) mostra a grade mapeada com o posicionamento das cordas do bolômetro e a posição do plasma. Na figura (b) um perfil de emitância foi computado na grade em uma escala de cores em unidades normalizadas.

Para simular o efeito do ângulo visada, para cada corda foi associado um fator de correção gaussiano, ou seja, a emissividade é multiplicada por um fator que tende a 0 na borda da corda, assume o valor 1 no centro e é modulado por uma gaussiana. Quanto mais afastado da fenda, maior a largura dessa gaussiana, simulando assim não apenas o 
ângulo de abertura, mas também a eficiência reduzida que o detector possui nas bordas.

O objeto de interesse neste trabalho não é a potência total irradiada pelo plasma, mas sim as oscilações que modulam os sinais de potência irradiada captados pelo bolômetro. Para simular essas perturbações basta somar ao perfil o efeito causado pela instabilidade que se deseja estudar.

Dois tipos de perturbações foram abordados: uma perturbação gaussiana simples, que mostrou ser de grande utilidade para modelar os efeitos causados pelo precursor das instabilidades dentes de serra, e uma perturbação de gaussiana dupla, que foi utilizada com sucesso para descrever os efeitos causados pelas ilhas magnéticas nas medidas bolométricas.

\subsubsection{Perturbação gaussiana}

Em uma abordagem simples, a perturbação no perfil de potência irradiada pode ser descrito, para o caso de um plasma ideal e cilíndrico, em termos de uma função dividida em duas componentes: uma que descreve os parâmetros radiais da perturbação e outra que descreve os parâmetros angulares.

Supondo que, não ocorra mudanças nos parâmetros radiais da perturbação, estas podem ser descritas por um perfil gaussiano radial. Uma função que pode ser utilizada para modelar essa componente radial da perturbação é [49]:

$$
\epsilon_{r}(r)=\epsilon_{0 r} e^{-\left[\left(r-r_{s}\right) / \sigma_{r}\right]^{2}}
$$

onde $r_{s}$ é a superfície ressonante, $\sigma_{r}$ a largura radial e $\epsilon_{0 r}$ é a amplitude da perturbação.

A parte que corresponde a componente angular $\theta$, é responsável pela determinação do modo e pelo deslocamento na perturbação gaussiana, fazendo com que ela viaje ao redor do eixo magnético do plasma com uma velocidade característica. Uma maneira simples de escrever essa componente é [50]:

$$
\epsilon_{\theta}(\theta, t)=\epsilon_{0 \theta}\left[1+\cos \left[m \theta(t)+\theta_{0}\right]\right]
$$

onde $m$ é o modo poloidal, $\theta_{0}$ é uma fase inicial, $\theta(t)=2 \pi f t$ é a posição angular poloidal da perturbação no plasma, $f$ é a frequência de rotação e $\epsilon_{0 \theta}$ sua amplitude.

A multiplicação das equações (4.2) e (4.3) descreve uma perturbação gaussiana radial que é poloidalmente modulada de acordo com seu modo $m$ : 


$$
\epsilon_{p}(r, \theta, t)=\epsilon_{0 p} e^{-\left[\left(r-r_{s}\right) / \sigma_{r}\right]^{2}}\left[1+\cos \left(m \theta(t)+\theta_{0}\right)\right]
$$

onde $\epsilon_{0 p}$ é a amplitude da perturtabação. Essa equação descreve uma perturbação gaussiana simples com modo $m$ bem definido. Para descrever mais modos em um mesmo plasma e com parâmetros diferentes, basta fazer uma somatória sobre todos os parâmetros para um mesmo instante de tempo:

$$
\epsilon_{p}(r, \theta, t)=\sum_{i} \epsilon_{0 p i} e^{-\left[\left(r-r_{s i}\right) / \sigma_{r i}\right]^{2}}\left[1+\cos \left(m_{i} 2 \pi f_{i} t+\theta_{0 i}\right)\right]
$$

O perfil de emitância total será, então, a soma do perfil da perturbação com o perfil de emissividade natural do plasma. A figura (4.2) mostra o perfil de emitância com a presença de uma perturbação gaussiana de modo $m=1$.
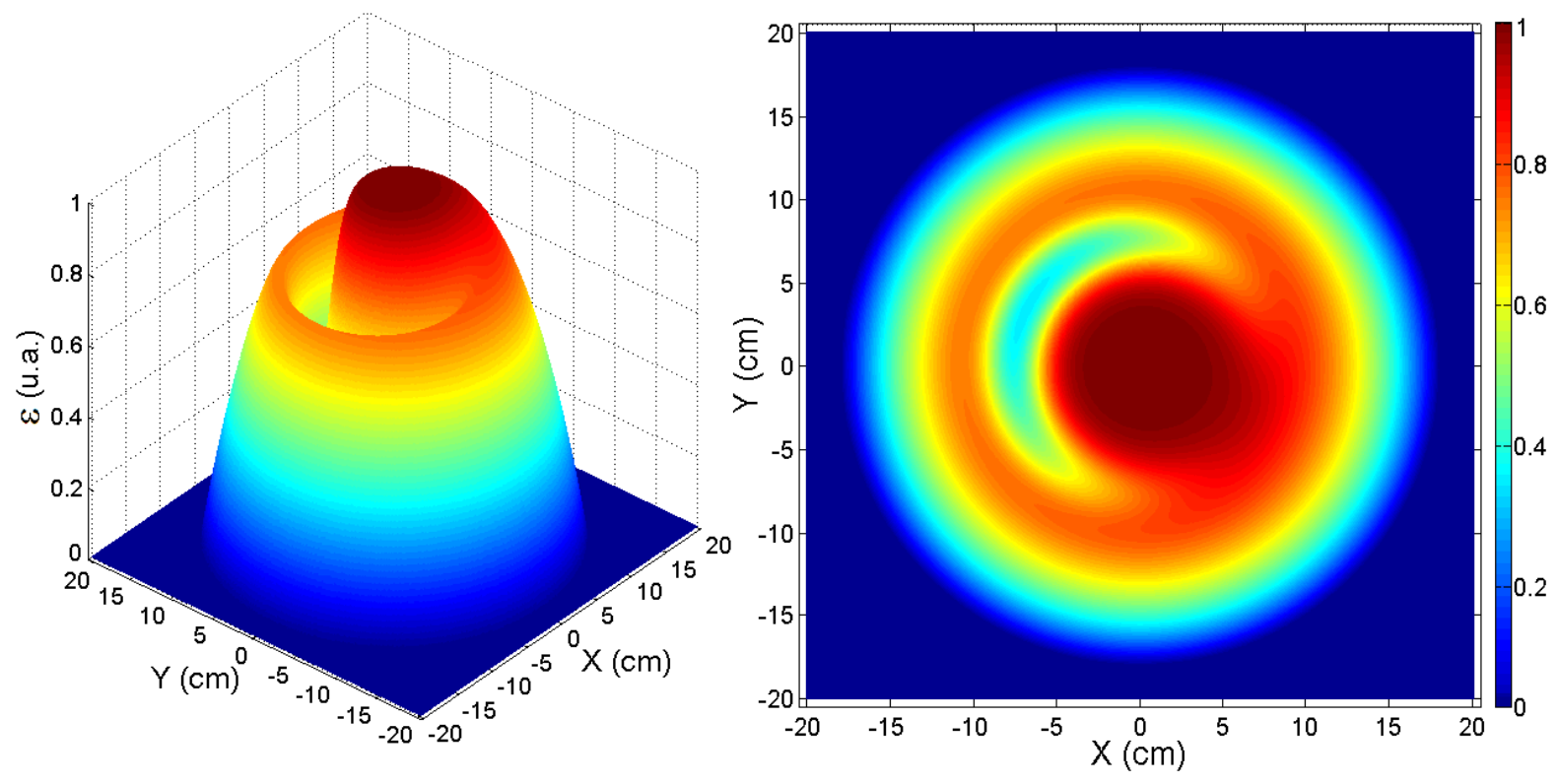

Figura 4.2: Perfil de emitância com a presença de uma perturbação gaussiana com modo $m=1$ em 3D (vista lateral e superior). A amplitude foi normalizada e os parâmetros são: $r_{s}=75 \mathrm{~mm}, \sigma_{r}=20 \mathrm{~mm}$ e $\epsilon_{0 p}=0,2$.

Estas perturbações gaussianas mostraram-se excelentes para simular instabilidades MHD do tipo dobra (kink).

As instabilidades do tipo dente de serra, que podem ser observadas frequentemente no tokamak TCABR, são caracterizadas pelo surgimento de um precursor no centro da coluna de plasma que cresce e causa um colapso da superfície magnética $q=1$, degradando o confinamento no centro da coluna de plasma.

As simulações com perturbações gaussianas mostraram-se muito eficazes para estudar 
o modo precursor das instabilidades dente de serra.

Na seção (5.2) serão mostrados algumas simulações que serão comparadas aos resultados experimentais.

\subsubsection{Perturbação gaussiana dupla}

Uma vez que o principal objetivo deste trabalho é caracterizar as ilhas magnéticas e as simulações feitas utilizando a equação (4.4) mostraram-se bastante eficientes na caracterização do modo precursor dos dentes de serra, optou-se por simular ilhas magnéticas usando a mesma expressão (4.4) com uma correção que será discutida a seguir.

Inicialmente, será analisado o efeito que as ilhas magnéticas provocam na emitância considerando que o plasma possua simetria cilíndrica e que a potência irradiada seja proporcional apenas ao perfil de densidade eletrônica.

Neste caso, sem a presença de ilhas magnéticas, as linhas de campo magnético devem formar superfícies magnéticas cilíndricas onde a densidade eletrônica depende apenas da posição radial, como está mostrado na figura (4.3a). Nesta figura a linha vermelha da esquerda representa uma linha de campo na qual a densidade é $n_{e}\left(r_{1}\right)$ e a linha vermelha da direita é outra linha de campo com uma densidade $n_{e}\left(r_{2}\right)$ menor que $n_{e}\left(r_{1}\right)$.

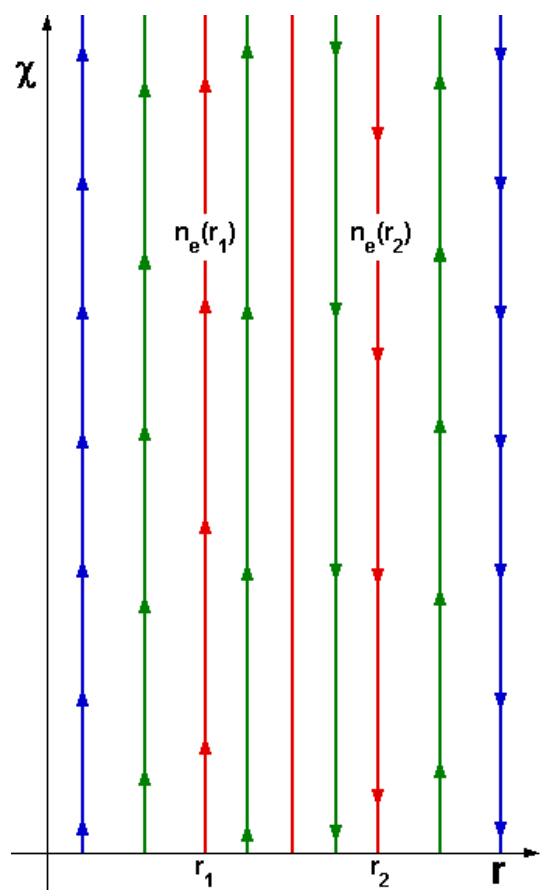

(a)

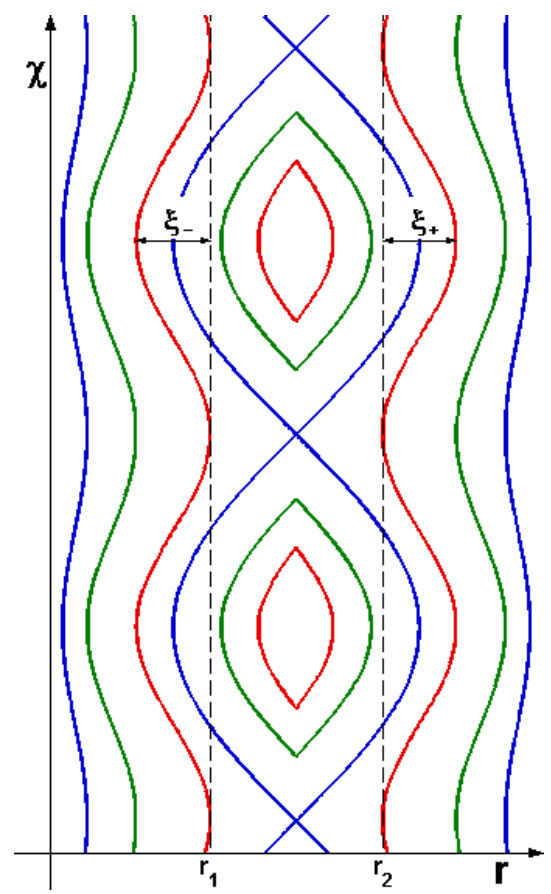

(b)

Figura 4.3: Em (a), linhas de campo sem ilhas magnéticas. Em (b), a presença das ilhas magnéticas provoca um deslocamento radial das linhas de campo e, consequentemente, um deslocamento da densidade do plasma. 
Por outro lado, quando existe a presença de uma ilha magnética, esta provoca um deslocamento radial das linhas de campo, que por sua vez, provoca uma perturbação com amplitude $\xi$ no perfil de densidade, como representado na figura (4.3b). Aqui é possível observar que a linha vermelha da esquerda foi deslocada para uma posição mais interna da coluna, onde a densidade é maior e, a linha vermelha da direita, foi deslocada para fora da coluna, onde a densidade é menor.

A figura (4.4) mostra o efeito que a rotação de uma ilha magnética, no caso, de modo $m=2$, causa ao perfil de densidade [51]. Um efeito parecido acontece com o perfil de temperatura eletrônica do plasma [52].

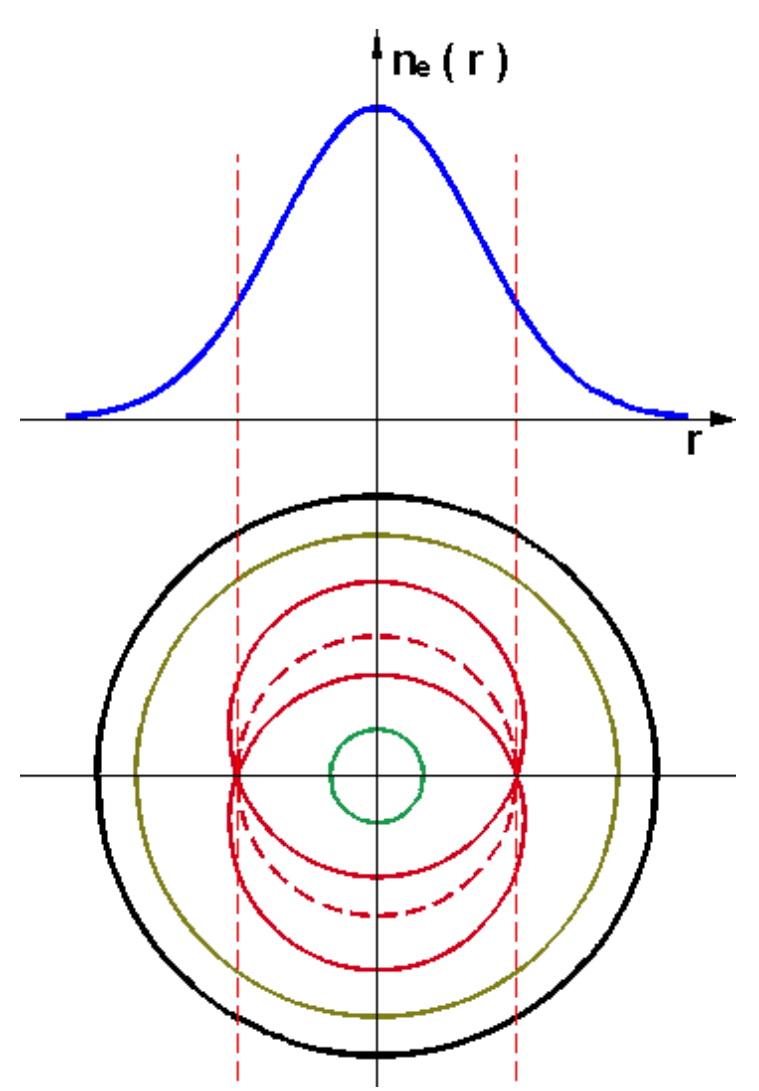

(a)

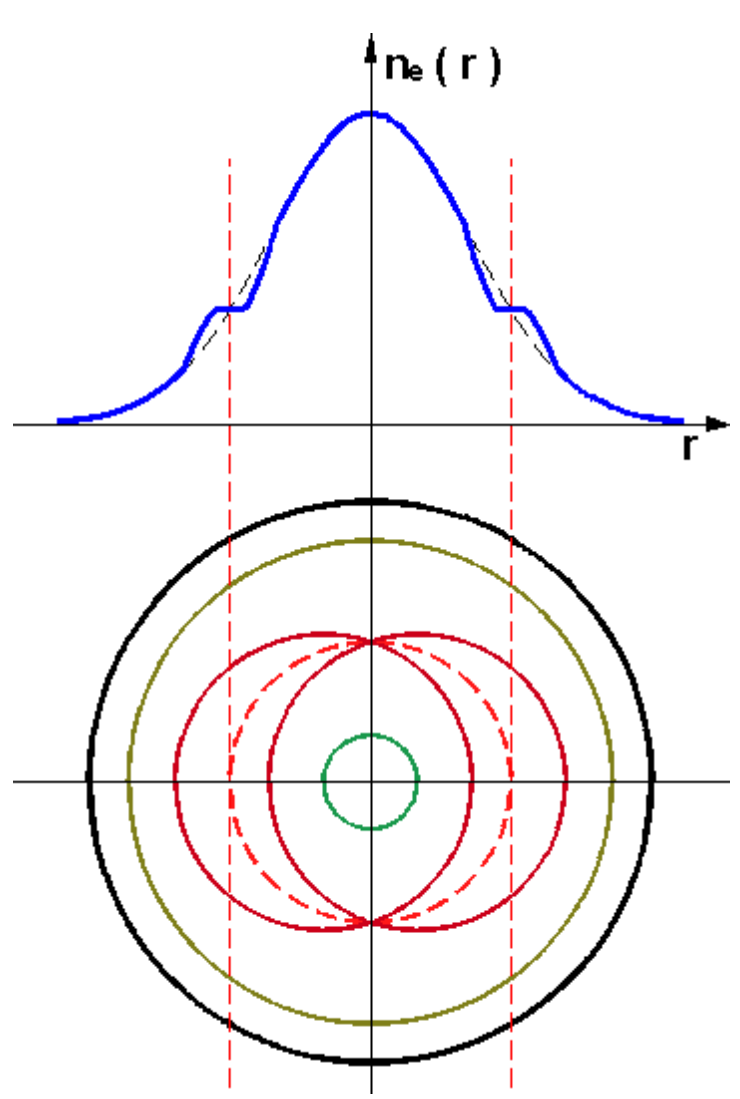

(b)

Figura 4.4: Esboço mostrando os efeitos da rotação de uma ilha magnética $m=2$ no perfil de densidade eletrônica de plasma. Em (a), o ponto $X$ da ilha cruza o eixo meridional, neste caso o perfil de densidade não sofre alteração. Em (b), o ponto $O$ da ilha está cruzando o eixo, o que causa alterações no perfil de densidade eletrônica.

É possível notar que o perfil de densidade não muda quando o ponto $X$ da ilha magnética cruza essa linha, entretanto, quando o ponto $O$ cruza, o perfil é alterado: a densidade aumenta na parte externa da ilha e diminui na região interna, como foi apresentado anteriormente na figura (4.3). 
A presença de uma ilha magnética de modo $m=1$ também provoca alterações no perfil de densidade, um esboço das alterações é apresentado na figura (4.5).

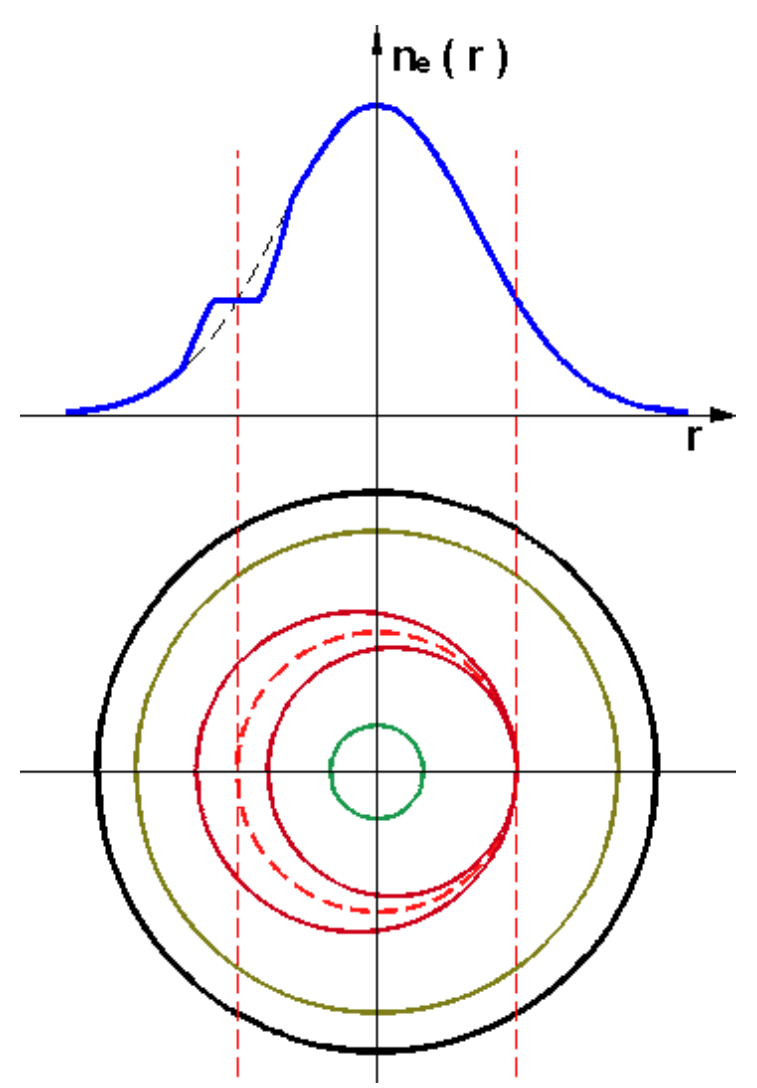

(a)

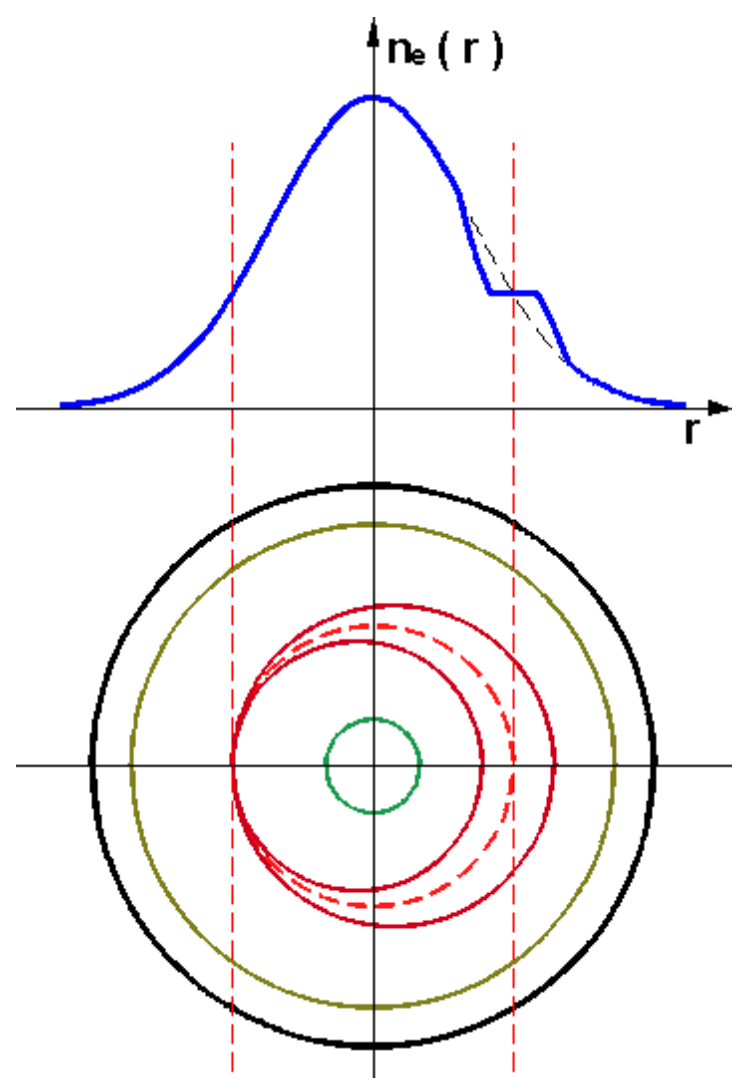

(b)

Figura 4.5: Esboço mostrando os efeitos da rotação de uma ilha magnética $m=1$ no perfil de densidade eletrônica de plasma em dois instantes onde há oposição na posição da ilha.

As amplitudes das oscilações no perfil de densidade, causadas pela rotação de uma ilha magnética, podem ser escritas através da diferença entre os perfis. No caso de um modo $m=2$, representados na figura (4.4), os pontos máximos são definidos pela interceptação do ponto $\mathrm{O}$ e do ponto $\mathrm{X}$ da ilha no eixo de medida. Para um modo $m=1$, a variação máxima ocorre entre dois instantes quando existe total oposição na posição da ilha magnética, como é mostrado na figura (4.5).

A figura (4.6) mostra a diferença dos perfis de densidade eletrônica para os casos onde existe a presença de ilhas magnéticas de modos $m=1$ e $m=2$. Intuitivamente, é simples analisar os efeitos destas ilhas magnéticas, porém, para modos com $m \geq 3$ é muito complicado imaginar como o perfil da densidade se comportaria, pois não existe mais simetria entre os dois lados da coluna de plasma.

Esses esboços são válidos também para o perfil de temperatura eletrônica, já que 
este também está associado à energia cinética das mesmas partículas que são deslocadas quando ocorre a passagem da ilha magnética.

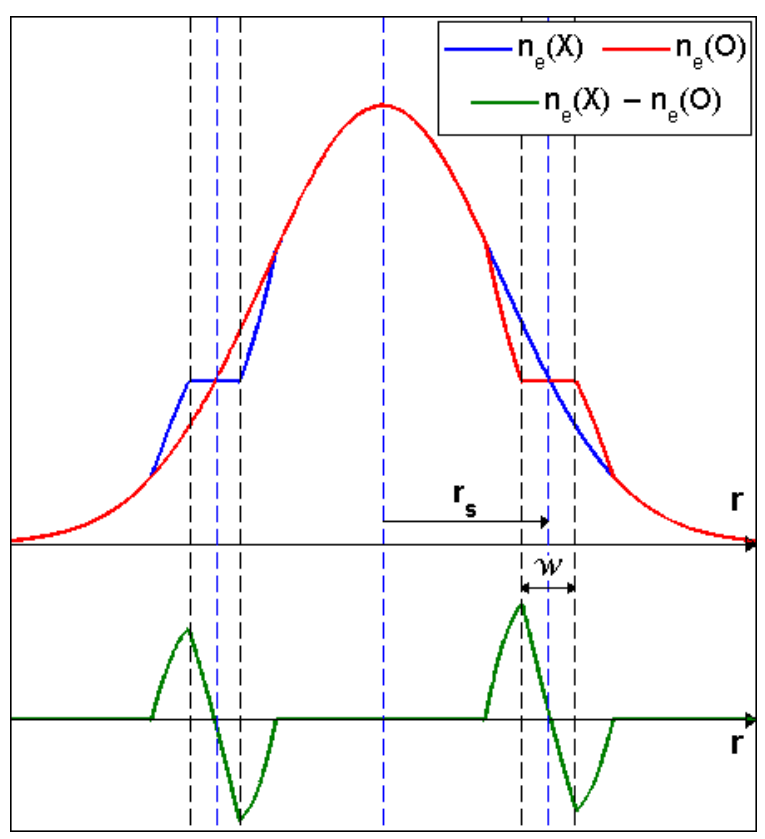

(a)

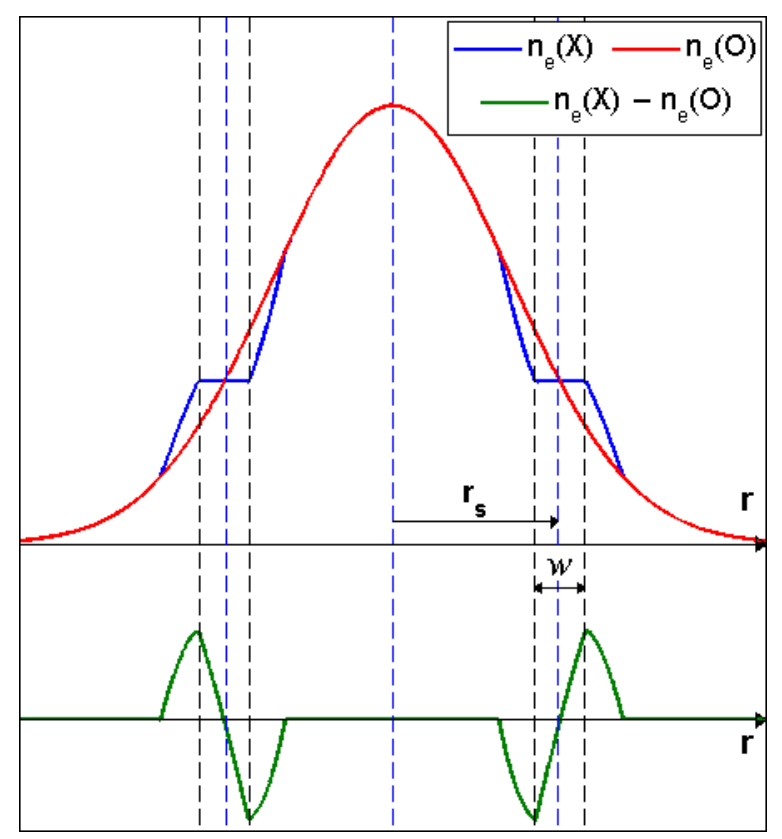

(b)

Figura 4.6: Esboço das alterações no perfil de densidade causado por uma ilha magnética de modo $m=1 \mathrm{em}$ (a) e modo $m=2 \mathrm{em}$ (b). A curva em verde é a subtração entre as duas densidades, portanto mostra variações máximas no perfil de densidade.

Partindo do fato de que a potência irradiada pelo plasma é proporcional principalmente a densidade e a temperatura eletrônica, é possível supor um modelo em que a perturbação causada pela ilha é proporcional a duas gaussianas ao redor da superfície ressonante, e a distância entre as gaussianas é uma informação sobre a largura dessa ilha magnética, como é sugerido pelos esboços da figura (4.6).

Esse modelo utilizado para simular essas perturbações no perfil de emitância do plasma pode ser escrito da seguinte forma:

$$
\epsilon_{p}(r, \theta, t)=\left(\epsilon_{1 p} e^{-\left[\left(r-\left(r_{s}-\sigma_{r} / 2\right)\right) / \sigma_{r}\right]^{2}}-\epsilon_{2 p} e^{-\left[\left(r-\left(r_{s}+\sigma_{r} / 2\right)\right) / \sigma_{r}\right]^{2}}\right)\left[1+\cos \left(m \theta(t)+\theta_{0}\right)\right]
$$

onde $\epsilon_{1 p}$ é a amplitude da emitância perturbada interna e $\epsilon_{2 p}$ a externa. Os parâmetros utilizados são os mesmos da equação (4.4), com a diferença de que agora se trata de uma subtração de gaussianas para definir a parte radial. Como está representado na figura (4.6), a ilha magnética causa variações muito maiores ao seu redor do que exatamente em sua posição. 
Essa soma de gaussianas deslocadas representou bem as perturbações laterais causadas pela presença de uma ilha. Utilizando esse tipo de simulação é possível obter uma informação sobre a posição da superfície ressonante $r_{s}$ e sobre a largura da ilha magnética, através do valor de $\sigma_{r}$.

A figura (4.7) é um exemplo do perfil de emitância em um instante de tempo $t$ simulado utilizando esse método. A perturbação apresentada é uma ilha magnética de modo $m=2$. Utilizando o mesmo método iterativo de antes, os sinais do bolômetro são simulados e podem ser ajustados aos dados reais.
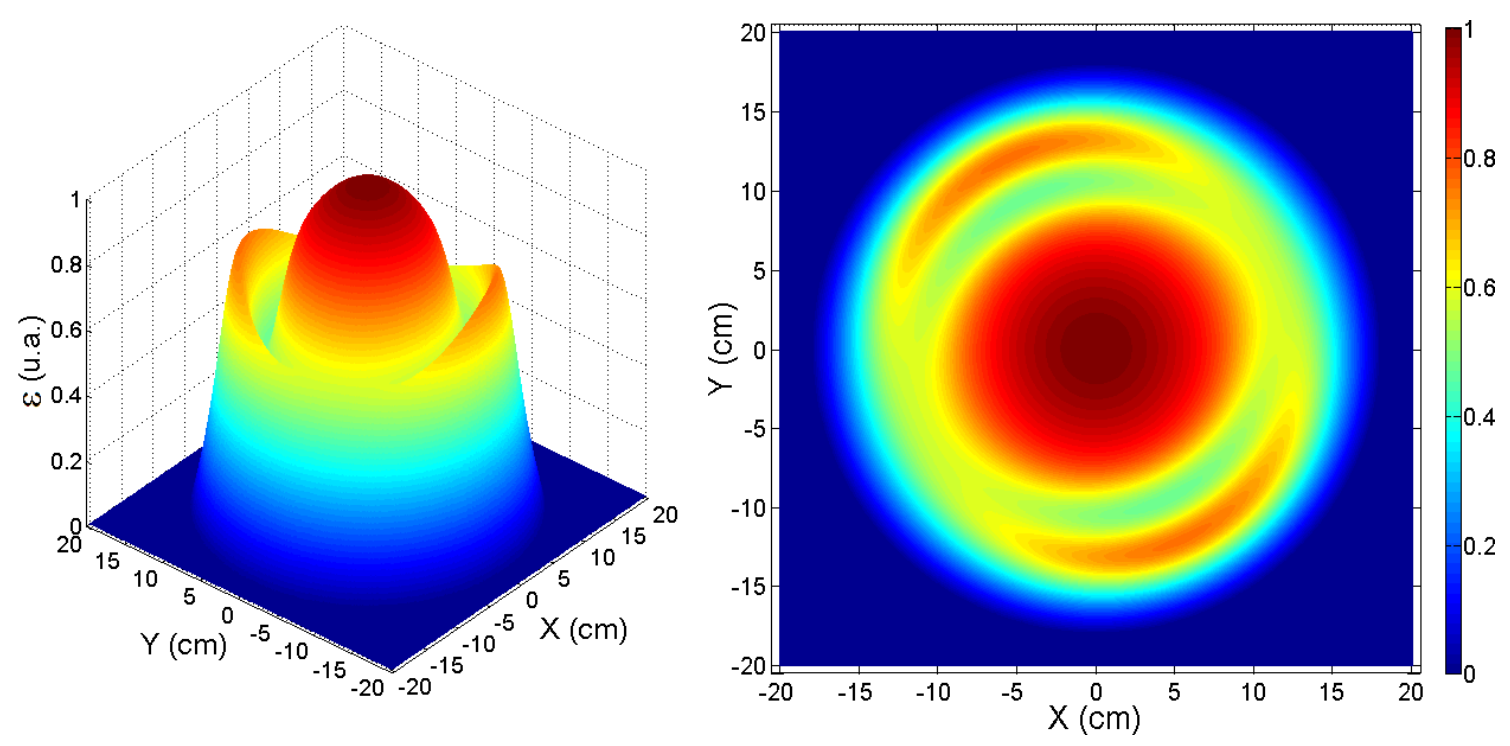

Figura 4.7: Perfil de emitância com a presença de uma perturbação do tipo ilha com modo $m=2$ em 3D (vista lateral e superior). A amplitude foi normalizada e os parâmetros são: $r_{s}=120 \mathrm{~mm}, \sigma_{r}=23 \mathrm{~mm}, \epsilon_{1 p}=0.3$ e $\epsilon_{2 p}=0.4$.

\subsection{Metodologia de análise}

O método utilizado neste trabalho para estudar a atividade MHD na coluna de plasma consiste em decompor, tanto os sinais provenientes do diagnóstico como os gerados nas simulações, em suas componentes de Fourier e comparar a amplitude e a localização deste espectro.

Essa técnica foi aplicada tanto para os sinais do diagnóstico de bolometria, quanto para o de raios $\mathrm{X}$ mole.

As oscilações no sinal de potência irradiada dependem da forma como a perturbação intercepta uma determinada corda. A figura (4.8) mostra exemplos de sinais simulados para algumas cordas do bolômetro. A perturbação é uma gaussiana simples, simulada através da equação (4.4), utilizando $r_{s}=70 \mathrm{~mm}, \sigma_{r}=20 \mathrm{~mm}$ e $f=11,2 \mathrm{kHz}$. 


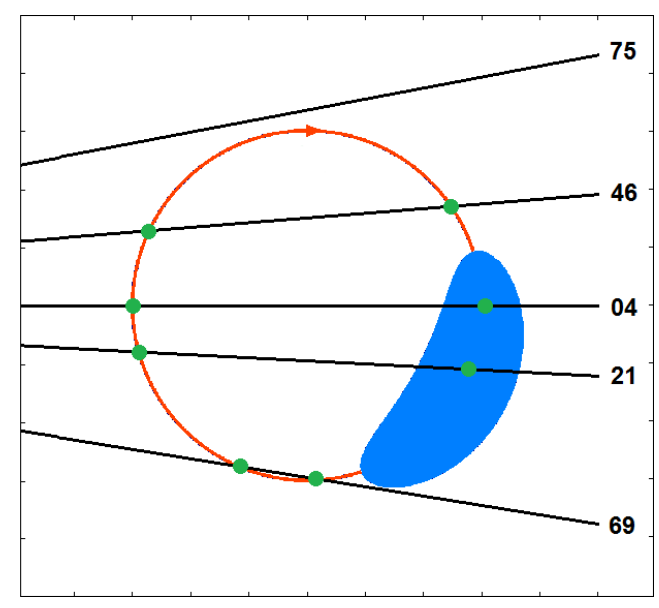

(a)

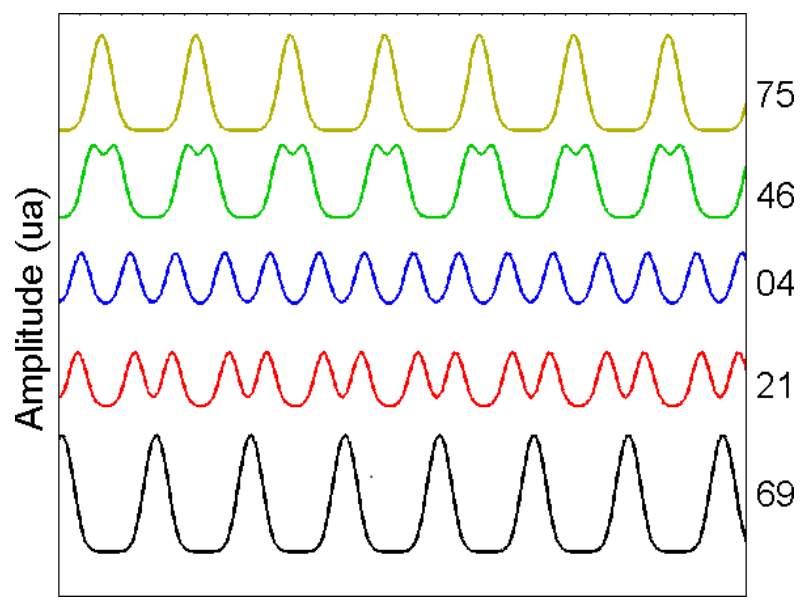

(b)

Figura 4.8: Em (a), representação de algumas cordas do bolômetro incerteptando a superfície ressonante de uma perturbação gaussiana e, em (b), são apresentados os sinais simulados, com amplitude arbitrária, para as respectivas cordas. O valor de $h$ para cada corda está apresentado ao lado das figuras.

Para cada corda é atribuído um valor do parâmetro $h$, que representa a menor distância da corda até o centro da coluna de plasma.

Nesta figura é clara a diferença na forma do sinal para as diferentes cordas, provocados pela rotação de uma perturbação gaussiana. A corda mais central $(04 \mathrm{~mm})$ possui amplitude inferior e maior frequência nas oscilações medidas quando comparada a uma corda que tangencia a superfície ressonante $(69 \mathrm{~mm})$.

Uma maneira mais clara de observar essas diferenças é através da transformada de Fourier destes sinais.

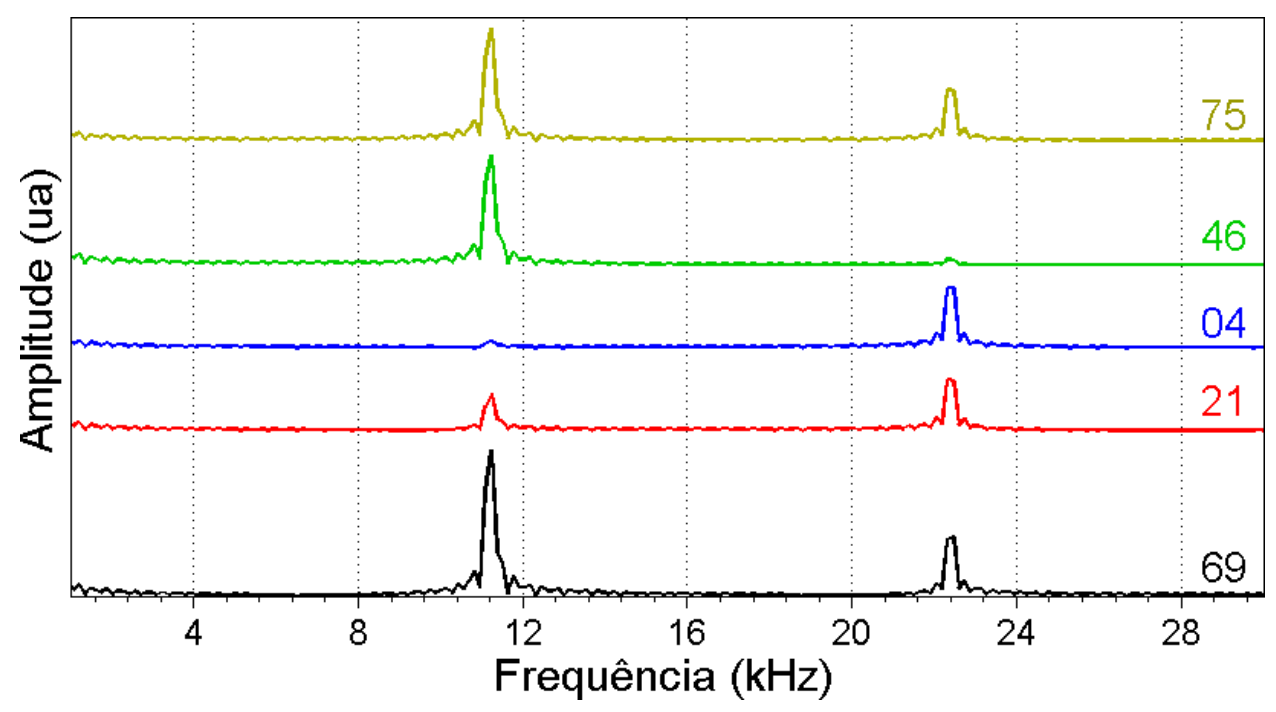

Figura 4.9: Transformadas de fourier dos sinais simulados apresentados na figura (4.8b). 
A figura (4.9), mostra as transformadas de Fourier dos mesmos sinais apresentados acima. Nota-se que as cordas mais centrais possuem um pico mais acentuado na frequência que corresponde ao dobro da frequência de rotação da perturbação. Além disso, a amplitude dos picos nas transformadas que tangenciam a perturbação são maiores que os outros.

Embora a transformada de Fourier seja mais rica em detalhes para a análise dos sinais, ela permite a investigação apenas em um curto intervalo de tempo, e não descreve a dinâmica do plasma. Uma maneira de solucionar esse problema é analisando os sinais através de um espectrograma.

O espectrograma é um gráfico tridimensional que mostra a evolução temporal das transformadas de Fourier de um mesmo sinal. Para construir esse gráfico o sinal é dividido em janelas temporais, que podem estar sobrepostas, e para cada janela é calculada uma transformada de Fourier. A essa transformada é atribuído um valor na régua de tempo, normalmente o valor médio da janela. A amplitude das transformadas é plotada em uma escala de cores, no terceiro eixo do gráfico.

A figura (4.10) mostra o espectrograma para os sinais simulados mostrados anteriormente. Como a frequência de rotação foi tomada como constante, não ocorre variações no espectro no intervalo de tempo analisado.

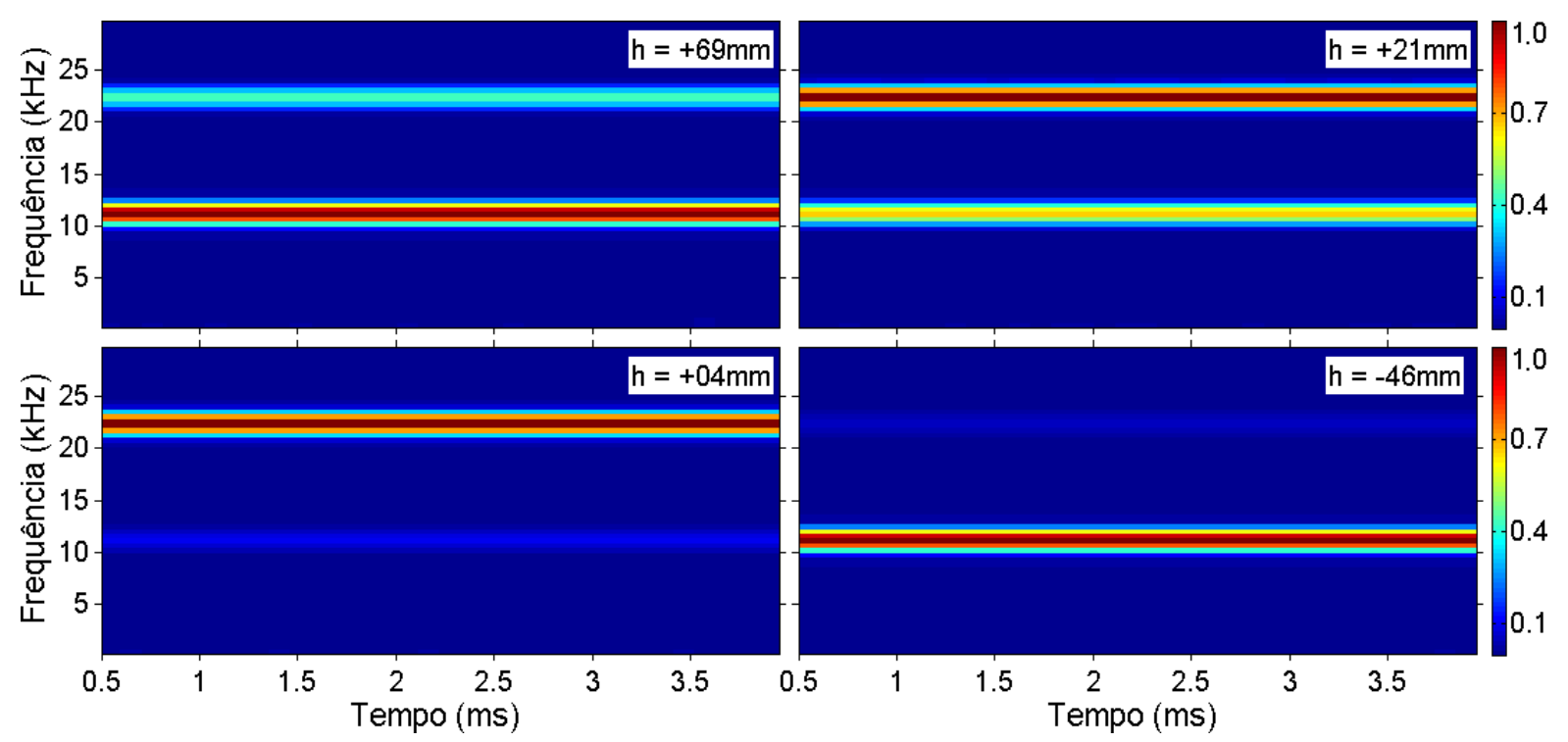

Figura 4.10: Espectrograma dos sinais simulados apresentados na figura (4.8b). Como a frequência de rotação das perturbações não muda durante a simulação, a frequência é constante em todo o espectrograma. A aplitude da potência espectral está em uma escala normalizada

Utilizando esse tipo de gráfico é possível escolher uma região de interesse para analisar 
todas as cordas de uma única vez. O próximo passo dessa análise é selecionar um pequeno intervalo de tempo e fazer uma média das amplitudes da potência espectral para todas as cordas para analisar os efeitos que a perturbação causa no plasma como um todo.

O gráfico apresentado na figura (4.11) mostra a média da potência espectral dos sinais simulados para cada uma das 24 cordas em um intervalo de tempo de $1 \mathrm{~ms}$.

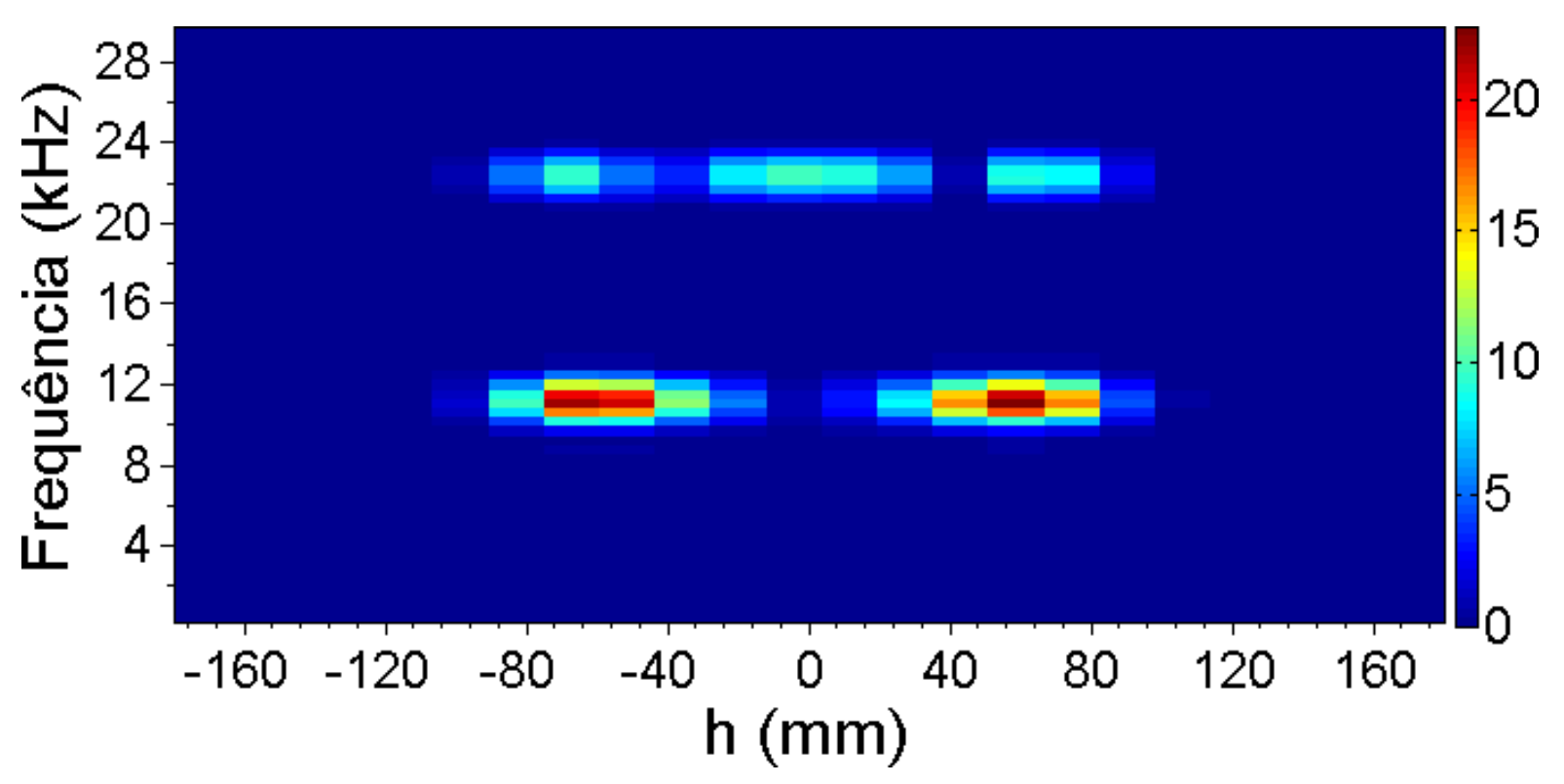

Figura 4.11: Média temporal do espectrograma do sinal simulado para cada corda do bolômetro. O valor da potência espectral e as frequências estão graficados em função do parâmetro de impacto (h) de cada corda.

No gráfico acima é possível observar que próximo à posição $h=70 \mathrm{~mm}$, para uma frequência $f=11,2 \mathrm{kHz}$ o valor da potência espectral é muito maior que em outras regiões. Esse gráfico é uma excelente ferramenta para analisar as oscilações em todas as cordas ao mesmo tempo.

Uma maneira de visualizar melhor o resultado é graficando a potência espectral em função do parâmetro de impacto de cada corda para uma frequência específica. No caso simulado que está apresentado acima, é interessante construir esse gráfico para uma frequência de 11, 2 kHz. A curva apresentada na figura (4.12) mostra esse resultado.

Outra característica importante da análise espectral é a diferença de fase entre dois sinais. Em um mesmo instante de tempo é possível identificar, através da diferença de fase dos sinais, a paridade da instabilidade que está sendo medida.

Perturbações com paridade par, possuem número de onda poloidal $m$ par, e as ímpares possuem $m$ ímpar. Um exemplo de cada foi apresentado: na figura (4.5), onde a ilha magnética de modo $m=1$ perturba o perfil de densidade de maneira alternada e, como 
pode ser visto na figura (4.4), a ilha magnética com $m=2$ perturba o perfil de densidade de maneira simétrica.

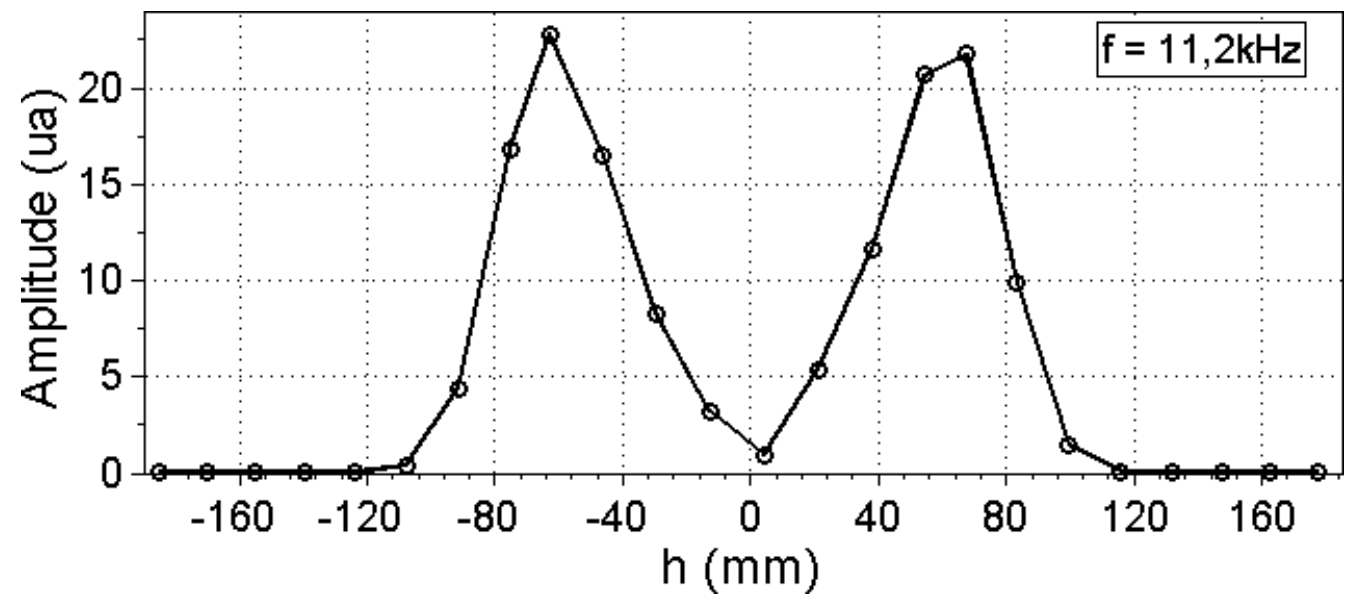

Figura 4.12: Gráfico da amplitude da potência espectral dos sinais simulados em função do parâmetro de impacto de cada corda para uma frequência específica.

A fase entre os sinais é definida relativamente a uma das cordas, ou seja, deve-se escolher uma corda de referência que terá fase $\phi=0$, e a partir dela é possível determinar a fase das outras. A figura (4.13) mostra um exemplo de diferença de fase entre os sinais simulados para as cordas $h=+69 \mathrm{~mm}$ e $h=-75 \mathrm{~mm}$.

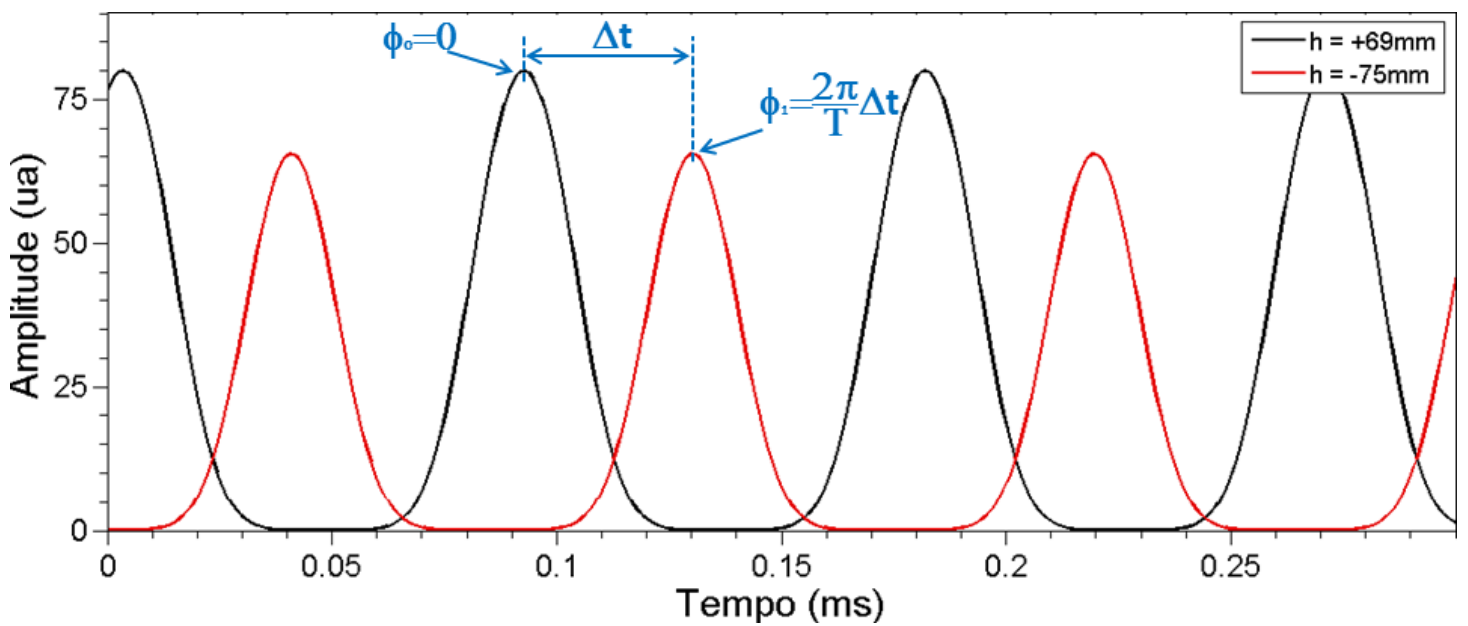

Figura 4.13: Sinais simulados de duas cordas opostas. Tomando a corda $h=+69 \mathrm{~mm}$ como referência é possível calcular a diferença de fase não apenas para a corda $h=$ $+69 \mathrm{~mm}$, mas para todas as outras.

Como a transformada de Fourier dos sinais é calculada através de um algoritmo de FFT, a partir dos resultados provenientes desse algorítmo também é possível calcular diretamente a diferença de fase entre os sinais.

Para visualizar essa diferença de fase na análise de sinais, a curva da amplitude 
da potência espectral em função das cordas (figura (4.12)) pode ser multiplicada pelo cosseno da fase. A figura (4.14b) mostra um exemplo para uma perturbação com $m=1$, e na figura (4.14b) é mostra um exemplo para uma perturbação com $m=2$.

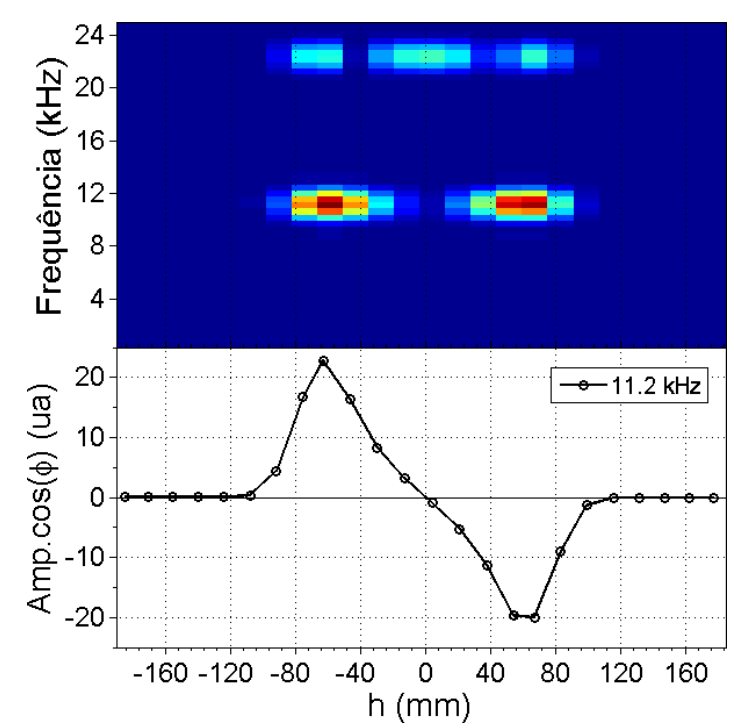

(a)

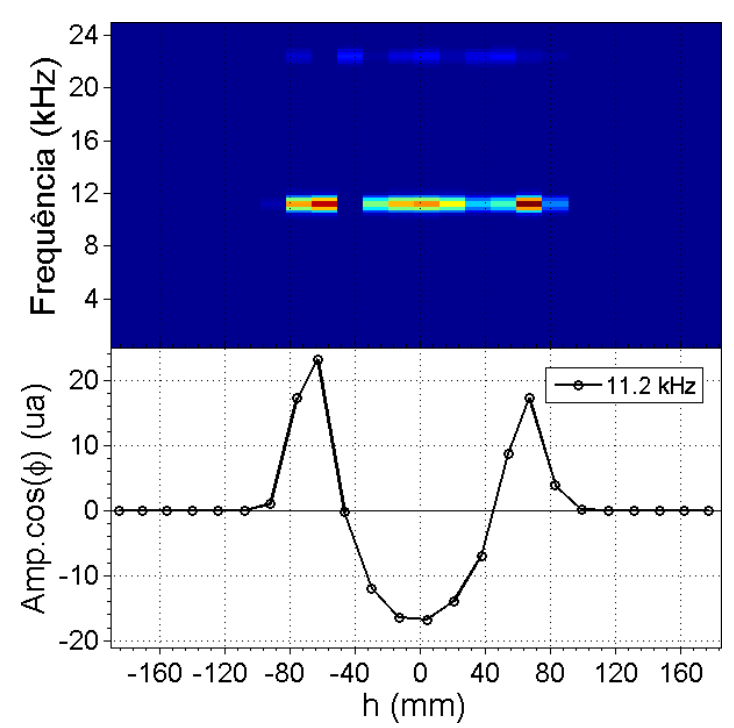

(b)

Figura 4.14: Análise espectral para uma perturbação gaussiana de modo $m=1$, em (a), e modo $m=2$, em (b). Aqui a amplitude da potência espectral foi multiplicada pelo ângulo de fase entre os sinais de cada corda. A curva foi traçada para a frequência de $11,2 k H z$ e foi utilizada a corda com $h=-62 \mathrm{~mm}$ como referência para o ângulo de fase.

Uma vantagem de se utilizar simulações é poder criar um diagnóstico com capacidade superior aos equipamentos utilizados no laboratório. Para ajustar os dados experimentais, por exemplo, é possível utilizar dados simulados com um número de cordas muito maior que o sistema original. A figura (4.15) mostra uma curva traçada para um bolômetro simulado com 87 cordas.

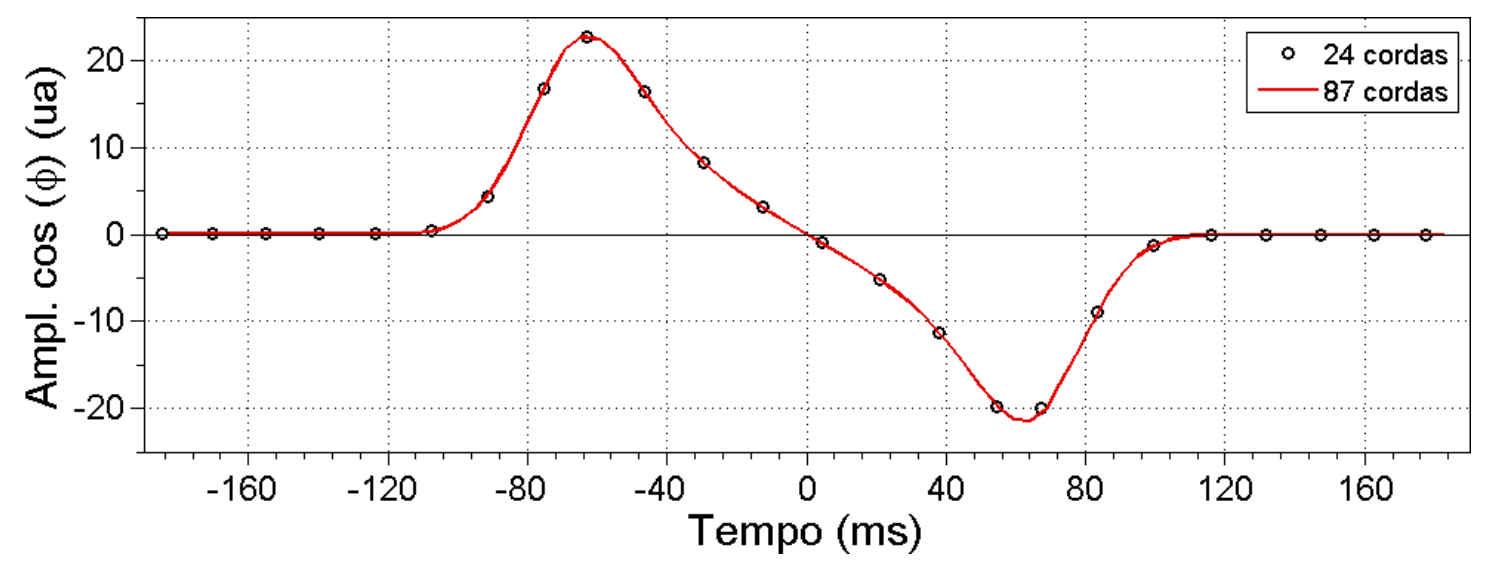

Figura 4.15: Análise espectral de sinais simulados para um bolômetro com 24 cordas sobreposta à mesma análise feita para sinais simulados em um bolômetro de 87 cordas. 


\section{Análise e resultados}

Neste capítulo serão apresentados os resultados obtidos utilizado o arranjo e o método propostos nos capítulos anteriores. A figura (5.1) mostra os sinais dos principais diagnósticos para o disparo 26134 e, na figura (5.2), é apresentado o sinal bolométrico proveniente da corda $11(\mathrm{~h}=29,6 \mathrm{~mm})$ para o mesmo disparo.
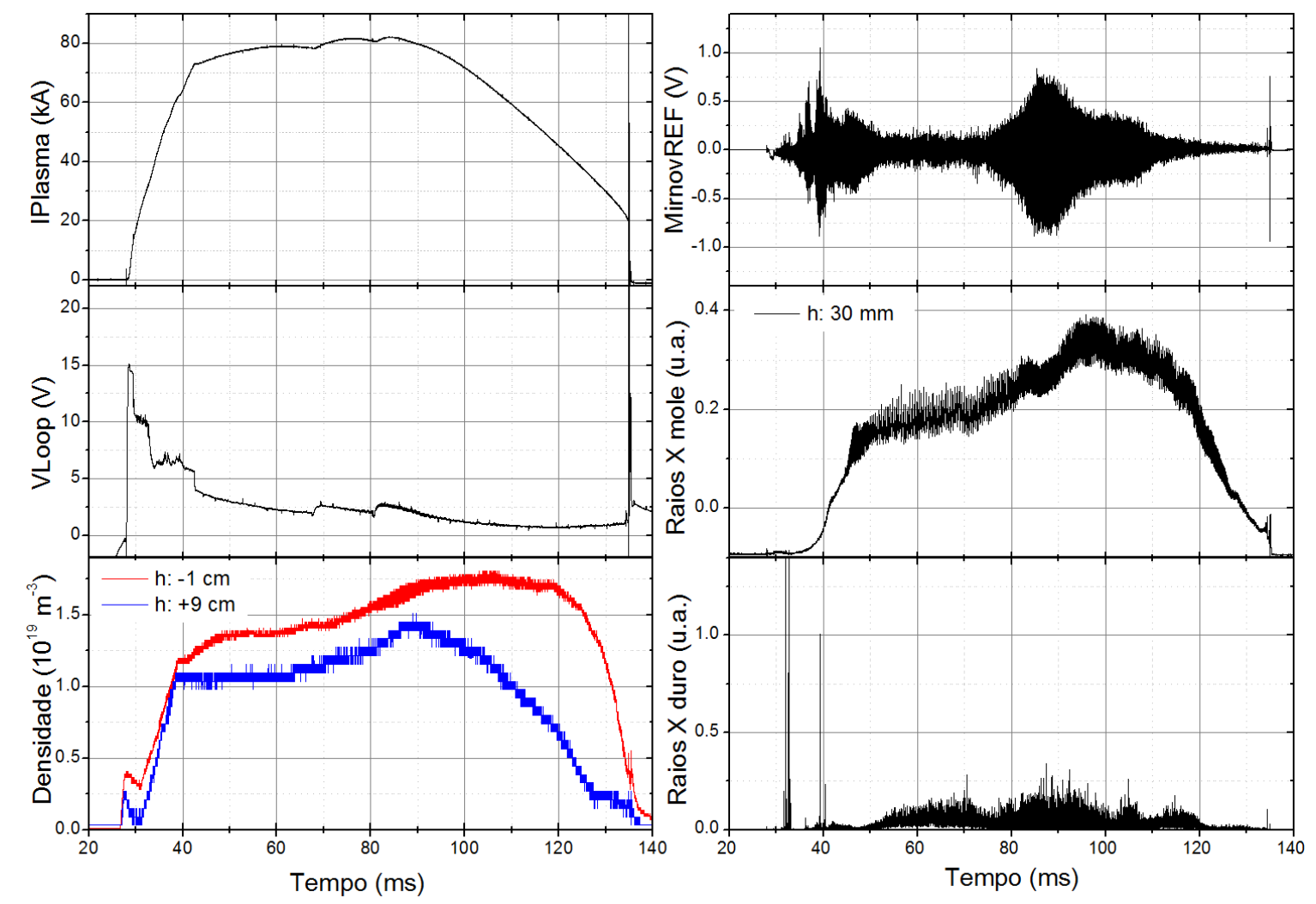

Figura 5.1: Evolução temporal dos principais parâmetros do plasma do tokamak TCABR para o disparo 26134. Da esquerda para a direita e de cima para baixo: a) corrente de plasma, b) tensão de enlace, c) densidade de elétrons em duas posições radiais, d) oscilações de Mirnov, e) raios X mole e f) raios X duro.

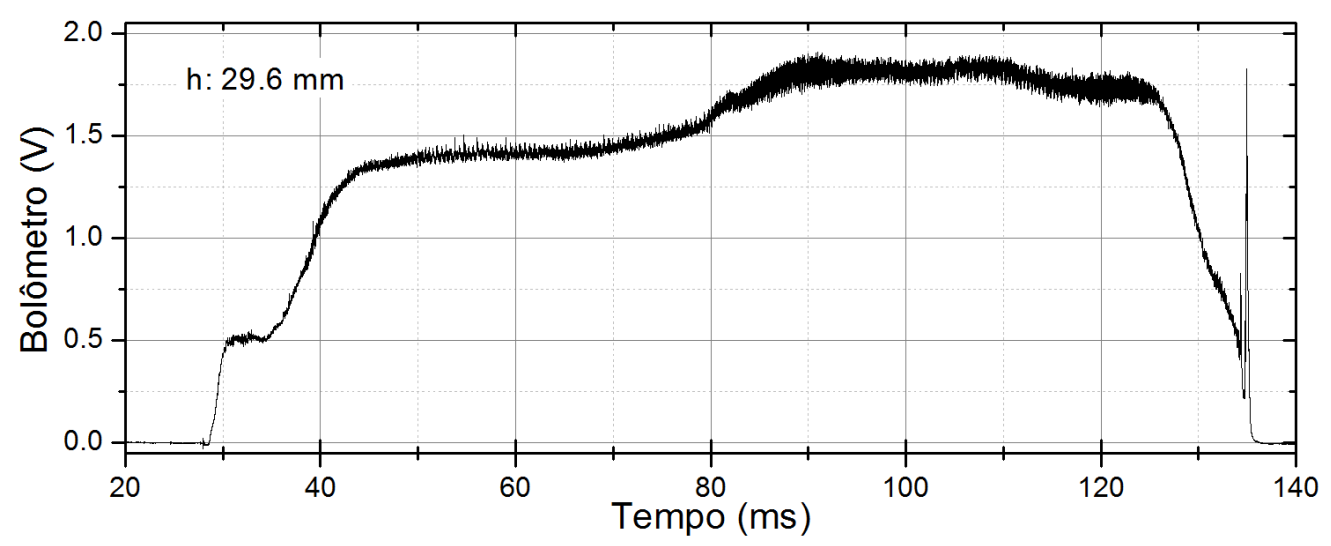

Figura 5.2: Sinal da corda 11 do bolômetro para o disparo 26134. 
É possível ver a partir do gráfico da figura (5.2) que a amplitude do sinal bolométrico acompanha os sinais de densidade, o que era esperado já que a potência radiante emitida pelo plasma é proporcional à densidade.

Neste mesmo gráfico é possível observar que no intervalo entre $t=50 \mathrm{~ms}$ e $t=80 \mathrm{~ms}$ este diagnóstico foi capaz de registrar as instabilidades do tipo dentes de serra, que pode ser confirmado através do diagnóstico de raios $\mathrm{X}$ mole.

Também é possível ver que quando ocorre um aumento das oscilações de mirnov, registrado pela sonda de Mirnov entre os instantes $t=83 \mathrm{~ms}$ e $\mathrm{t}=97 \mathrm{~ms}$, o bolômetro também registra um aumento na amplitude das oscilações.

Essas são evidências de que a atividade MHD modula a densidade e a temperatura do plasma, que por sua vez, modulam a potência irradiada.

Uma maneira de ver todos os sinais bolométricos em um único gráfico é apresentando a amplitude dos sinais em uma escala de cores, como é mostrado na figura (5.3). Nesta figura, que mostra o perfil de potência irradiada pelo plasma, é possível ver fenômenos interessantes como a formação e estabilização do plasma e o deslocamento da coluna para o centro do tokamak no final da descarga.

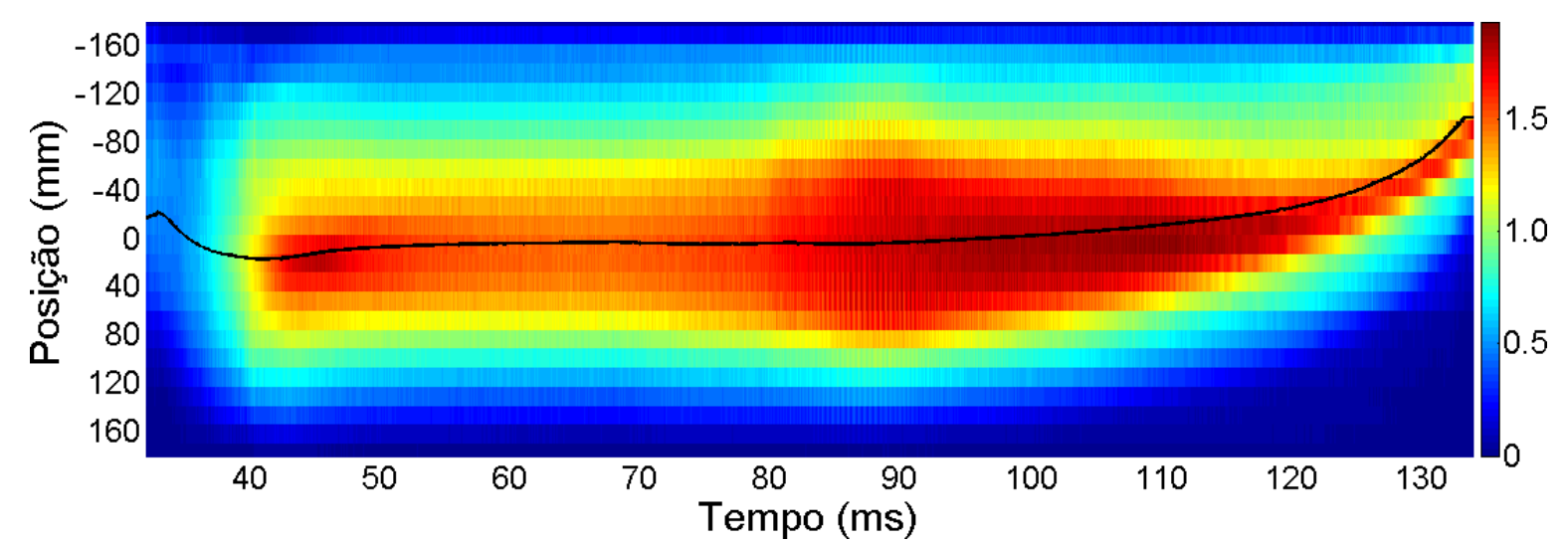

Figura 5.3: Evolução temporal dos 24 sinais bolométricos. As diferentes cordas estão apresentadas horizontalmente e a amplitude (em Volts) está apresentada em uma escala de cores. A curva em preto é a posição radial da coluna de plasma calculada a partir de sensores magnéticos.

Nesta mesma figura é possível acompanhar a evolução do perfil de potência irradiada juntamente com a posição da coluna de plasma, calculada a partir de medidas magnéticas e apresentada como uma curva em preto apresentada na mesma figura.

Nas seções que seguem serão apresentados resultados da análise das oscilações MHD dos sinais bolométricos utilizando os métodos e simulações apresentados no capítulo 4. 


\subsection{Instabilidades dentes de serra}

Para estudar as instabilidades do tipo dentes de serra em plasmas de tokamak é comum utilizar o diagnóstico detector de raios $\mathrm{X}$ mole, que é um detector de radiação na frequência de raios X de baixo comprimento de onda (entre $0,1 \mathrm{~nm}$ e $10 \mathrm{~nm}$ ).

O diagnóstico de raios X mole é similar ao bolômetro: consiste de uma câmara contendo um array de fotodiodos, uma fenda colimadora e um filtro de berílio para selecionar apenas a radiação desejada. Diferentemente do bolômetro, a câmara de raios $\mathrm{X}$ mole está posicionada horizontalmente à câmara toroidal, como mostra a figura (5.4).

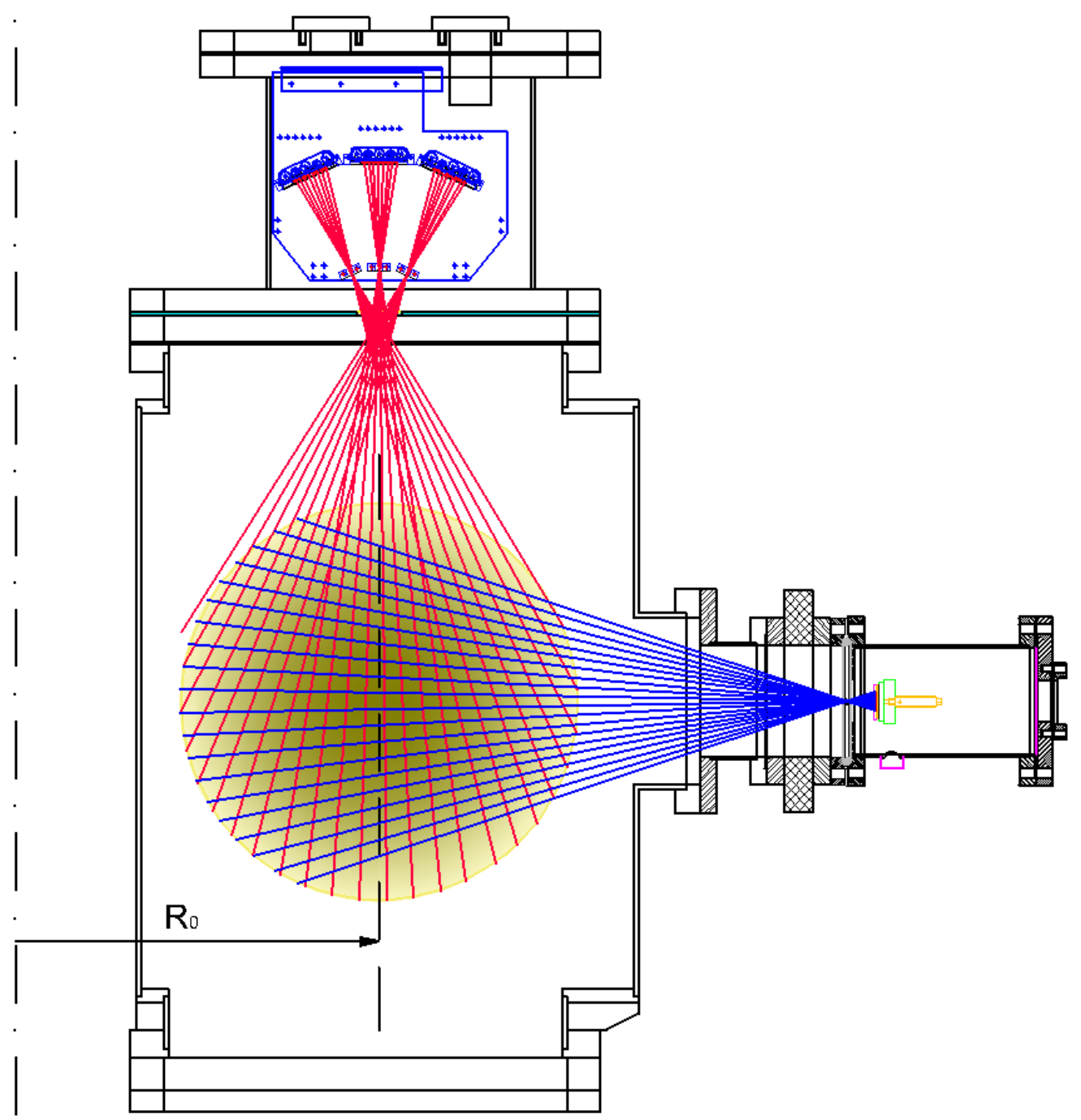

Figura 5.4: Representação da câmara do tokamak e do posicionamento da câmara bolométrica, com cordas em vermelho, e da câmara de raios $\mathrm{X}$ mole, com cordas em azul. Nessa figura também está representada a direção do raio maior do tokamak, definido a partir de sua posição central.

Esse diagnóstico apresenta um sinal menos ruidoso que o bolômetro, porém, detecta 
apenas a radiação de energia mais alta, proveniente do centro da coluna de plasma, o que o impede de ser utilizado para estudar ilhas magnéticas no tokamak TCABR. O fato deste diagnóstico ser semelhante ao bolômetro possibilita a utilização do programa desenvolvido para simular as medidas de perturbação.

A partir do diagnóstico de raios X mole é possível identificar, entre os instantes $45 \mathrm{~ms}$ e $80 \mathrm{~ms}$, instabilidades do tipo dente de serra no disparo 26134 do tokamak TCABR. O sinal do desse diagnóstico e outros parâmetros importantes do plasma foram apresentados na figura (5.1).

O diagnóstico de raios X mole permite identificar com clareza tais instabilidades, como pode ser visto na figura (5.5a). Fazendo um espectrograma deste sinal é possível identificar a frequência característica dessa instabilidade, como pode ser visto na figura $(5.5 \mathrm{~b})$.

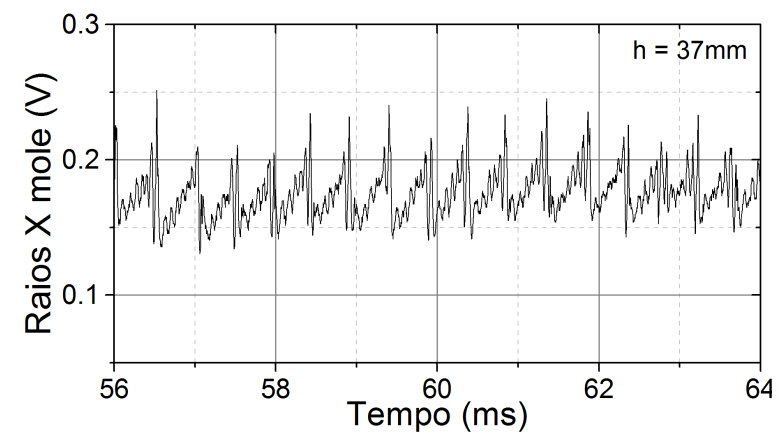

(a)

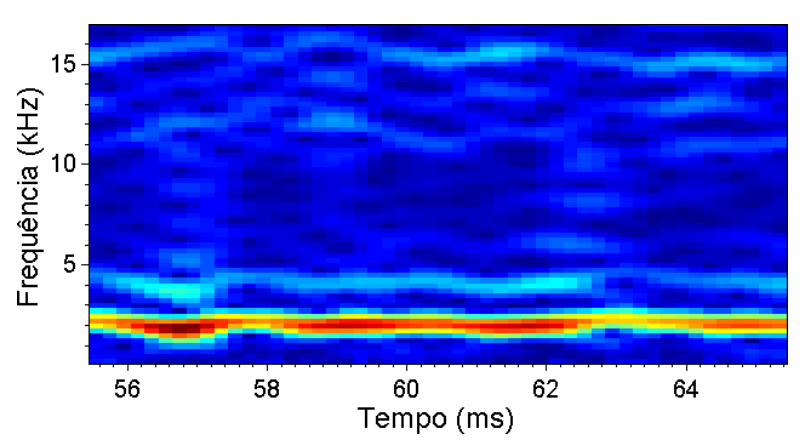

(b)

Figura 5.5: Em (a) é mostrada a evolução temporal do sinal de raios X mole (h:37mm), onde é possível identificar as intabilidades dentes de serra. Em (b) é mostrado um espectrograma onde é possível identificar a frequência característica destas instabilidades e sua evolução temporal.

Esse gráfico mostra que a frequência característica das oscilações do tipo dente de serra é próxima de $2 \mathrm{kHz}$, um valor esperado e bem conhecido para o tokamak TCABR. Uma análise mais interessante é fazer uma média em um pequeno intervalo de tempo do espectrograma de todas as cordas do sistema, como fora proposto na seção 4.2. A figura (5.6a) mostra o resultado desta análise.

A mesma frequência é detectada pelo diagnóstico de bolometria e, embora o sinal seja mais ruidoso, é possível fazer a mesma análise feita para os sinais de raios X mole, como está apresentado na figura (5.6b).

O padrão apresentado na figura (5.6) será seguido pelo resto deste trabalho. Para o diagnóstico de raios $\mathrm{X}$ mole, foi definido que os valores de $h$ crescem da parte inferior 
do plasma para a parte superior. No caso do bolômetro, foi definido que os valores de $h$ crescem da parte interna para a parte externa da coluna de plasma.

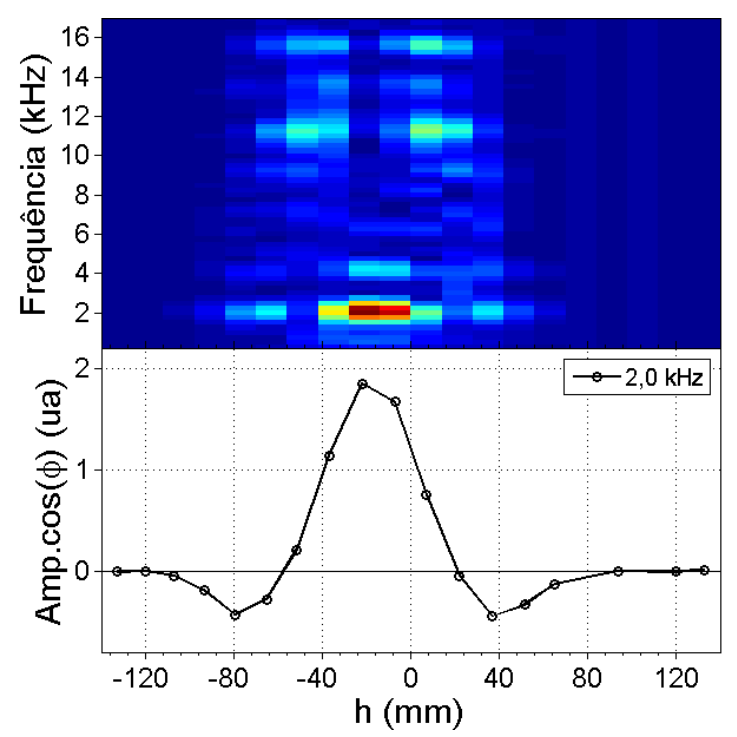

(a)

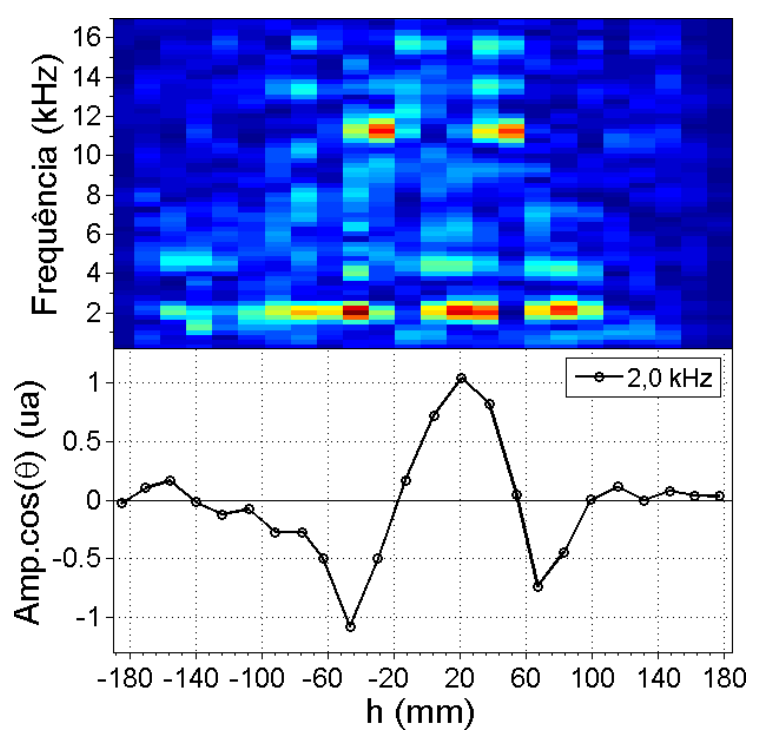

(b)

Figura 5.6: Análise espectral para estudar as oscilações dentes de serra durante o disparo 26134 entre os instantes $t=65 \mathrm{~ms}$ e $t=67 \mathrm{~ms}$. Em (a), para o diagnóstico de raios $\mathrm{X}$ mole utilizando o canal 09 como referência para o ângulo de fase e, em (b), para o sistema bolométrico, foi utilizado o canal 14 como referência.

A figura (5.7) mostra um resultado semelhante, obtido para o disparo 26146, mostrando a reprodutibilidade destes resultados.

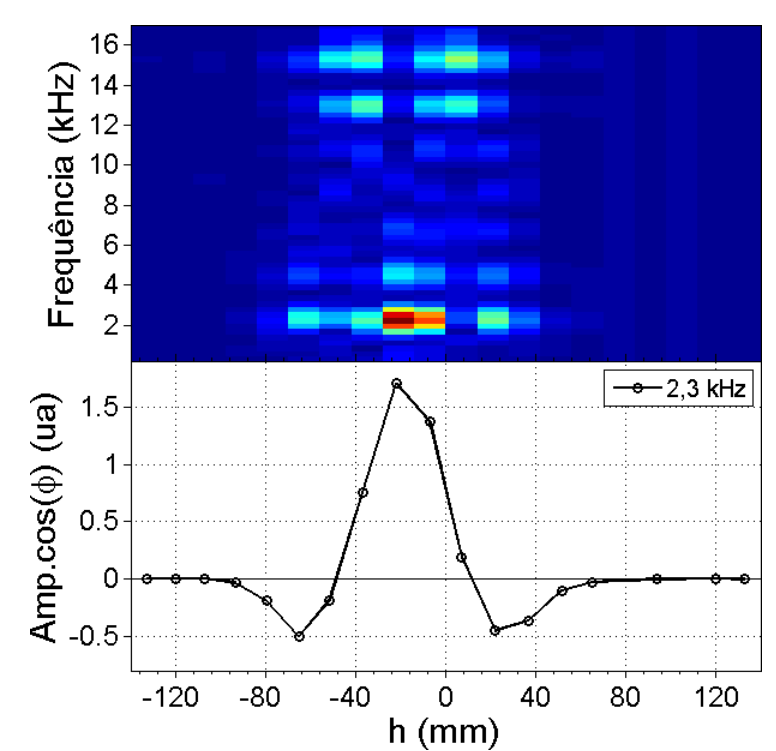

(a)

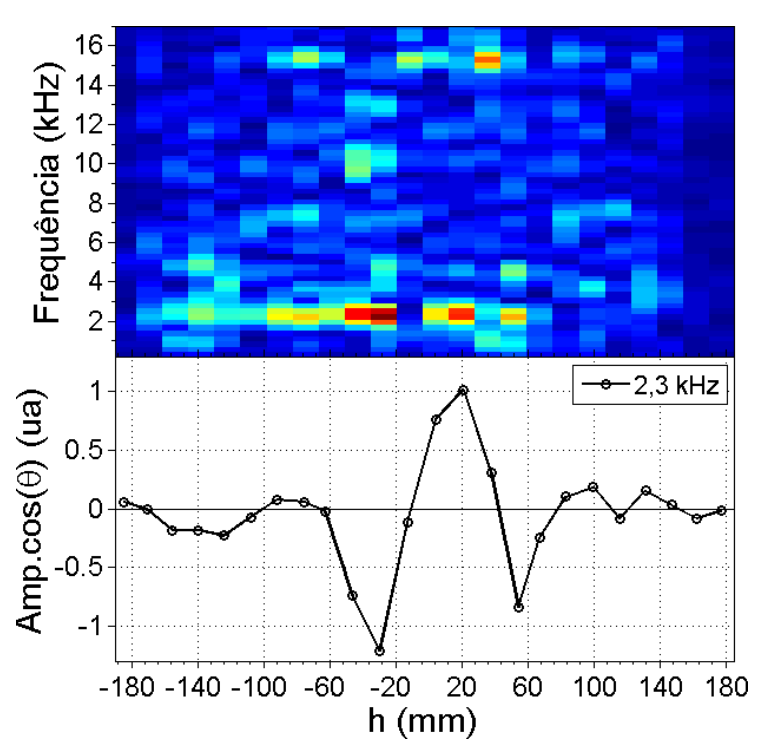

(b)

Figura 5.7: Análise espectral para o disparo 26146 entre os instantes $t=56 \mathrm{~ms}$ e $t=$ $58 \mathrm{~ms}$. Em (a), para o diagnóstico de raios X mole utilizando o canal 09 como referência para o ângulo de fase e, em (b), para o sistema bolométrico, utilizando o canal 14. 
As figuras (5.6a) e (5.7a) mostram que as oscilações próximas de $2 \mathrm{kHz}$ ocorrem no centro do plasma e que existe uma inversão de fase conforme a posição radial aumenta. Esse comportamento também é observado para os resultados do bolômetro, como pode ser visto nas figuras (5.6b) e (5.7b).

O diagnóstico de raios X mole mede o plasma em uma posição lateral e, a princípio, deveria ser observada uma simetria com relação ao eixo onde $h=0 \mathrm{~mm}$, entretanto, como pode ser observado nas análises para esse diagnóstico, existe um deslocamento de aproximadamente $18 \mathrm{~mm}$ do centro nas oscilações para o eixo $h=0 \mathrm{~mm}$.

Dois fatores podem causar esse efeito: ou plasma está se formando $18 \mathrm{~mm}$ abaixo do esperado ou o suporte dos detectores está deslocado. Esse deslocamento não é necessariamente vertical, já que uma pequena inclinação dos sensores já causa esse efeito de deslocamento.

Utilizando o sistema de simulações apresentadas no capítulo 4 estimou-se que é necessário uma inclinação de apenas $2,4^{\circ}$ para que a medida do centro esteja deslocada de $18 \mathrm{~mm}$.

O fato de estar descentralizado não compromete as medidas e muitas conclusões ainda podem ser tiradas deste diagnóstico, como por exemplo, o ponto de inversão dos dentes de serra.

As inversões de fase, no intervalo analisado para o disparo 26134, ocorrem em $r=$ $-57 \mathrm{~mm}$ e em $r=+21 \mathrm{~mm}$ e, aplicando a correção para o deslocamento de $\Delta r=$ $+18 \mathrm{~mm}$ é possível concluir que a superfície $q=1$ está situada na posição $r_{q 1}=39 \mathrm{~mm}$ durante o intervalo analisado.

Para o disparo 26146, as inversões ocorrem em $r=-48 \mathrm{~mm}$ e em $r=+12 \mathrm{~mm}$ e, aplicando o deslocamento de $\Delta r=+18 \mathrm{~mm}$, portanto, é possível concluir que a superfície $q=1$ está situada na posição $r_{q 1}=30 \mathrm{~mm}$ durante o intervalo analisado.

É possível realizar a mesma análise para os sinais provenientes do bolômetro. Como pode ser observado nas figuras (5.6b) e (5.7b), também existe um deslocamento do centro das oscilações dentes de serra com relação ao eixo $h=0 \mathrm{~mm}$. Essa medida pode estar sujeita ao mesmo problema de deslocamento do plasma ou inclinação dos suportes dos detectores, entretanto, por se tratar de uma câmara com visão vertical, as medidas deste diagnóstico também estão sujeitas aos efeitos do deslocamento de Shafranov [53].

Quando os efeitos toroidais são incluídos nos cálculos de equilíbrio MHD, as superfícies magnéticas formam circunferências não concêntricas, como é mostrado na figura (5.8). O centro das circunferências são deslocadas de $\Delta(r)$ com relação a última super- 
fície de fluxo fechada e o deslocamento do eixo magnético, ou seja $\Delta(0)$, é chamado de deslocamento de Shafranov [16].

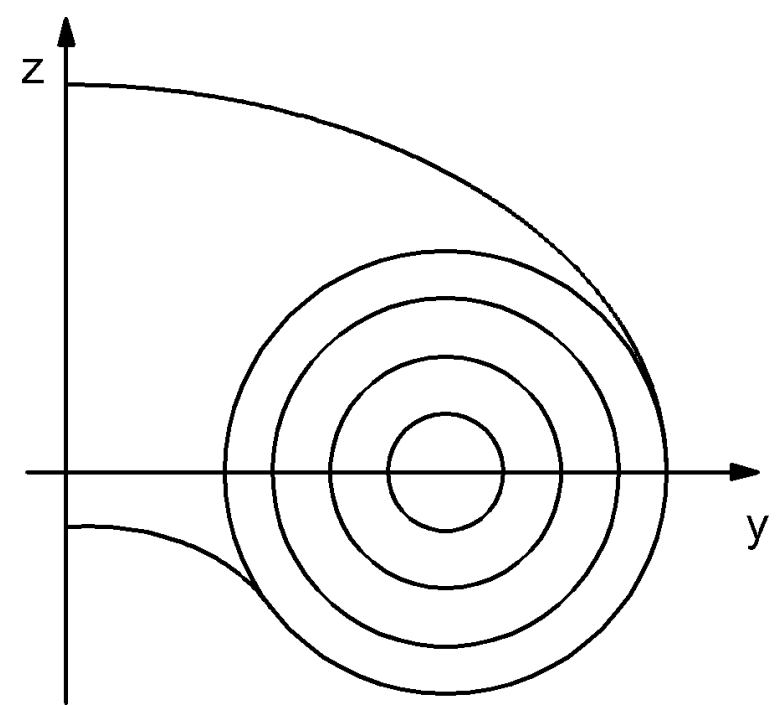

(a)

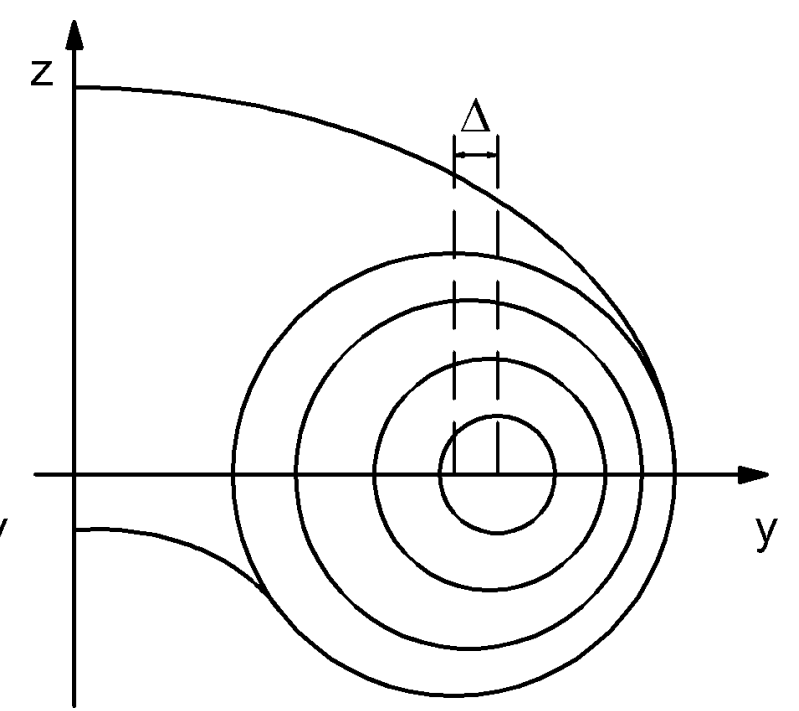

(b)

Figura 5.8: Em (a) é mostrada uma representação das superfícies magnéticas concêntricas e, em (b), é mostrada as superfícies magnéticas em uma situação de equilíbrio caracterizada pelo deslocamento do centro das superfícies magnéticas, denominado deslocamento de Shafranov.

A soma dos possíveis efeitos causadores do deslocamento do centro do plasma nas medidas de bolometria não permite a determinação exata da contribuição de cada um. No entanto, esses efeitos não impedem que seja calculada a posição da superfície $q=1$ utilizando o mesmo procedimento do raio X mole.

Para o disparo 26134, as inversões ocorrem em $r=-18 \mathrm{~mm}$ e em $r=+56 \mathrm{~mm}$. Considerando um deslocamento de $19 \mathrm{~mm}$, devido a uma possível inclinação dos sensores e devido ao deslocamento de Shafranov, é possível concluir que a superfície $q=1$ está situada na posição $r_{q 1}=37 \mathrm{~mm}$ durante o intervalo analisado.

As inversões ocorrem em $r=-13 \mathrm{~mm}$ e em $r=+43 \mathrm{~mm}$, para o disparo 25146, o que resulta em uma superfície $q=1$ localizada em $r_{q 1}=28 \mathrm{~mm}$. Diferentemente do valor obtido para o disparo 26134, o deslocamento do centro é de $15 \mathrm{~mm}$.

Essa diferença pode ser causada por diversos fatores, como diferentes valores do deslocamento de Shafranov, e principalmente devido às diferentes posições radiais do plasma. Para os instantes de análise, a posição radial do plasma é $\Delta R=+3.1 \mathrm{~mm}$ para o disparo 26134 e $\Delta R=0.9 \mathrm{~mm}$ para o disparo 26146 .

A tabela (5.1) mostra resultados deste tipo de análise obtidos para diferentes disparos. Na tabela também são mostrados alguns parâmetros do plasma no instante da análise. 


\begin{tabular}{|c|c|c|c|c|c|c|}
\hline Disparo & $I_{P}(k A)$ & $n_{e}\left(10^{-19} m^{-3}\right)$ & $t(m s)$ & freq $(\mathrm{kHz})$ & $r_{q 1 B O L}(\mathrm{~mm})$ & $r_{q 1 S X R}(\mathrm{~mm})$ \\
\hline 26134 & 78,8 & 1,4 & 66 & 2,0 & 37 & 39 \\
\hline 26135 & 74,9 & 1,7 & 65 & 2,2 & 32 & 35 \\
\hline 26136 & 75,4 & 1,7 & 86 & 2,2 & 31 & 34 \\
\hline 26137 & 75,8 & 1,7 & 73 & 1,9 & 30 & 32 \\
\hline 26140 & 80,3 & 1,1 & 53 & 2,4 & 26 & 24 \\
\hline 26143 & 80,5 & 1,1 & 52 & 2,3 & 26 & 27 \\
\hline 26146 & 76,6 & 1,4 & 57 & 2,3 & 28 & 30 \\
\hline
\end{tabular}

Tabela 5.1: Posição radial da superfície $q=1$ para diferentes disparos.

Automatizando esse processo de análise, é possível acompanhar a evolução temporal desses parâmetros. Os gráficos da figura (5.9) mostram a amplitude da potência espectral vezes o cosseno do ângulo de fase para vários instantes de tempo do disparo 26135 para os dois diagnósticos.

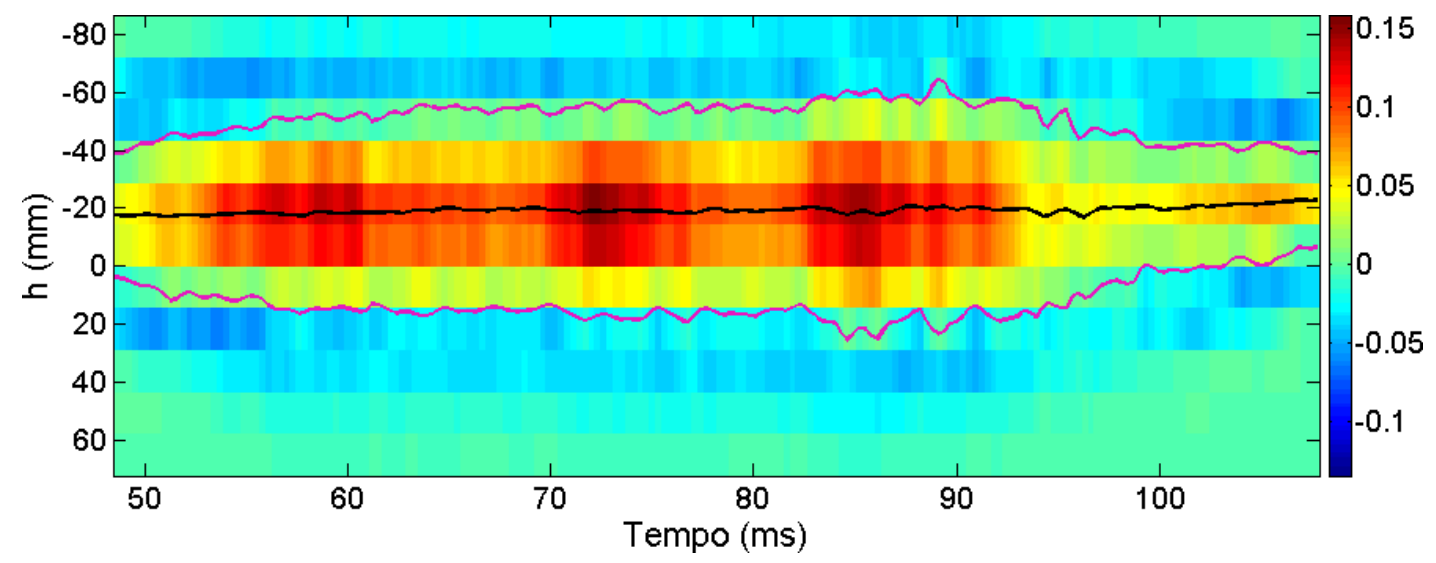

(a) raios $\mathrm{X}$ mole

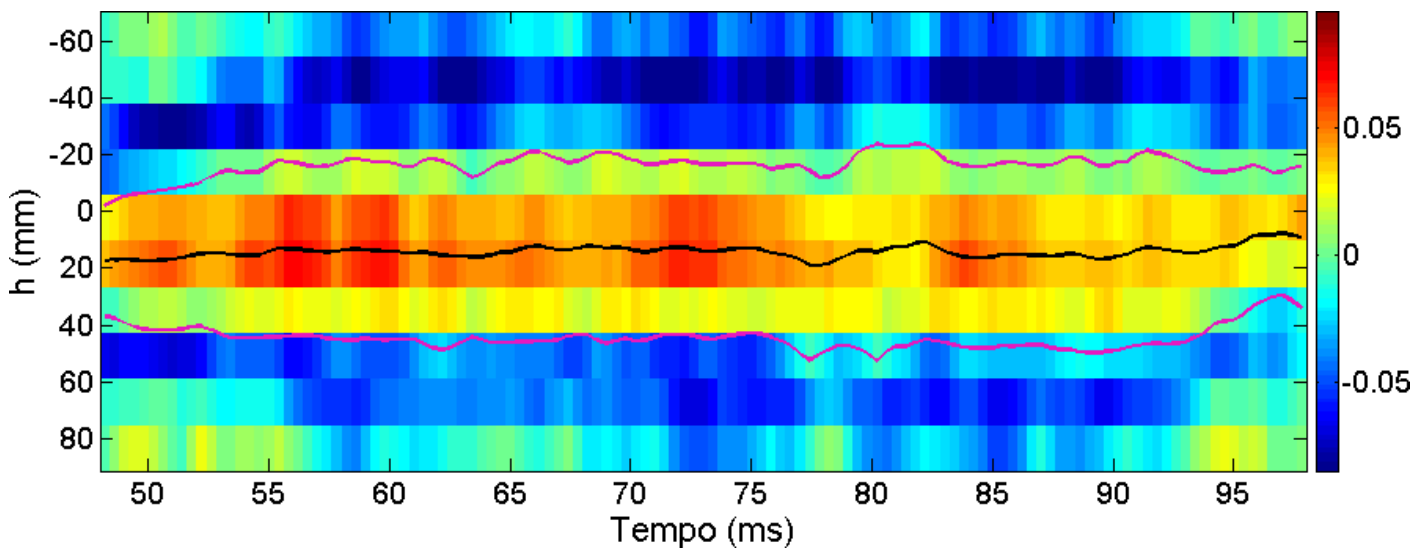

(b) bolômetro

Figura 5.9: Análise espectral contínua dos sinais de raios X mole (canal 09 como referência) e bolometria (canal 14 como referência). As curvas em magenta delimitam a mudança de fase, o que caracteriza a posição da superfície $q=1$ e, a curva preta, mostra do centro dessa superfície. 
A partir dos resultados dessa análise é possível determinar a posição radial da superfície $q=1$ e o centro dessa superfície ao longo do tempo. A partir da flutuação desses parâmetros é possível estimar um valor médio ao longo do tempo, assim como um erro estatístico para essa análise. A figura (5.10) mostra os principais parâmetro do disparo 26135, assim como os resultados dessa análise.
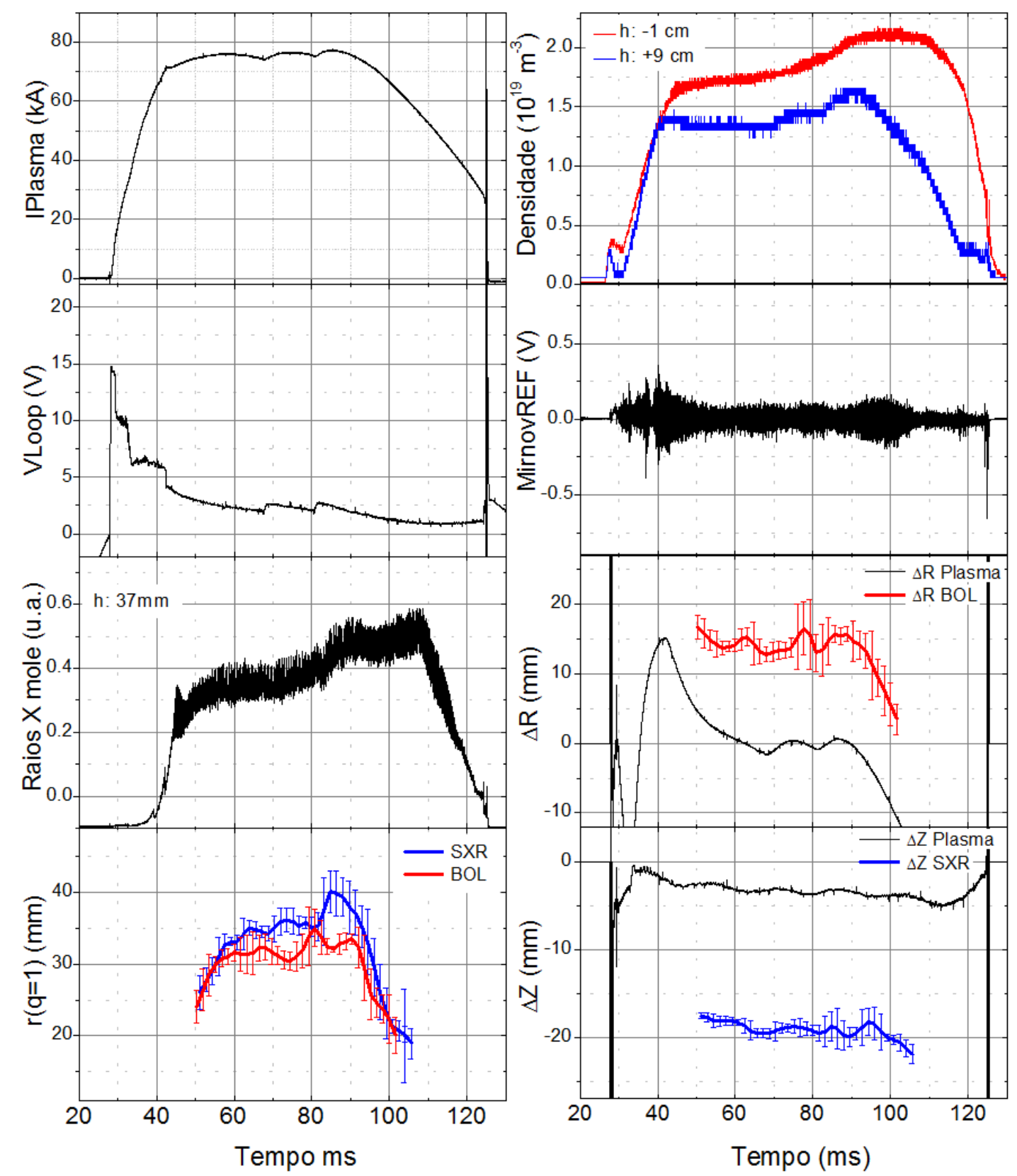

Figura 5.10: Evolução temporal dos principais parâmetros do plasma do tokamak TCABR para o disparo 26135. Da esquerda para a direita e de cima para baixo: a) corrente de plasma, b) tensão de enlace, c) raios X mole, d) posição radial da superfície $r(q=1)$, e) densidade eletrônica, f) oscilações de Mirnov, g) posição radial do plasma e deslocamento medido com bolômetro e h) posição vertical do plasma e deslocamento com raios X mole. 


\subsection{Caracterização do precursor dos dentes de serra}

$\mathrm{Na}$ análise apresentada nas figuras (5.6) e (5.7) é possível observar oscilações com frequências próximas de $11,5 \mathrm{kHz}$ e $15,0 \mathrm{kHz}$, respectivamente. Estas oscilações, provenientes do centro da coluna de plasma, são provocadas pelo precursor dos dentes de serra.

Essas oscilações também podem ser observadas na figura (5.5), que aparecem como oscilações senoidais de amplitude relativamente menor que a dos dentes de serra. É possível analisar essas oscilações construindo um gráfico da potência espectral da frequência desejada vezes o cosseno do ângulo de fase, como fora utilizado para as figuras (5.6) e (5.7) para as frequências de $2,0 k H z$ e 2,3kHz. A figura (5.11) mostra a análise feita para estas frequências.

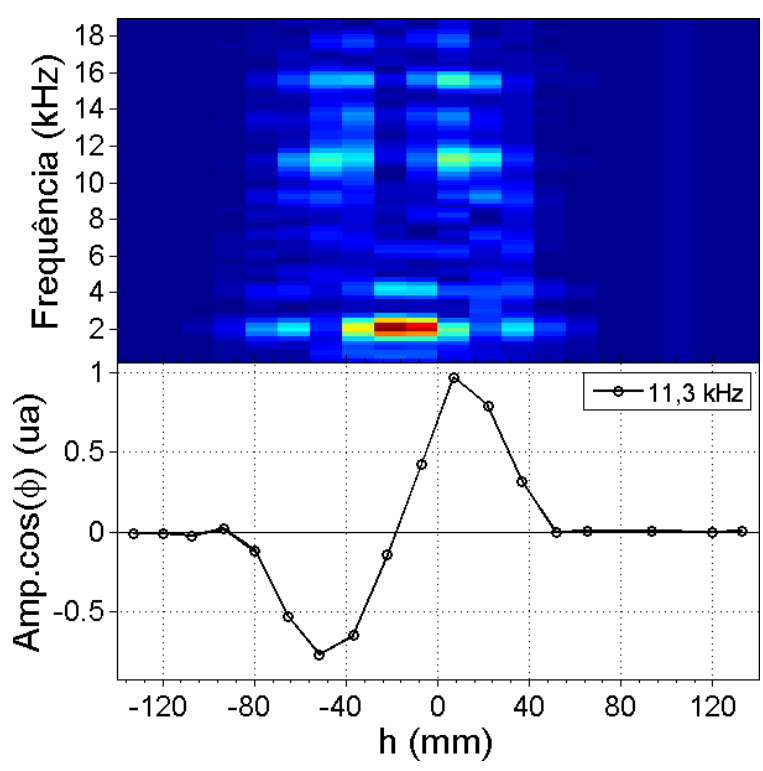

(a) raios $\mathrm{X}$ mole

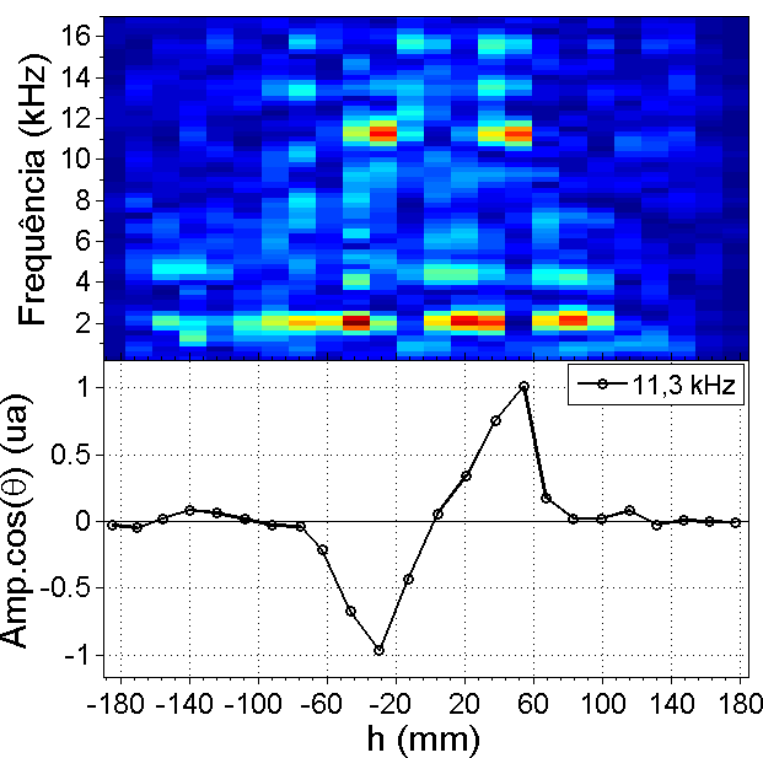

(b) bolômetro

Figura 5.11: Análise espectral dos sinais de: (a) raios X mole e (b) Bolômetro. Para essa análise utilizaram-se os canais $11(+7,0 \mathrm{~mm})$ do diagnóstico de raios X mole e o canal $16(+54,6 \mathrm{~mm})$ do bolômetro como referências para o ângulo de fase.

Essas oscilações são provenientes do modo precursor das instabilidades dentes de serra. Os resultados apresentados na figura (5.11) são muito próximos aos da simulação mostrada na figura (4.14a), onde foi simulada a medida de uma perturbação gaussiana de modo $m=1$.

Embora não seja possível estudar a dinâmica da evolução desse modo precursor, é possível avaliar sua largura e posição médias utilizando para isso as simulações de 
perturbações gaussianas, descritas na seção (4.1.1).

Tais simulações descrevem bem o comportamento do precursor dos dentes de serra, e os valores utilizados nas simulações, como a superfícies ressonante $r_{s}$ e a largura radial $\sigma_{r}$, podem ser utilizados como informações médias do fenômeno que ocorre dentro do plasma. A figura (5.12) mostra uma representação da perturbação utilizada na simulação e os parâmetros de interesse.

Na figura (5.13) é mostrada a sobreposição dos resultados obtidos através da análise espectral dos dados experimentais

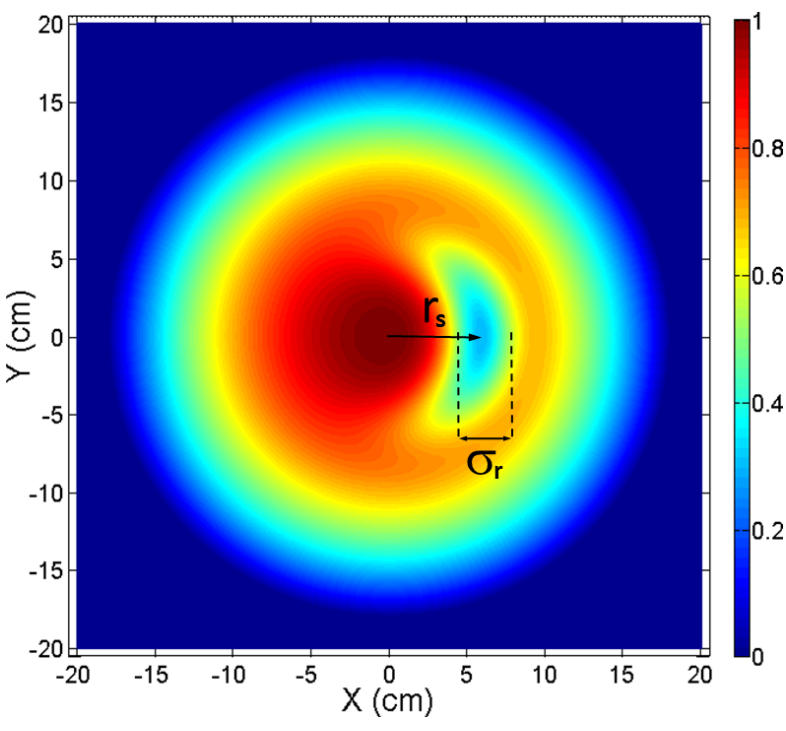

Figura 5.12: Representação dos principais parâmetros de interesse de uma perturbação $m=1$ simulada em um plasma de tokamak. do diagnóstico de raios $\mathrm{X}$ mole, aos obtidos através da simulação de medidas de uma perturbação gaussiana, aos quais foram aplicados e o mesmo método e procedimento de análise.

Para realizar esse ajuste utilizou-se uma simulação de medidas para uma perturbação gaussiana com os seguintes parâmetros: $r_{s}=34 \mathrm{~mm}, \sigma_{r}=22 \mathrm{~mm}$ e $\epsilon_{0 p}=5,5 \cdot 10^{-4}$. Além disso, a coluna de plasma foi deslocada verticalmente $18,5 \mathrm{~mm}$. Esse resultado reflete o comportamento médio da dinâmica do centro da coluna de plasma durante as instabilidades dentes de serra.

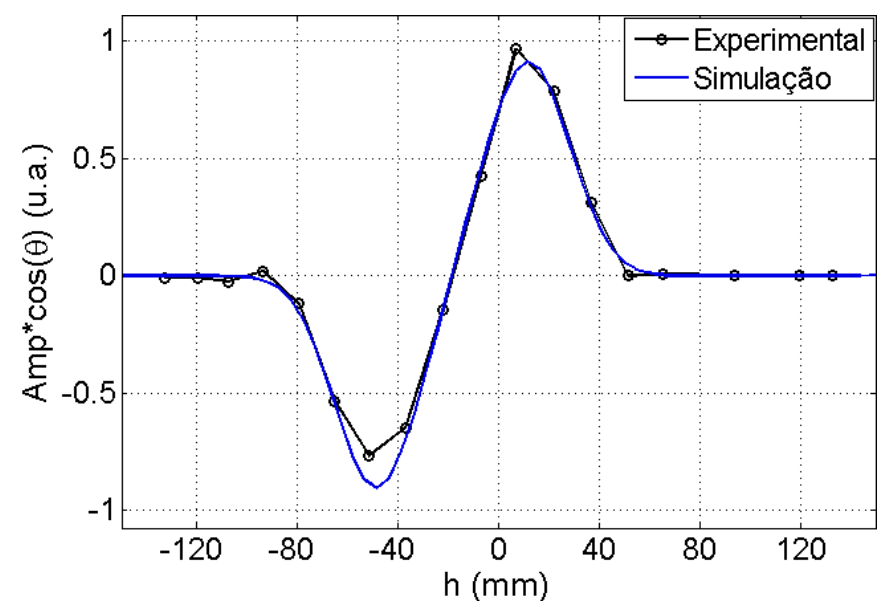

Figura 5.13: Curva experimental da potência espectral vezes o cosseno do ângulo de fase sobreposta pelo resultado simulado para os sinais de raios X mole. Na simulação, o centro do plasma foi deslocado verticalmente $18,5 \mathrm{~mm}$ para baixo e os seguintes parâmetros foram utilizados: $r_{s}=34 \mathrm{~mm}, \sigma_{r}=22 \mathrm{~mm}$ e $\epsilon_{0 p}=5,5 \cdot 10^{-4}$.

Utilizando esse procedimento de ajuste, não é possível determinar uma incerteza estatística rigorosa para os valores obtidos, entretanto, é possível estimar uma incerteza baseada no erros que podem ser cometidos ao fazer o ajuste do modelo. Para fazer esta 
estimativa, basta variar cada parâmetro individualmente até que a curva visualmente não ajuste adequadamente os resultados experimentais. A figura (5.14) mostra os "erros" máximos e mínimos que podem ser cometidos nos parâmetro de posição e largura da perturbação gaussiana para ajustar os dados experimentais.

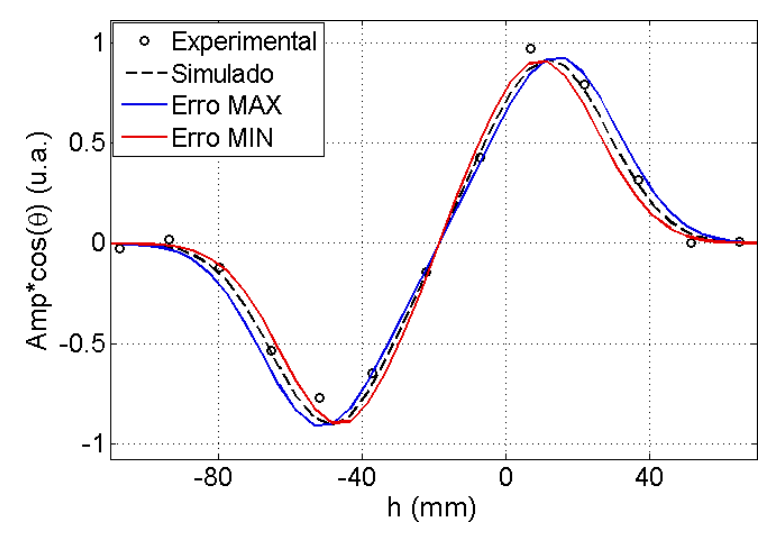

(a)

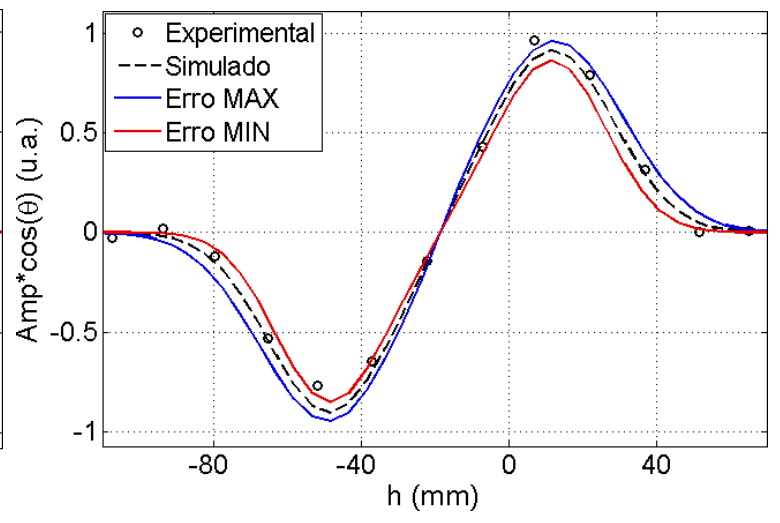

(b)

Figura 5.14: Estimativa da incerteza do ajuste do modelo. Em (a) estão apresentados os desvios ao redor de $r_{s}=34 \mathrm{~mm}$, para valores de $r_{s M A X}=37 \mathrm{~mm}$ e $r_{s M I N}=31 \mathrm{~mm}$. Em (b), são mostrados os desvios em $\sigma_{r}=22 \mathrm{~mm}$, com valores $\sigma_{r M A X}=25 \mathrm{~mm}$ e $\sigma_{r M I N}=19 \mathrm{~mm}$.

Através dessa análise é possível afirmar que $r_{s}=(34 \pm 3) m m, \sigma_{r}=(22 \pm 3) m m$, sendo que essa incerteza é devido ao ajuste do modelo. Esse mesmo procedimento será utilizado nos ajustes que seguem.

A figura (5.15) mostra a mesma técnica de sobreposição de resultados experimentais ao modelo simulado, desta vez feita para os resultados da análise espectral dos dados experimentais do bolômetro.

Figura 5.15: Curva experimental da potência espectral vezes o cosseno do ângulo de fase sobreposta pelo resultado simulado para os sinais de bolometria. A simulação para a região de alto campo (HF) foram utilizados os seguintes parâmetros: $r_{s}=(36 \pm 4) m m, \sigma_{r}=(23 \pm 4) m m$ e $\epsilon_{0 p}=5,8 \cdot 10^{-4}$. Para a região de baixo campo magnético (LF) foram utilizados: $r_{s}=(50 \pm 4) \mathrm{mm}$, $\sigma_{r}=(15 \pm 4) m m$ e $\epsilon_{0 p}=5,9 \cdot 10^{-4}$

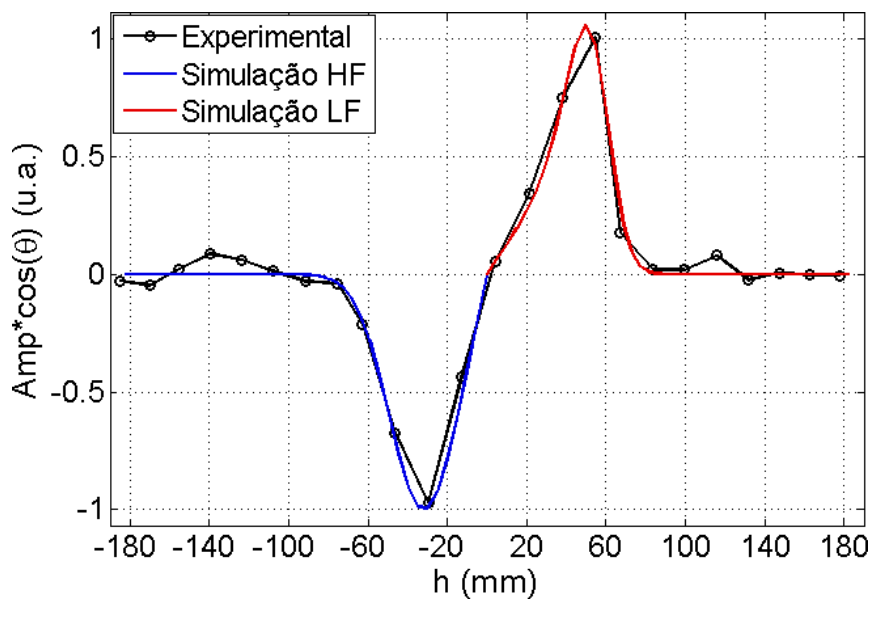

Devido as diferenças entre as regiões de alto campo magnético toroidal (High Field, 
HF) e baixo campo magnético toroidal (Low Field, LF), o bolômetro registra diferenças entre os dois lados da coluna de plasma. Para solucionar esse problema foram feitas simulações distintas para as regiões HF e LF.

A incerteza devido ao ajuste também pode ser obtida independentemente para cada região de campo magnético utilizando o mesmo procedimento mostrado na figura (5.14). A incerteza obtida para o bolômetro é, entretanto, maior que a determinada nas medidas usando o diagnóstico de raios X mole. Isso se deve ao fato deste último ter maior resolução espacial no centro da coluna de plasma, quando comparado ao bolômetro.

Os efeitos da diferença de campo magnético são claramente perceptíveis na análise dos resultados do bolômetro: a superfície ressonante é deslocada para fora, por conta do deslocamento de Shafranov, e a largura da perturbação também foi bem reduzida, causada pela aglutinação das linhas de campo no LF, como é mostrado na figura (5.8).

Esses modos precursores estão presentes na maioria dos disparos do tokamak TCABR e podem ser identificados no centro da coluna de plasma através de oscilações com amplitudes relativamente altas. Essas oscilações possuem frequências muito próximas das frequências das ilhas magnéticas e acabam dificultando a visualização de ilhas através de diagnósticos que medem integrais de linha.

\subsection{Caracterização de ilhas magnéticas}

A figura (5.16) mostra o disparo tokamak 26128 onde fortes indícios da presença de ilhas magnéticas podem ser observados entre os instantes $t=70 \mathrm{~ms}$ e $t=95 \mathrm{~ms}$ devido às elevadas amplitudes das oscilações magnéticas que foram registradas pelas bobinas de Mirnov. Para confirmar isso, e para determinar qual o possível modo dessa ilha magnética, foi feita uma análise dos sinais das 24 bobinas.

Essa análise é baseada em uma transformada de Fourier bidimensional: uma dimensão é o tempo e a outra o espaço angular poloidal. A posição angular poloidal está associada diretamente com a posição de cada sonda magnética, ou seja, o conjunto de 24 sondas equivale a 24 posições angulares ao redor da coluna de plasma. 

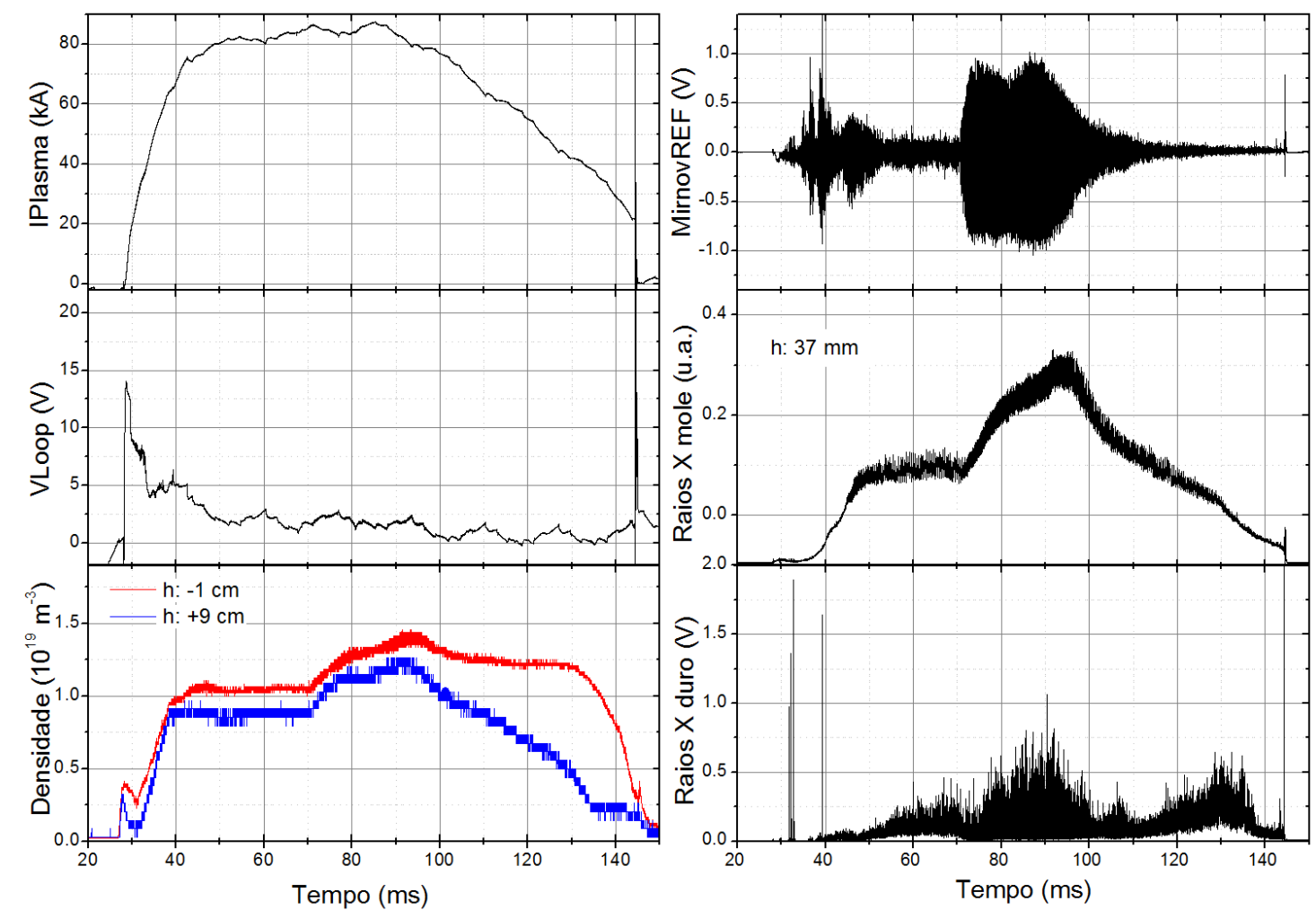

Figura 5.16: Evolução temporal dos principais parâmetros de plasma para o disparo 26128 do tokamak TCABR.

Como em um espectrograma, é possível fazer uma análise janelada para todos os instantes de tempo. A figura (5.17) mostra a análise para o disparo 26128.

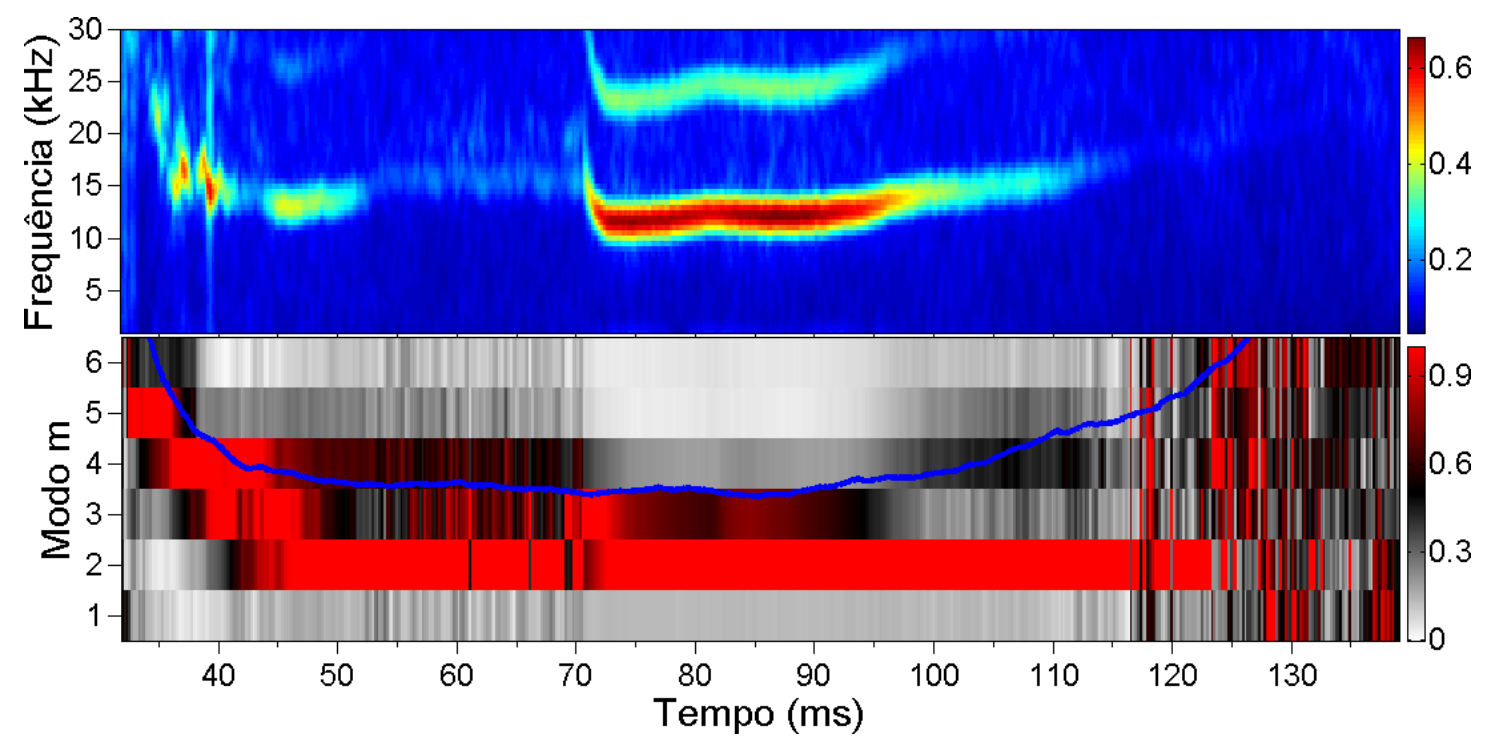

Figura 5.17: Espectrograma do sinal da sonda de Mirnov de referência seguido de uma análise dos modos MHD. A curva em azul mostra o valor de $q$ calculado para a borda do plasma. É possível observar que, no intervalo onde a atividade MHD é alta o fator de segurança na borda é $q(a)=3$ e o modo predominante é $m=2$. 
Nesta figura, o gráfico superior é o espectrograma do sinal da sonda de Mirnov de referência, onde é possível confirmar que existe uma oscilação muito forte próximo de $12,5 \mathrm{kHz}$. Isso é um indicativo da presença de uma ilha magnética.

O gráfico inferior é o resultado da transformada de Fourier bidimensional janelada no mesmo intervalo de tempo. Esse resultado leva em conta o sinal de todas as sondas de Mirnov. O gráfico mostra o que seria a decomposição em modos $m$ para diferentes instantes de tempo em uma escala de cores. A curva azul sobreposta representa o valor de $q=q(a)$ na borda do plasma calculado utilizando os parâmetros do plasma e serve como um indicativo, já que $r<a$ implica em $q(r)<q(a)$.

A informação importante que se pode tirar deste gráfico é que, no intervalo de interesse, os modos predominantes são os que possuem $m \leq 3$ e, portanto, a oscilação de $12,5 \mathrm{kHz}$ é provavelmente causada por uma ilha magnética de modo $m=2$.

A figura (5.18) mostra a análise espectral para os sinais bolométricos entre os instante $t=84 \mathrm{~ms}$ e $t=86 \mathrm{~ms}$. No gráfico superior é possível observar que as oscilações de $12,2 k H z$ são dominantes e muito intensas, o que facilita a análise. O gráfico inferior da figura mostra duas curvas da potência espectral vezes o cosseno do ângulo de fase, cada uma com referência em um canal diferente.

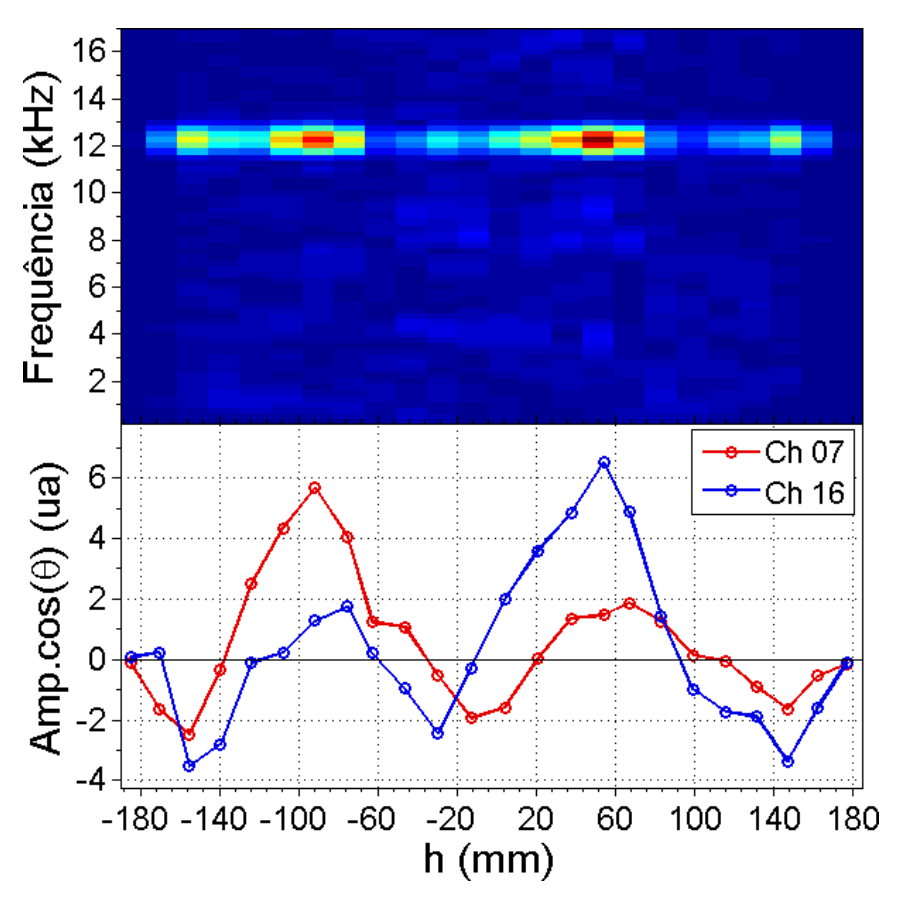

Figura 5.18: Análise espectral dos sinais do bolômetro entre os instantes $84,0 \mathrm{~ms}$ e $86,0 \mathrm{~ms}$. O gráfico inferior mostra duas curvas traçadas para a mesma frequência de $12,2 k H z$. A curva vermelha foi traçada utilizando o canal 07 $(h=-91,5 \mathrm{~mm})$ como referência e, a curva azul, foi traçado usando o canal $16(h=+54,6 \mathrm{~mm})$ como referência para $\theta$.

Por se tratar de um modo $\mathrm{m}$ par $(\mathrm{m}=2)$ era de se esperar que os dois lados da curva tivessem a mesma amplitude e que as curvas, traçadas com referências angulares diferentes, fossem idênticas. Essa diferença se deve à geometria do sistema de medida, que é composto por cordas colimadas por uma fenda que interceptam o plasma formando 
um ângulo com a horizontal que corta o centro do plasma.

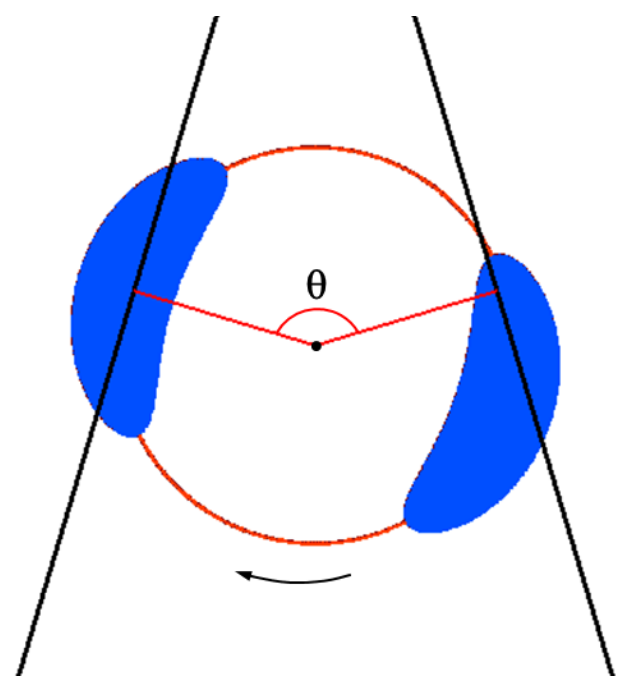

Figura 5.19: Representação de uma perturbação de modo $m=2$ e de duas cordas que interceptam a superfície ressonante da perturbação. Enquanto a perturbação é registrada com intensidade máxima pela corda da direita, o mesmo não acontece com a corda da esquerda, pois a diferença angular entre as cordas é $\theta<\pi$.

A figura (5.19) mostra uma representação dessa medida. A diferença de fase entre os dois pontos de máximo da perturbação é de $\theta=\pi$, enquanto que a interceptação das cordas bolométricas pela superfície ressonante é $\theta<\pi$. Isso faz com que, quando a medida da corda da direita seja máxima, a oposta não seja.

Esse fenômeno dificulta a análise de sinais provenientes deste tipo de geometria, entretanto, esse efeito também é observado nas simulações, não as desqualificando como uma fonte de informações confiável para comparação de resultados.

Como foi feito para o modo $m=1$ precursor do dente de serra, é possível caracterizar essa ilha magnética através da sobreposição de uma curva simulada. A figura (5.20) mostra um exemplo da perturbação simulada provocada por uma ilha onde são identificados os principais parâmetros da perturbação da ilha $m=2$.

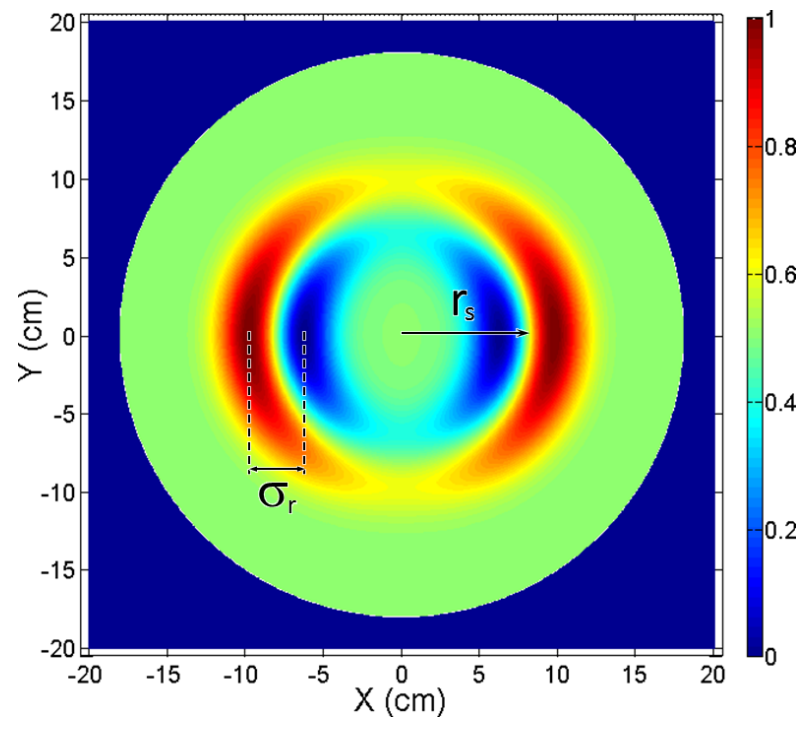

Figura 5.20: Representação dos principais parâmetros de interesse de uma perturbação do tipo ilha magnética de modo $m=2$.

A figura (5.21) mostra a sobreposição das curvas experimentais, obtidas utilizando como referência os canais $07(h=-91,5 \mathrm{~mm})$ e $16(h=+54,6 \mathrm{~mm})$ do bolômetro, pela curva obtida através do modelo de perturbações simuladas, com referência no mesmo canal. Novamente a simulação foi dividida em duas partes, por conta das diferenças existentes entre o HF e o LF. 


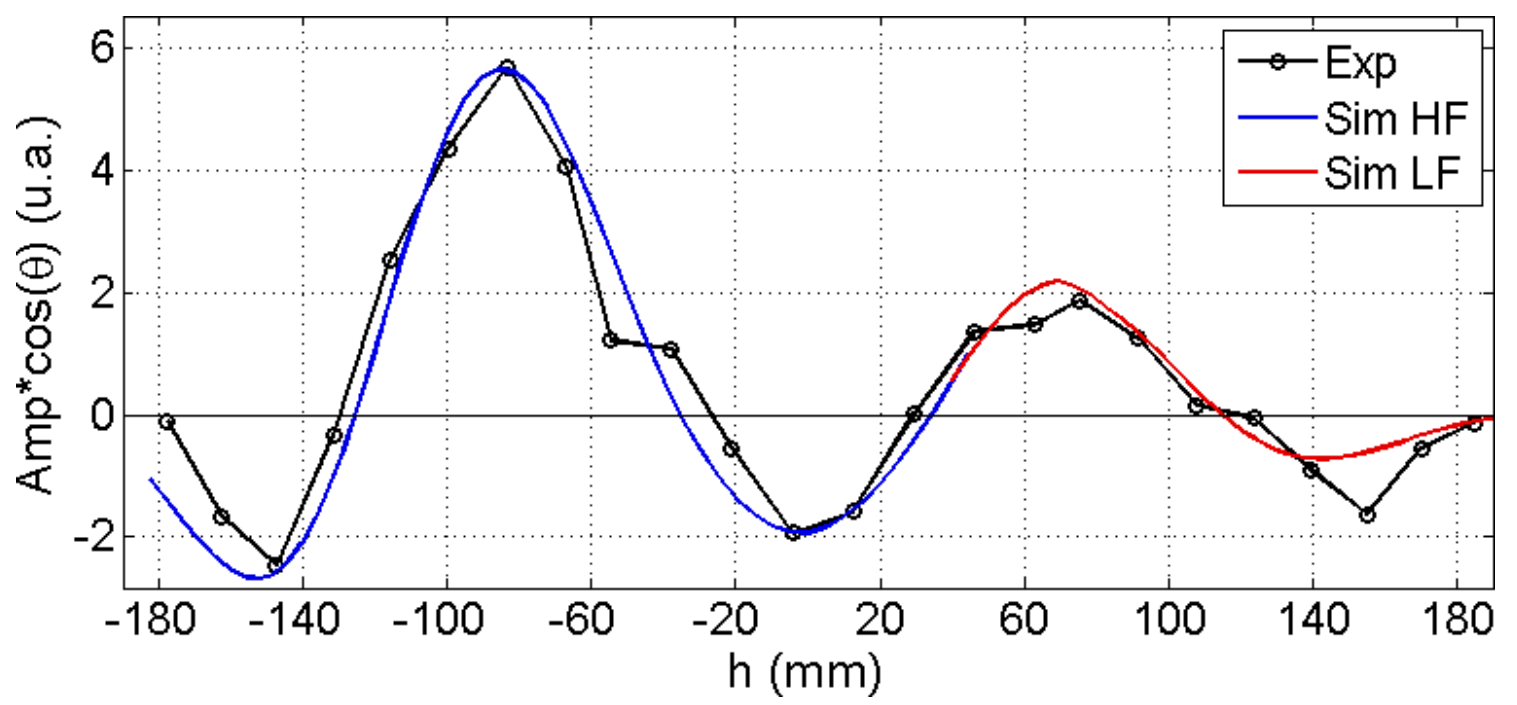

(a)

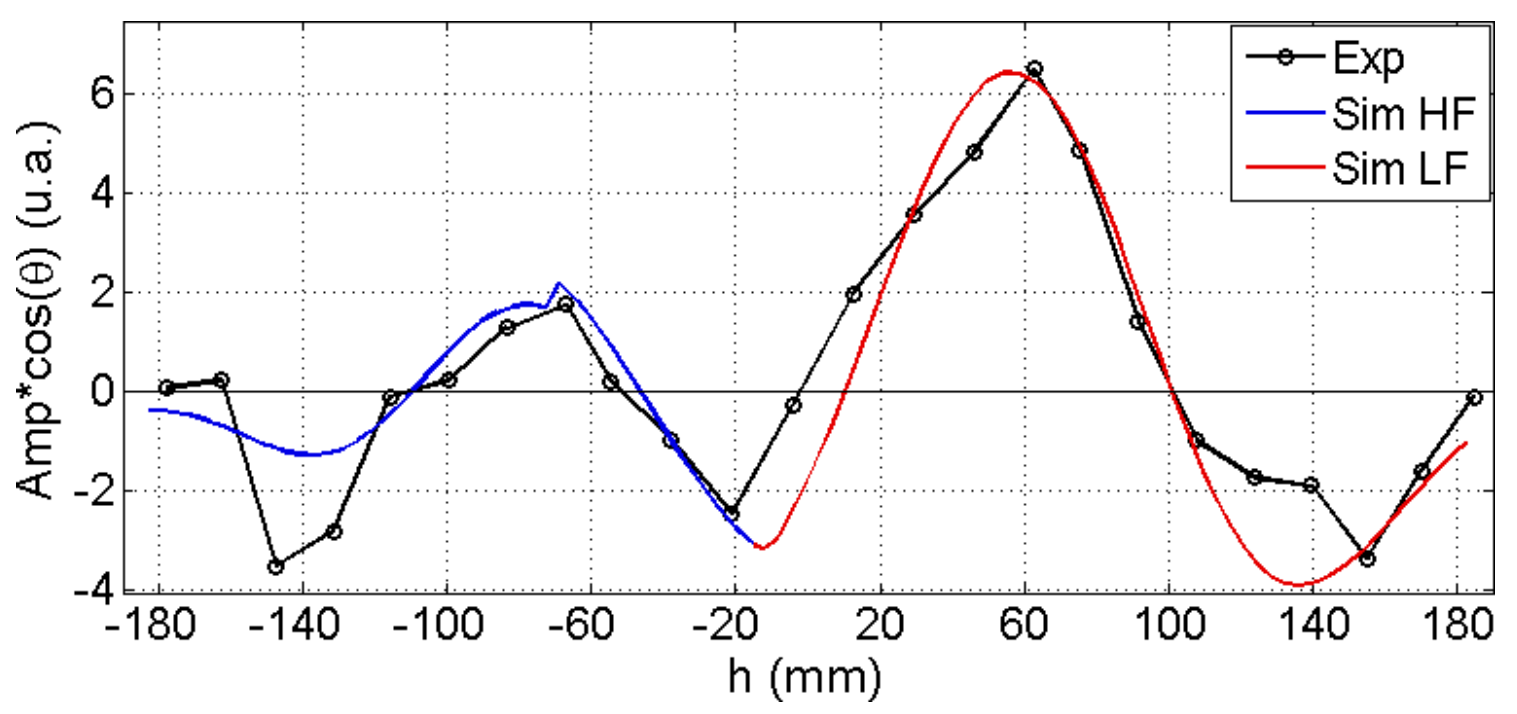

(b)

Figura 5.21: Curva experimental com dados do bolômetro da potência espectral vezes o cosseno do ângulo de fase. Em (a), foi utilizado como referência o canal 07 e, em (b), o canal 16. Essas curvas foram sobrepostas pelos resultados simulados nas regiões de alto campo magnético (HF) e baixo campo magnético (LF). Na simulação para HF foram utilizados os seguintes parâmetros: $r_{s}=(122 \pm 4) m m, \sigma_{r}=(46 \pm 3) \mathrm{mm}$ e $\epsilon_{0 p}=2,1 \cdot 10^{-3}$. Para o LF: $r_{s}=(110 \pm 5) m m, \sigma_{r}=(54 \pm 4) m m$ e $\epsilon_{1 p}=1,9 \cdot 10^{-3}$. Foi utilizado $\epsilon_{2 p}=0,7 \cdot \epsilon_{1 p}$ nos dois casos.

A incerteza dos valores foi determinada como na seção anterior. Através da metodologia de sobreposição foi possível determinar 3 parâmetros importantes da ilha magnética presente no disparo 26128: o modo poloidal $m=2$, que pode ser confirmado pelo gráfico apresentado na figura (5.17), a posição radial: $r_{s}=(122 \pm 4) \mathrm{mm}$ para o $\mathrm{HF}$ e $r_{s}=(110 \pm 5) \mathrm{mm}$ para o LF, e sua largura: $\sigma_{r}=(46 \pm 3) \mathrm{mm}$ para o $\mathrm{HF}$ e $\sigma_{r}=(54 \pm 4) m m$ para o LF. 
A amplitude das oscilações causadas por ilhas com modo poloidal $m>2$ é relativamente menor que as ilhas com modo $m=2$ e isso acaba dificultando sua identificação. No tokamak TCABR esses modos aparecem principalmente durante a formação do plasma. A figura (5.22) mostra um gráfico da evolução temporal dos principais parâmetros do plasma para o disparo 26277, que será utilizado para exemplificar esse caso.
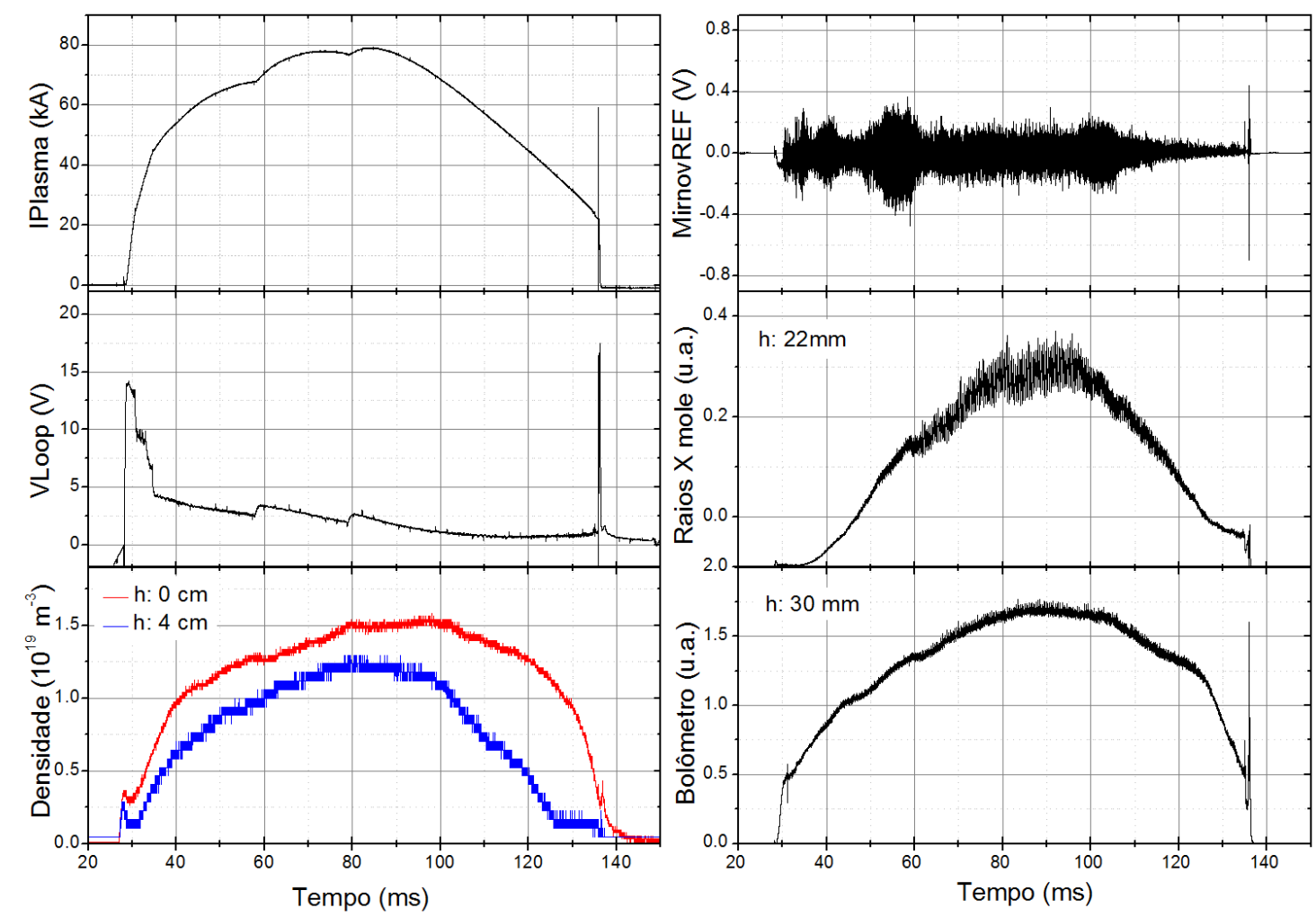

Figura 5.22: Evolução temporal dos principais parâmetros de plasma para o disparo 26277 do tokamak TCABR.

O aumento na amplitude das oscilações de Mirnov, entre os instantes $t=49 \mathrm{~ms}$ e $t=$ $60 \mathrm{~ms}$, é um indicativo da presença de uma ilha magnética que cresce e, posteriormente é suprimida. Entre os instantes $t=52 \mathrm{~ms}$ e $t=54 \mathrm{~ms}$, quando a amplitude nas oscilações é máxima, é mais fácil identificar e estudar essa ilha magnética. A figura (5.23) mostra a análise de modos das sondas de Mirnov para o disparo 26277.

Utilizando a mesma metodologia do caso anterior, a figura (5.24) mostra a análise espectral entre os instantes $t=52 \mathrm{~ms}$ e $t=54 \mathrm{~ms}$, onde duas curvas de potência espectral vezes o cosseno do ângulo de fase foram traçadas com referência em diferentes canais do bolômetro. 


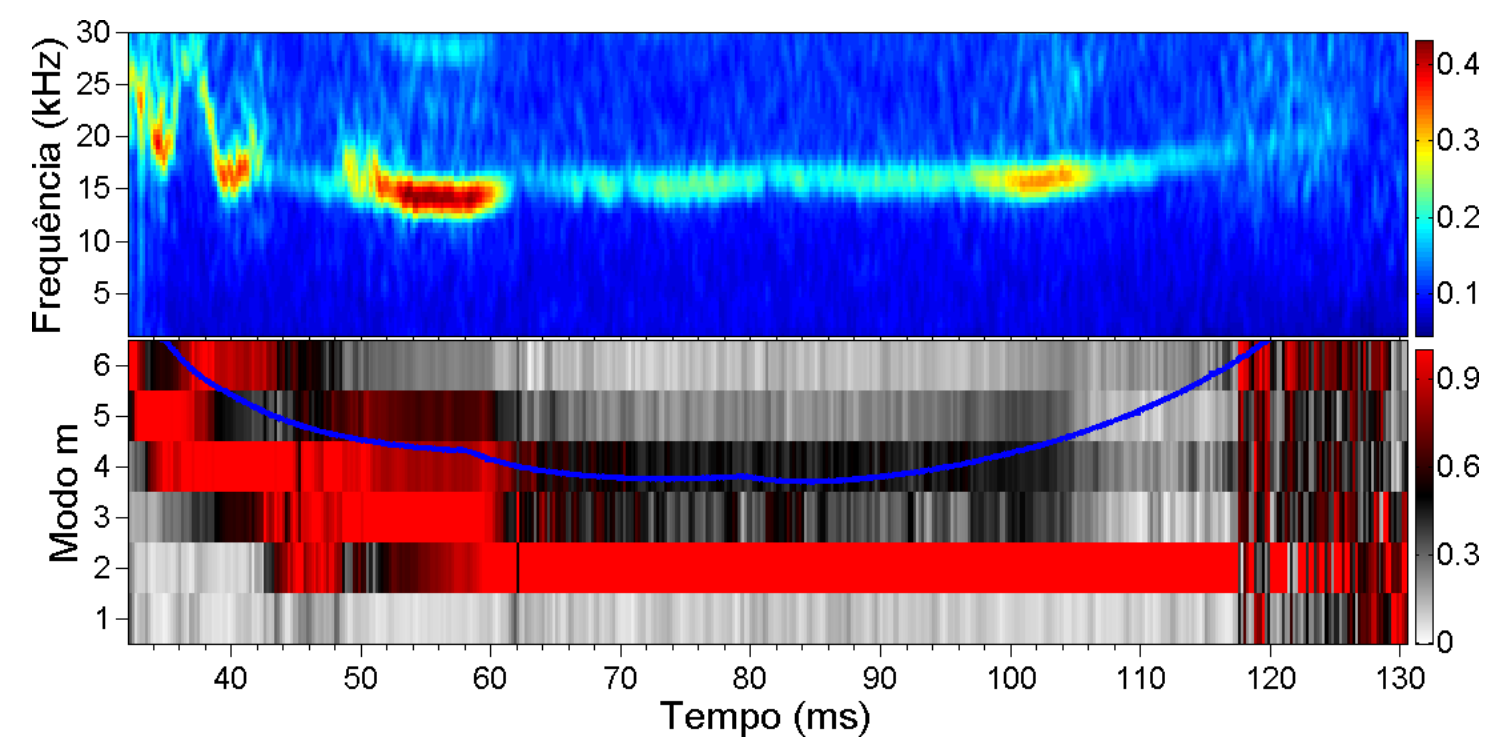

Figura 5.23: Espectrograma do sinal da sonda de Mirnov de referência seguido de uma análise dos modos MHD. A curva em azul mostra o valor de $q$ calculado para a borda do plasma. É possível observar que, entre os instantes $t=52 \mathrm{~ms}$ e $t=54 \mathrm{~ms}$, o fator de segurança na borda é $q(a) \geq 4$ e o modo predominante é $m=3$.

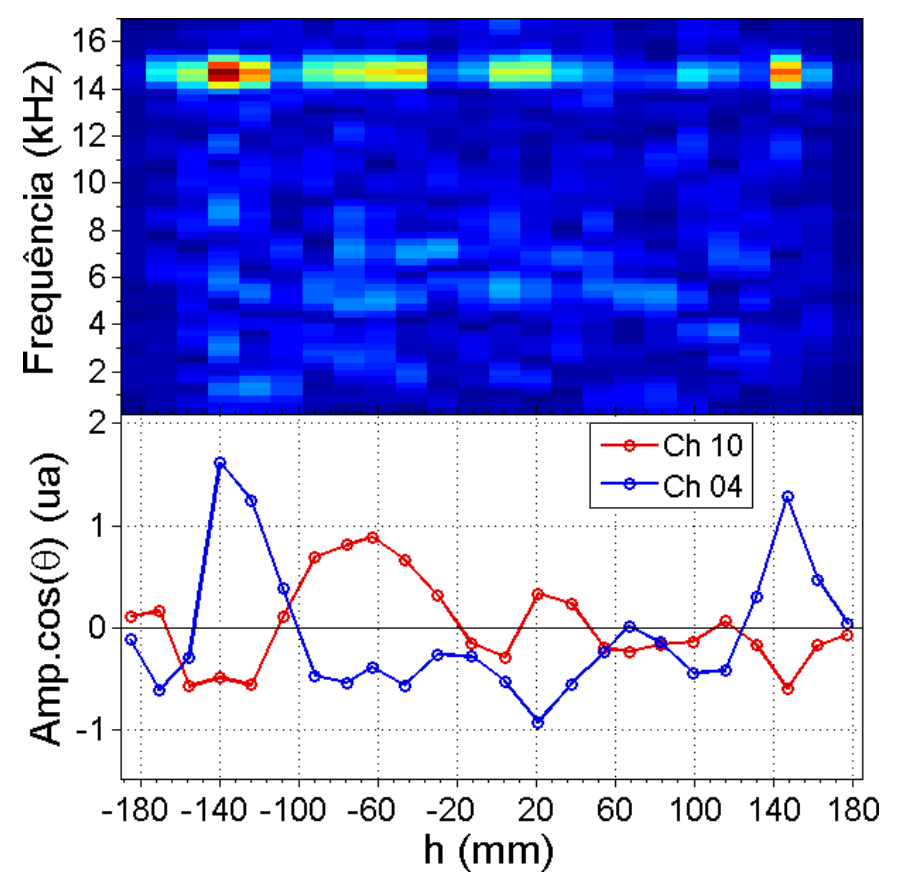

Figura 5.24: Análise espectral dos sinais do bolômetro entre os instantes $52,0 \mathrm{~ms}$ e $54,0 \mathrm{~ms}$. O gráfico inferior mostra duas curvas traçadas para a mesma frequência de $14,7 \mathrm{kHz}$. A curva vermelha foi traçada utilizando o canal 10 $(h=-46,3 \mathrm{~mm})$ como referência e, a curva azul, foi traçado usando o canal $04(h=-139,6 \mathrm{~mm})$ como referência para $\theta$.

Comparando as amplitudes dos gráficos inferiores das figuras (5.18) e (5.24) é possível notar a grande diferença relativa de amplitude entre os sinais.

Além de menor, essa ilha aparece quando o plasma ainda está se formando, ou seja, a corrente e a densidade não estão estáveis, o que dificulta a análise. Outro problema é que os valores absolutos de densidade e corrente são muito mais baixos que os do disparo 26128 e isso se reflete na intensidade da potência irradiada pelo plasma, registrada por 
meio do diagnóstico de bolometria.

Isso acaba dificultando a análise através da sobreposição de resultados simulados, pois outras perturbações que na análise anterior eram desprezíveis, nesta análise tornam-se mais expressivas. Os maiores problemas acontecem para as cordas centrais do bolômetro, que interceptam e registram perturbações causadas por instabilidades do tipo dentes de serra ou até mesmo ilhas de menor amplitude.

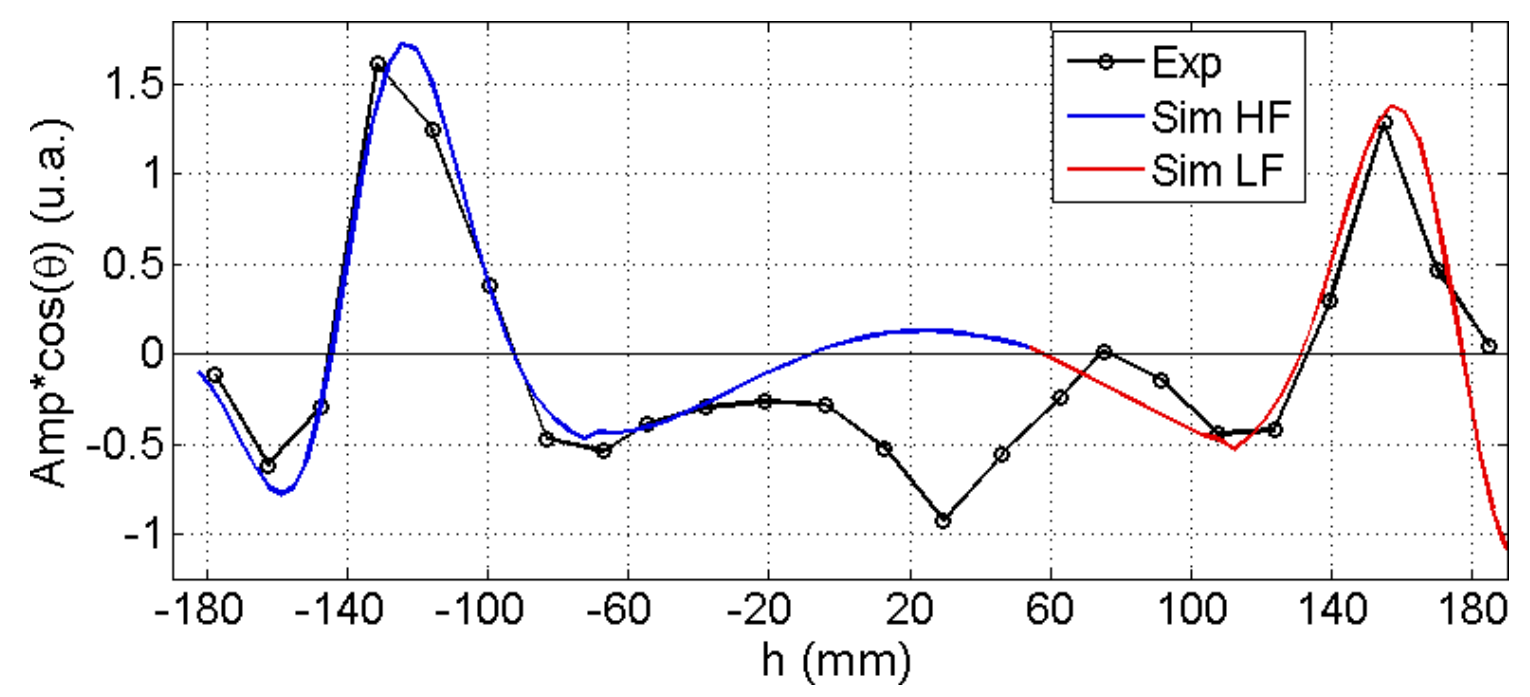

(a)

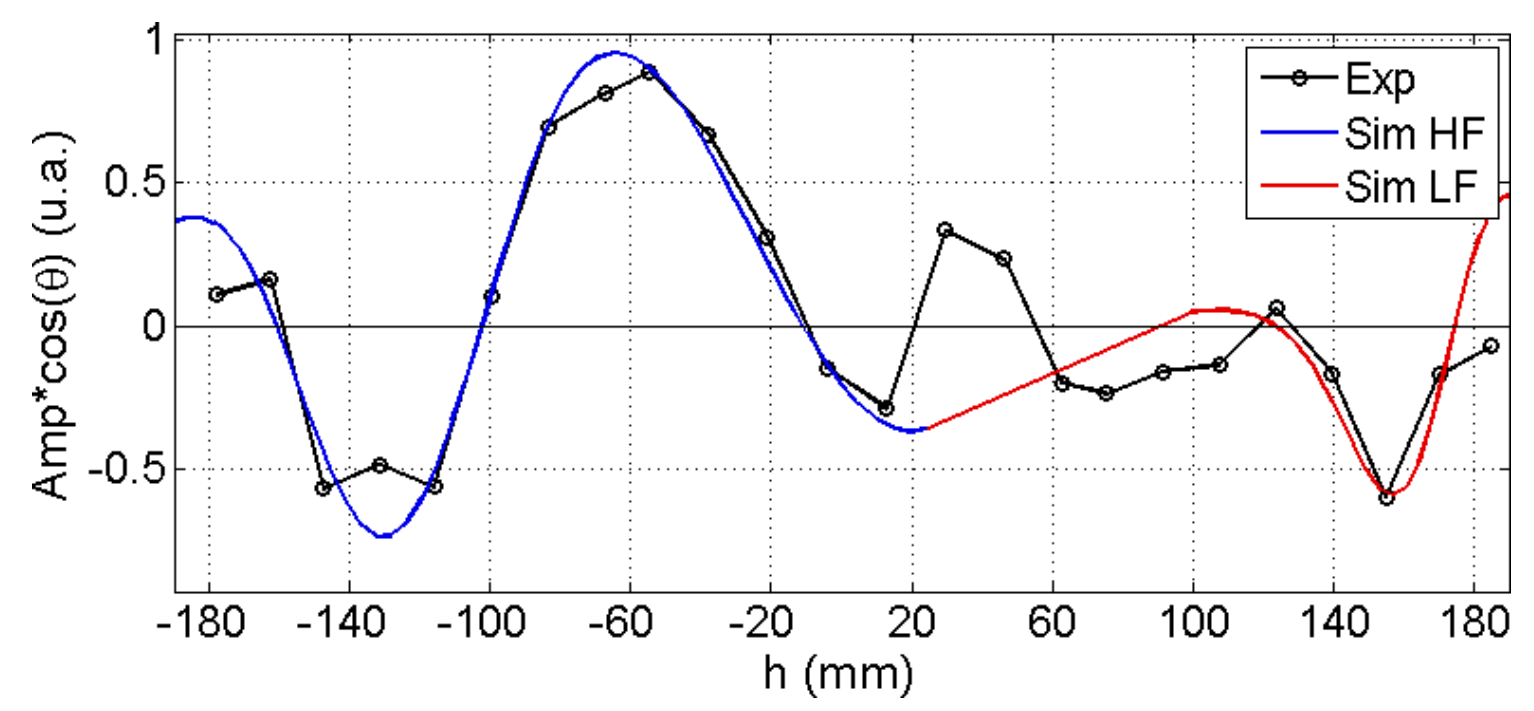

(b)

Figura 5.25: Curva experimental com dados do bolômetro da potência espectral vezes o cosseno do ângulo de fase. Em (a), foi utilizado como referência o canal 04 e, em (b), o canal 10. Essas curvas foram sobrepostas pelos resultados simulados nas regiões de alto campo magnético (HF) e baixo campo magnético (LF). Na simulação para HF foram utilizados os seguintes parâmetros: $r_{s}=(143 \pm 4) \mathrm{mm}, \sigma_{r}=(22 \pm 4) \mathrm{mm}$ e $\epsilon_{0 p}=0,8 \cdot 10^{-3}$. Para o LF: $r_{s}=(139 \pm 5) m m, \sigma_{r}=(25 \pm 4) m m$ e $\epsilon_{1 p}=0,8 \cdot 10^{-3}$. Foi utilizado $\epsilon_{2 p}=0,7 \cdot \epsilon_{1 p}$ nos dois casos. 
A figura (5.25) mostra a sobreposição das curvas experimentais pela obtida através do modelo de perturbações simuladas utilizando uma perturbação do tipo ilha magnética com modo $m=3$. A simulação foi dividida em duas partes, por conta das diferenças existentes entre o HF e o LF.

Utilizando a mesma metodologia, foi possível determinar os seguintes parâmetros da ilha magnética presente no início do disparo 26277: o modo poloidal $m=3$, que pode ser confirmado pelo gráfico apresentado na figura (5.23), a posição radial: $r_{s}=(143 \pm 4) \mathrm{mm}$ para o HF e $r_{s}=(139 \pm 5) m m$ para o LF, e sua largura: $\sigma_{r}=(22 \pm 4) m m$ para o HF e $\sigma_{r}=(25 \pm 4) m m$ para o LF.

Tendo em vista que os modos observados são modos com $n=1$, é possível verificar a veracidade da posição desta ilha comparando o modo poloidal $m$ da ilha com o valor do fator de segurança na posição radial $r_{s}$ da ilha, dado pela equação (2.11):

$$
q\left(r_{s}\right)=q(a) \frac{\left(\frac{r_{s}}{a}\right)^{2}}{1-\left[1-\left(\frac{r_{s}}{a}\right)^{2}\right]^{\nu+1}}
$$

onde $q(a)$, o fator de segurança na borda, é dado ela equação (2.10):

$$
q(a)=\frac{2 \pi a^{2} B_{\phi}}{\mu_{0} I_{P} R_{0}}
$$

Sendo que os parâmetros do tokamak são: raio maior do tokamak $R_{0}=615 \mathrm{~mm}$, raio menor (raio do plasma) $a=(180 \pm 5) \mathrm{mm}$ e campo magnético toroidal $B_{\phi}=(1,07 \pm$ $0,02) T$. Os valores de corrente de plasma utilizados são $I_{P}=(85,9 \pm 0,6) k A$, para o disparo 26128 e $I_{P}=(66,4 \pm 0,6) k A$, para o disparo 26277.

Para estimar a veracidade dos dados, o valor do parâmetro $\nu$ foi estimado a partir da posição da inversão dos dentes de serra, que foi determinada através da metodologia apresentada na seção 5.1. Aplicando o valor de $r(q=1)$ na equação (5.1), se obtém $\nu=2,34$ para o disparo 26128 e $\nu=3,45$ para o disparo 26277.

\begin{tabular}{|c|c|c||c|c|}
\hline & \multicolumn{2}{|c||}{26128} & \multicolumn{2}{c|}{26277} \\
\hline & $r_{s}(m m)$ & $q\left(r_{s}\right)$ & $r_{s}(m m)$ & $q\left(r_{s}\right)$ \\
\hline LF & $122 \pm 4$ & $1,69 \pm 0,19$ & $143 \pm 4$ & $2,72 \pm 0,15$ \\
\hline HF & $110 \pm 5$ & $1,52 \pm 0,23$ & $139 \pm 5$ & $2,59 \pm 0,22$ \\
\hline
\end{tabular}

Tabela 5.2: Cálculo de $q\left(r_{s}\right)$ para os parâmetros obtidos para cada ilha analisada. Os valores obtidos são compatíveis com o modo $m$ de cada ilha.

As incertezas dos valores apresentados na tabela são referentes ao ajuste obtido pelo 
método de sobreposição de curvas simuladas aos dados experimentais e à propagação das incertezas. Os resultados mostrados na tabela mostram que os valores obtidos para a posição das superfícies ressonantes é compatível com o valor esperado para cada modo.

Outra maneira de estimar a veracidade destes dados é comparar com as medidas da velocidade de rotação poloidal do plasma para o tokamak TCABR [54].

Assumindo que a velocidade de rotação do plasma é a mesma das ilhas magnéticas e utilizando os valores de frequência $f$ da perturbação, modo poloidal $m$, e a posição radial experimental $r_{s}$, é possível determinar a velocidade de rotação da ilha magnética através da seguinte relação:

$$
v\left(r_{s}\right)=\frac{2 \pi r_{s} f}{m}
$$

Os valores calculados estão apresentados no gráfico (5.26), que também mostra o perfil da rotação do plasma no tokamak TCABR. As incertezas para os valores de rotação poloidal das ilhas magnéticas foram calculadas propagando a incerteza das posições radiais obtidas experimentalmente.

Analisando os valores apresentados no gráfico, é possível constatar que a velocidade de rotação das ilhas é compatível com o perfil experimental de rotação poloidal do plasma.

Os valores obtidos experimentalmente para a largura das ilhas podem ser comparados com o modelo teórico que relaciona essa largura com a amplitude das oscilações do campo poloidals, entre outros fatores. A equação (2.32), mostrada abaixo, mostra a rela-

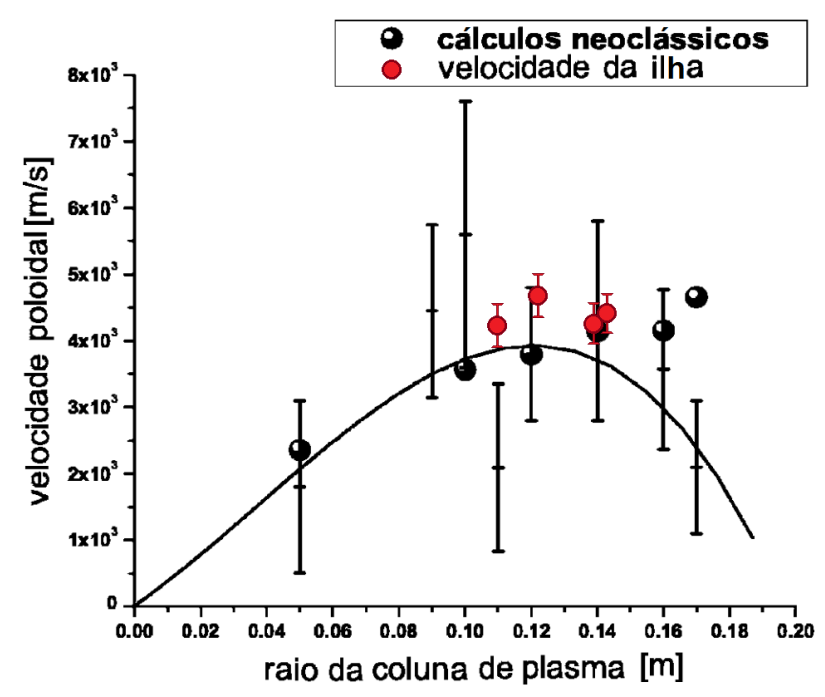

Figura 5.26: Perfil da velocidade de rotação poloidal do plasma do tokamak TCABR (extraído de [54]). Os pontos em vermelho representam a velocidade de rotação das ilhas, calculadas a partir de (5.3). ção da largura com os diversos parâmetros experimentais, dentre eles o campo magnético poloidal perturbado $B_{\theta}\left(r_{b}\right)$, que pode ser obtido através das bobinas de Mirnov:

$$
\sigma_{r}=4\left(\frac{r_{s}^{2-m} r_{b}^{m+1} \tilde{B}_{\theta}\left(r_{b}\right)}{2 a m B_{\theta}(a)\left[1-\left(1+\nu\left(\frac{r_{s}}{a}\right)^{2}\right)\left(1-\left(\frac{r_{s}}{a}\right)^{2}\right)^{\nu}\right]}\right)^{1 / 2}
$$


Outros parâmetros do sistema são: o campo magnético poloidal na borda do plasma $B_{\theta}(a)$, que pode ser calculado através da equação (2.3), e as posições radiais da superfície ressonante $r_{s}$ e das sondas de Mirnov $r_{b}$. A tabela (5.3) mostra os resultados dos valores calculados e respectivas comparações com os obtidos pelo ajuste.

\begin{tabular}{|c|c|c|c|c|}
\hline & \multicolumn{2}{|c|}{$\sigma_{r}(\mathrm{~mm}) \mathrm{HF}$} & \multicolumn{2}{c|}{$\sigma_{r}(\mathrm{~mm}) \mathrm{LF}$} \\
\hline & 26128 & 26277 & 26128 & 26277 \\
\hline Ajustado & $46 \pm 3$ & $22 \pm 4$ & $54 \pm 3$ & $25 \pm 4$ \\
\hline Calculado & $46 \pm 6$ & $22 \pm 2$ & $53 \pm 8$ & $23 \pm 2$ \\
\hline
\end{tabular}

Tabela 5.3: Valores obtidos para a largura da ilha magnética, tanto para o HF quanto para o LF, para os disparos 26128 e 26277 do tokamak TCABR. Na tabela são apresentados os resultados do ajuste da simulação e os resultados calculados utilizando (5.4).

As incertezas dos valores calculados da tabela (5.3) foram obtidos através da propagação das incertezas nos valores de $r_{s}$ e dos parâmetros utilizados nos cálculos. A partir dessas incertezas é possível constatar que os resultados obtidos pelos dois métodos são compatíveis.

A diferença de valores encontrados para a largura da ilha entre o HF e o LF pode ser estimada a partir da equação (2.41):

$$
\frac{\sigma_{r}(H F)}{\sigma_{r}(L F)}=\left(\frac{R_{0}-r_{s}}{R_{0}+r_{s}}\right)^{\frac{1}{2}}
$$

Para o disparo 26128, a razão $\sigma_{r}(H F) / \sigma_{r}(L F)$ experimental é $0,85 \pm 0,08$ e a calculada $0,82 \pm 0,01$. A incerteza deste último resultado é devida à posição da superfície ressonante $r_{s}$ e, considerando essas incertezas, os resultados são compatíveis.

A razão $\sigma_{r}(H F) / \sigma_{r}(L F)$ para o disparo 26277 foi de $0,88 \pm 0,21$ e a calculada $0,79 \pm 0,01$, que é um resultado é compatível. 


\section{Conclusões}

Neste trabalho um novo sistema de bolometria foi instalado no tokamak TCABR contendo 24 cordas verticais, onde cada corda é capaz de medir a potência irradiada integrada ao longo de todo seu ângulo de visada.

Embora esse diagnóstico não forneça a potência absoluta irradiada pelo plasma, tal sistema mostrou-se bastante eficiente na medida da evolução temporal da potência ao longo do perfil radial da coluna de plasma.

Se por um lado o diagnóstico bolométrico constituído de fotodiodos, por apresentar uma curva de resposta dependente do comprimento de onda, não é eficiente para medidas da potência total irradiada pelo plasma, este sistema mostrou ser extremamente útil nas medidas das flutuações da radiação.

Através da análise espectral dos sinais provenientes do diagnóstico de bolometria foi possível determinar o ponto de inversão das oscilações dentes de serra.

Como as emissões nas frequências de raios-X mole são provenientes principalmente do centro da coluna de plasma, o diagnóstico de Raios-X mole é a principal ferramenta usada no estudo das instabilidades dentes de serra e, portanto, para a determinação da posição de inversão nas oscilações, onde se atribui a posição da superfície ressonante $q=1$.

Os diversos resultados obtidos para o diagnóstico de bolometria mostraram-se compatíveis com os provenientes do diagnóstico de raios-X mole, apresentando valores que variavam entre $r(q=1)=(24 \sim 39) \mathrm{mm}$. Além disso, foi possível determinar a evolução temporal da posição da superfície $q=1$ ao longo de um disparo, resultado este obtido pela primeira vez no tokamak TCABR.

Tratando ainda as instabilidades do tipo dente de serra, também foi possível caracterizar o procursor do crash dos dentes de serra. Esse precursor é identificado como um modo $m=1$ de dobra interno à superfície $q=1$ e com frequência que corresponde à velocidade de rotação do plasma na região $(11,5 \mathrm{kHz}$ e $15 \mathrm{kHz})$.

Para caracterizar esse modo utilizou-se dos artifícios de simulação de medidas de perturbações através de modelos gaussianos para a perturbação da emitância e que mostrou ser muito eficiente para ajustar os resultados obtidos experimentalmente.

A análise apresentada no trabalho foi feita para o disparo 26134 e os valores obtidos foram de $r_{s}=(34 \pm 3) m m$ e $\sigma_{r}=(22 \pm 3) \mathrm{mm}$ para os resultados obtidos através do diagnóstico de raios-X mole. 
Diferentes resultados foram obtidos para as regiões de HF e LF do tokamak, que apresentam diferenças devido ao deslocamento de Shafranov e a complicada dinâmica do centro da coluna de plasma. Na análise realizada com os resultados do bolômetro foram utilizandas duas simulações independentes: uma para o HF e outra para o LF. Para a região do $\mathrm{HF}$ os valores obtidos foram de $r_{s}=(36 \pm 4) m m$ e $\sigma_{r}=(23 \pm 4) m m$, e para a região de $\mathrm{LF}, r_{s}=(50 \pm 3) m m$ e $\sigma_{r}=(15 \pm 3) \mathrm{mm}$.

Esses resultados mostraram-se coerentes com o fato desse precursor estar no limiar da superfície onde $q=1$, já que essa nova estrutura topológica se forma ao lado da região onde $q<1$, sendo que ela mesma possui $q>1$, como é previsto pelo modelo de Kadomtsev. Além disso, o fato do resultados obtidos em medidas de um mesmo fenômeno serem compatíveis quando feita em diagnósticos distintos é um forte indicativo da boa qualidade dos resultados.

Através do método de sobreposição da análise espectral dos resultados experimentais com os obtidos através da simulação, foi possível caracterizar a ilha magnética de modo $m=2$ com os seguintes parâmetros: para o HF foram obtidos $r_{s}=(122 \pm 4) \mathrm{mm}$ e $\sigma_{r}=(46 \pm 3) \mathrm{mm}$, e para a região de LF: $r_{s}=(110 \pm 3) m m$ e $\sigma_{r}=(54 \pm 3) \mathrm{mm}$.

Durante a formação do plasma no disparo 26277 foi possível caracterizar uma ilha magnética de modo $m=3$. Os parâmetros da ilha magnética observada foram: para o $\mathrm{HF} r_{s}=(143 \pm 4) m m$ e $\sigma_{r}=(22 \pm 4) m m$, e para a região de LF $r_{s}=(139 \pm 3) m m$ e $\sigma_{r}=(25 \pm 4) m m$

Além dos indícios do modo $m$ correspondente de cada uma dessas ilhas, apresentados pela análise do conjunto de sinais das bobinas de Mirnov, esses resultados também foram comparados com previsões teóricas calculadas a partir dos modelos MHD, modos de ruptura clássico e rotação de plasma. Em todas essas comparações os resultados obtidos experimentalmente são compatíveis com as previsões desses modelos.

Em resumo, o trabalho apresentado nesta dissertação mostra a viabilidade da utilização de medidas experimentais de potência irradiada pelo plasma, detectadas pelo diagnóstico de bolometria, para o estudo das instabilidades MHD no tokamak TCABR, utilizando para isso técnicas de análise espectral e a comparação com resultados simulados através de modelos simplificados. 


\subsection{Perspectivas e propostas futuras}

Melhorias podem ser efetuadas no sistema bolométrico e na metodologia de análise empregada neste trabalho. A seguir estão apresentadas algumas propostas de modificações do sistema e também dos programas desenvolvidos para simular as medidas de perturbações no TCABR.

A proposta imediata de aperfeiçoamento do bolômetro é ampliar a quantidade de canais bolométricos. Neste trabalho foram apresentados resultados de um sistema de 24 cordas colimadas por fendas de $1,9 \mathrm{~mm}$, o que corresponde a apenas metade dos fotodiodos disponíveis e uma resolução de aproximadamente $1,92 \mathrm{~cm}$. Realizando a ligação de todos os fotodiodos e utilizando uma fenda de $0,4 \mathrm{~mm}$ é possível compor um sistema de 48 canais com resolução de $1,02 \mathrm{~cm}$, como mostra a figura (6.1)

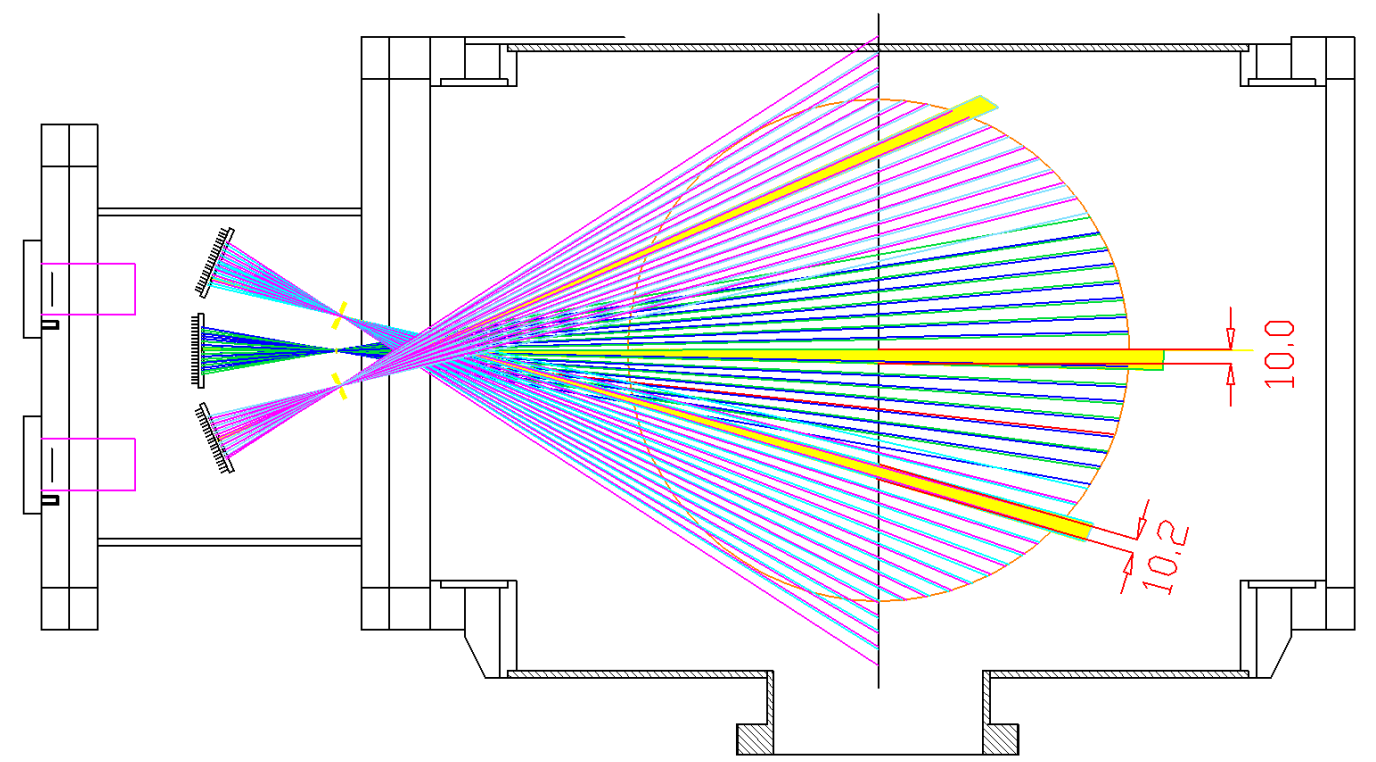

Figura 6.1: Esquema mostrando o projeto de ampliação de canais e melhora da resolução para o sistema bolométricos. As dimensões das aberturas no eixo central estão mostradas em milímetros.

O sistema com mais canais e melhor resolução favorece a caracterização de modos perturbativos no plasma. A figura (6.2) mostra os resultados da análise de sinais simulados de um modo $m=1$ gaussiano para um sistema com 24 cordas e outro com 48 cordas.

Outra proposta, que demanda mais tempo e recursos, é a construção de um sistema bolométrico de cordas horizontais, de modo a monitorar todo o plano meridional da coluna de plasma. A proposta seria construir uma nova câmara, com novos sensores e amplificadores. 


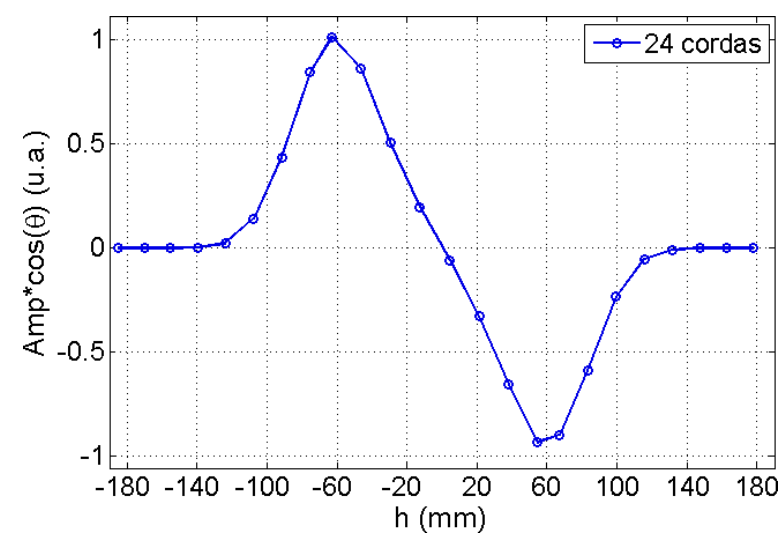

(a)

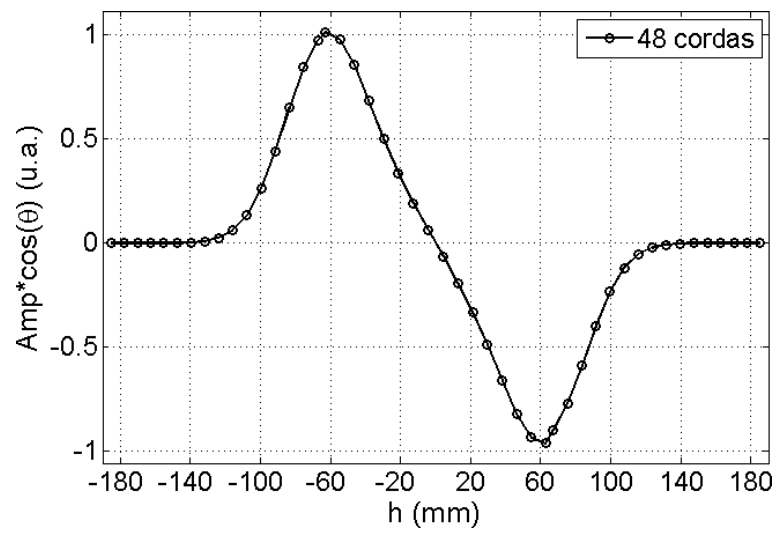

(b)

Figura 6.2: Análise espectral de sinais simulados para um sistema com 24 cordas em (a) e 48 cordas em (b).

Uma nova câmara horizontal proporcionaria a possibilidade de estudar as ilhas magnéticas sem a interferência dos efeitos de deslocamento de Shafranov e diferença na largura da ilha causada pela diferença no campo toroidal. Além disso, utilizando os sinais provenientes das duas câmaras é possível obter o perfil radial de emissividade, através de técnicas de tomografia.

Através de uma análise mais sofisticada, utilizando esse sistema tomográfico seria possível reconstruir o perfil poloidal das perturbações, como foi feito por Savrukhin para o caso de ilhas magnéticas de modos poloidais $(m)$ altos [50].

Por fim, é necessário desenvolver um estudo sobre as incertezas envolvidas em todo o processo de caracterização das instabilidades, desde as incertezas instrumentais até a análise estatística do ajuste dos resultados simulados sobre os experimentais.

A eletrônica geral do sistema interfere nos resultados finais do experimento. Essa interferência se dá de diversas maneiras como, por exemplo, não preservando a fase real relativa entre os sinais de diagnósticos diferentes, atrasando temporalmente os sinais em relação ao sistema de aquisição, aplicando diferentes valores de ganho para os diferentes canais entre outros. Normalmente os efeitos desses problemas não são muito grandes, entretanto provocam erros sistemáticos e devem ser estudados, para que se conheçam as limitações do instrumento de trabalho.

Um estudo muito importante que deve ser feito ainda é analisar a dependência do ruído nos resultados experimentais. Para realizar este estudo é possível utilizar a simulação de sinais com a introdução de diferentes níveis de ruído. Esse ruído provoca variação estatística na análise que se reflete em um erro nos parâmetros ajustados no final do procedimento. 
A proposta é analisar a relação entre o ruído do sinal de entrada e o erro nos parâmetros ajustados. Com isso é possível determinar não apenas o erro estatístico dos parâmetros experimentais devido ao nível de ruído do sistema, mas também fazer previsões sobre a incerteza dos sinais caso o ângulo de visada seja reduzido, como por exemplo, utilizando uma fenda menor.

A última fonte de incertezas a ser estudada é a proveniente do ajuste dos resultados simulados aos dados experimentais. Como ainda não existe um método automatizado para realizar esse ajuste, por exemplo, através da minimização dos resíduos não é possível obter nenhuma informação sobre a qualidade do ajuste realizado no procedimento descrito neste trabalho.

Para determinar resultados com incertezas baseadas em uma estatística sólida é necessário um programa iterativo, que simule os resultados, determine os parâmetros e, baseado nesses resultados, realize uma nova simulação até convergir para o melhor valor possível.

Com a finalidade de confirmar os resultados através de medidas de sistema independente, é possível realizar as medidas de posição e largura de ilhas magnéticas utilizando as medidas do diagnóstico ECE. Esse tipo de medida já foi realizada no tokamak TCABR pelo Dr. António M. M. Fonseca em seu trabalho de doutoramento [55]. 


\section{Apêndice A}

\section{Sistema de coordenadas cilíndricas}

O sistema de coordenadas cilíndricas é extremamente utilizado em física de plasmas e, em muitos casos, a utilização deste sistema simples nos permite obter modelos que descrevem bem os resultados experimentais obtidos em tokamaks, principalmente nos que possuem grande razão de aspecto.

As coordenadas cilíndricas se relacionam com as cartesianas da forma que segue:

$$
\left\{\begin{array}{l}
x=\rho \sin (\varphi) \\
y=\rho \cos (\varphi) \\
z=z
\end{array}\right.
$$

Com isso é possível escrever o vetor posição $\vec{r}$ do sistema de coordenadas cartesianas:

$$
\vec{r}(x, y, z)=x \hat{i}+y \hat{j}+z \hat{k}
$$

em coordenadas cilíndricas:

$$
\vec{\rho}(\rho, \varphi, z)=\rho \sin (\varphi) \hat{i}+\rho \cos (\varphi) \hat{j}+z \hat{k}
$$

Utilizando o vetor posição, é possível calcular os fatores de escala para cada uma das coordenadas do sistema. O fator de escala é definido como:

$$
h_{i}\left(q_{1}, q_{2}, q_{3}\right)=\left\|\frac{\partial \vec{\rho}}{\partial q_{i}}\right\|
$$

Onde $h_{i}$ é o fator de escala referente a coordenada $q_{i}$. Para o sistema de coordenadas cilíndricas os fatores de escala são:

$$
h_{r}=1, \quad h_{\varphi}=\rho, \quad h_{z}=1
$$

Os fatores de escala, entre outras funções na geometria diferencial, são utilizados para determinar operadores diferencias em coordenadas específicas. O divergente de um campo vetorial $\vec{F}\left(q_{1}, q_{2}, q_{3}\right)$ é calculado da seguinte forma:

$$
\nabla \cdot \vec{F}=\frac{1}{h_{1} h_{2} h_{3}}\left(\frac{\partial\left(F_{1} h_{2} h_{3}\right)}{\partial q_{1}}+\frac{\partial\left(h_{1} F_{2} h_{3}\right)}{\partial q_{2}}+\frac{\partial\left(h_{1} h_{2} F_{3}\right)}{\partial q_{3}}\right)
$$


Onde $F_{i}=\vec{F} \cdot \hat{q}_{i}$. Utilizando, então, os fatores de escala (A.1) se obtém o divergente em coordenadas cilíndricas para um dado campo vetorial $\vec{F}=\vec{F}(\rho, \varphi, z)$ :

$$
\nabla \cdot \vec{F}=\frac{1}{\rho} \frac{\partial\left(\rho F_{\rho}\right)}{\partial \rho}+\frac{1}{\rho} \frac{\partial F_{\varphi}}{\partial \varphi}+\frac{\partial F_{z}}{\partial z}
$$

Outro operador diferencial que é possível determinar é o rotacional, obtido pela seguinte relação:

$$
\nabla \times \vec{F}=\frac{1}{h_{1} h_{2} h_{3}}\left|\begin{array}{ccc}
h_{1} \hat{q_{1}} & h_{2} \hat{q_{2}} & h_{3} \hat{q_{3}} \\
\frac{\partial}{\partial q_{1}} & \frac{\partial}{\partial q_{2}} & \frac{\partial}{\partial q_{3}} \\
h_{1} F_{1} & h_{2} F_{2} & h_{3} F_{3}
\end{array}\right|
$$

Então, o rotacional em coordenadas cilíndricas de uma função $\vec{F}(\rho, \varphi, z)$, é obtido calculando esse determinante para os fatores de escalas (A.1):

$$
\nabla \times \vec{F}=\left(\frac{\partial F_{z}}{\partial \varphi}-\rho \frac{\partial F_{\varphi}}{\partial z}\right) \frac{\hat{\rho}}{\rho}+\left(\frac{\partial F_{\rho}}{\partial z}-\frac{\partial F_{z}}{\partial \rho}\right) \hat{\varphi}+\left(\frac{\partial\left(\rho F_{\varphi}\right)}{\partial \rho}-\frac{\partial F_{\rho}}{\partial \varphi}\right) \frac{\hat{z}}{\rho}
$$

Para um dado um potencial $\phi=\phi(\rho, \varphi, z)$, o gradiente pode ser calculado através da seguinte relação:

$$
\nabla \phi=\frac{1}{h_{1}} \frac{\partial \phi}{\partial q_{1}} \hat{q_{1}}+\frac{1}{h_{2}} \frac{\partial \phi}{\partial q_{2}} \hat{q_{2}}+\frac{1}{h_{3}} \frac{\partial \phi}{\partial q_{3}} \hat{q_{3}}
$$

Com isso se determinar o gradiente em coordenadas cilíndricas:

$$
\nabla \phi=\frac{\partial \phi}{\partial \rho} \hat{\rho}+\frac{1}{\rho} \frac{\partial \phi}{\partial \varphi} \hat{\varphi}+\frac{\partial \phi}{\partial z} \hat{z}
$$




\section{Apêndice B}

\section{Radiometria}

A radiometia tem por objetivo descrever a transferência de energia radiânte entre a fonte e o detetor admitindo para isto ser válido o modelo geométrico de trajetórias retilíneas dos raios de luz e a conservação de energia ao longo do meio óptico. Como consequência disto, os efeitos de difração e interferência não são considerados. O estudo da transferência de energia entre o emissor e o receptor, quando as frequências da radição são restritas à resposta do olho humano, é chamada de fotometria.

Historicamente, como os dispositivos ópticos (câmera fotográfica) foram projetados para trabalhar na região visível do espectro, é conveniente expressar a resposta destes dispositivos em unidade fotométricas. Porém quando se utiliza detetores com respostas espectral mais ampla, como é o caso deste trabalho, é necessário utilizar as unidades radiométricas.

A radiação incoerente é caracterizada pela aleatoriedade dos valores de amplitude e fase das ondas que a compõem. Em uma fonte térmica a radiação é sempre incoerente, pois os diferentes elementos da fonte irradiam independentemente.

Em um tratamento rigoroso do fluxo radiativo, onde seja necessário levar em consideração a coerência da radiação, a abordagem do problema deve ser feita utilizando a teoria do eletromagnetismo, derivado das equações de Maxwell [56]. Essa abordagem, entretanto, é desnecessária para o tratamento da maioria dos problemas de radiometria, inclusive para os problemas envolvendo a radiação emitida por um plasma de fusão, que é essencialmente uma fonte térmica de radiação.

\section{B.1 Definições básicas}

A seguir são descritas algumas grandezas radiométricas cujos conceitos foram utilizados neste trabalho.

Energia radiante é o termo utilizado para designar toda a energia transferida, recebida ou emitida em forma de radiação eletromagnética. A unidade de medida é o Joule $(J)$.

A densidade de energia radiante é a medida da distribuição espacial de energia radiante, já que representa a quantidade de energia radiante contida em um elemento 
de volume. Essa densidade de energia está diretamente relacionada com a densidade de energia utilizada na termodinâmica e mecânica estatística [57]. Sua unidade é o Joule/metro ${ }^{3}\left(\mathrm{~J} / \mathrm{m}^{3}\right)$.

$$
u=\frac{d Q}{d V}
$$

Fluxo radiante ou potência radiante, é a taxa com que a energia radiante é transferida, recebida ou emitida por unidade de tempo. A unidade desta taxa de medida é o watt $(W)$ e é definida da através da expressão:

$$
\Phi=\frac{d Q}{d t}
$$

A irradiância é a taxa de potência radiante incidente em um elemento infinitesimal de superfície projetada perpendicularmente ao raio de incidência. A grosso modo, a irradiância é uma medida da densidade ou da distribuição da radiação incidente em uma superfície $d$, projetada perpendicularmente ao raio de incidência da radiação, como mostrado na figura (B.1a). A irradiância é medida em watt $/$ metro $^{2}\left(W / m^{2}\right)$ :

$$
M=\frac{d \Phi}{d A_{\text {proj }}}=\frac{1}{\cos \left(\theta_{d}\right)} \frac{d \Phi}{d A_{d}}
$$

A convenção aceita para as grandezas radiométricas faz uma distinção entre a grandeza irradiância e emitância. Enquato a Irradiância mede a densidade de potência incidente em uma superfície, a emitância mede a densidade de potência emitida por uma superfície. Rigorosamente, a emitância é a taxa de potência radiante sendo emitida por um elemento infinitesimal de uma fonte " $s$ " projetada perpendicularmente ao raio de emissão. Matematicamente, a irradiância e a emitância são calculadas da mesma maneira:

$$
E=\frac{d \Phi}{d A_{\text {proj }}}=\frac{1}{\cos \theta_{s}} \frac{d \Phi}{d A_{s}}
$$

O ângulo sólido é um ângulo espacial que compreende um objeto visto a partir de um ponto dado. Para calcular o ângulo sólido basta dividir a porção de área observada " $A$ " pela distância ao quadrado até esta área. A unidade de ângulo sólido no SI é o esferorradiano $(s r)$ :

$$
d \Omega=\frac{d A}{r^{2}}
$$




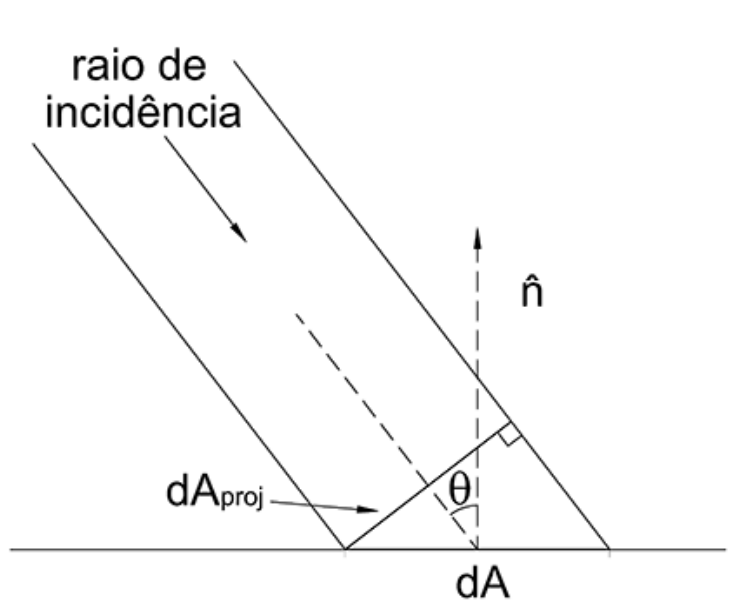

(a)

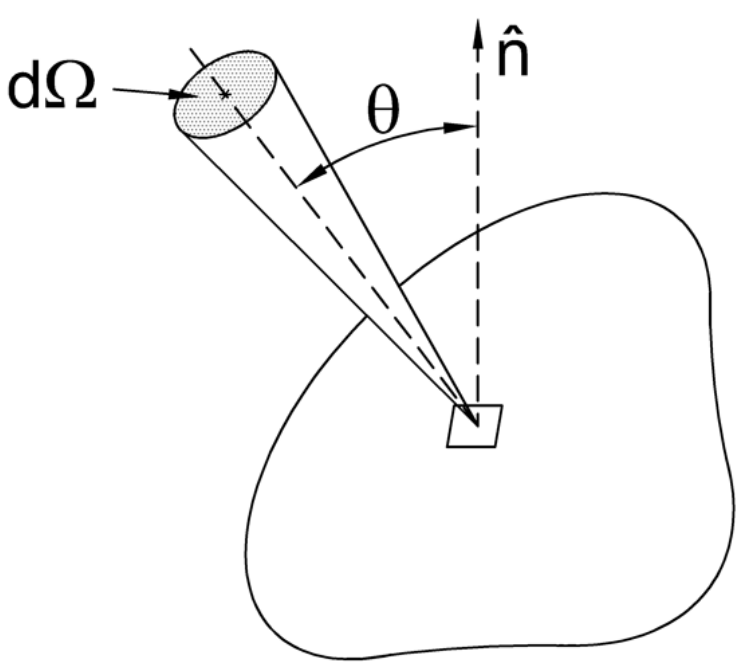

(b)

Figura B.1: Em (a) está representada a definição geométrica de área projetada e em (b) a radinância em uma superfície infinitesimal $d A$.

Intensidade radiânte, ou apenas intensidade, é a taxa de potência radiante emitida por uma fonte pontual através de um elemento de ângulo sólido. Sua unidade é $(W / s r)$ :

$$
I=\frac{d \Phi}{d \Omega}
$$

Para completar o quadro de grandezas radiométricas, basta definir a radiância, que é taxa de potência radiante emitida (ou recebida) por um elemento de área projetada, sob um ângulo sólido, como esta representado na figura (B.1b). A radiância pode ser definida tanto para a superfície de uma fonte, como para a de um receptor de radiação ou para qualquer ponto no caminho óptico da radiação. A radiância é medida em $\left(W s r^{-1} m^{-2}\right)$ :

$$
L=\frac{d^{2} \Phi}{d A_{\text {proj }} d \Omega}=\frac{1}{\cos \theta_{s}} \frac{d^{2} \Phi}{d A_{s} d \Omega}
$$

\section{B.2 Transferência de potência radiânte}

A grandeza definida como radiância tem um papel importante em problemas de radiometria pois, em um sistema óptico característico, a propagação da radiância é conservada. Esse fato é conhecido como Teorema da Conservação da Radiância para Meios Homogêneos [58], cujo enunciado é: 
Em um meio sem perdas, isotrópico, homogêneo, para um sistema óptico perfeito (sem aberrações) e ignorando efeitos de interferência e difração, a radiância é conservada ao longo de um raio que atravessa esse sistema óptico.

Supondo um sistema onde este teorema seja válido, a transferência de energia radiante de um elemento de superfície $S_{1}$ para um elemento $S_{2}$, pode ser escrita através da definição de radiância para cada elemento sendo que, $L_{12}$ é a radiância do elemento $S_{1}$ que aponta direção do elemento $S_{2}$ e $L_{21}$ que aponta na direção contrária:

$$
\Delta \Phi=d \Phi_{12}-d \Phi_{21}=\frac{\left(L_{12}-L_{21}\right) \cos \theta_{1} \cos \theta_{2} d A_{1} d A_{2}}{r_{12}^{2}}
$$

onde $\theta_{1}$ e $\theta_{2}$ são os ângulos entre o raio $r_{12}$ e as normais as superfícies $S_{1}$ e $S_{2}$ respectivamente, como está mostrado na figura (B.2). A radiação total transferida entre as duas superfícies é dada pela integral sobre ambas as áreas:

$$
\Phi=\int_{A_{1}} \int_{A_{2}} \frac{\left(L_{12}-L_{21}\right) \cos \theta_{1} \cos \theta_{2}}{r_{12}^{2}} d A_{1} d A_{2}
$$

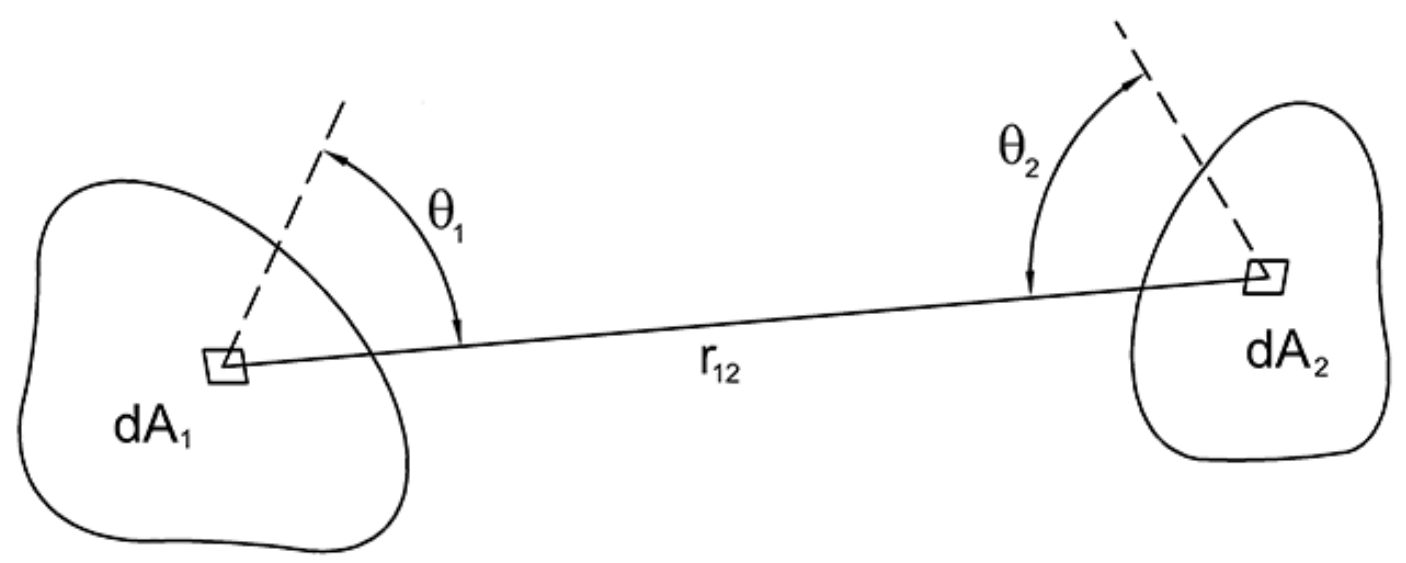

Figura B.2: Potência radiânte transferido entre os elementos de superfície $d A_{1}$ e $d A_{2}$.

A equação (B.9) descreve a transferência de potência radiante entre duas fontes. No caso particular de uma fonte e um receptor, a potência radiante emitida pelo receptor deve ser zero por definição. Por conta disso a radiância da superfície receptora deve ser zero.

Por exemplo, se a superfície que contém o elemento $d A_{2}$ for um receptor então $L_{21}=0$. Nesse caso é possível reescrever a equação (B.9) de uma forma particular: 


$$
\Phi=\int_{A_{d}} \int_{A_{f}} \frac{L \cos \theta_{d} \cos \theta_{f}}{r_{f d}^{2}} d A_{f} d A_{d}
$$

onde os parâmetros com índices $d$ se referem ao detector e com índices $f$ à fonte de energia radiante. Como a radiância é proveniente apenas da fonte, o índice pode ser omitido.

Um conceito muito importante que ajuda a simplificar os cálculos de transferência de potencia radiante é o de fonte lambertiana. Uma fonte lambertiana é uma fonte cuja radiância é uniforme em toda a superfície e a emissão ocorre de maneira uniforme em todas as direções. Isso implica que a radiância não possui nenhuma dependência espacial, e a equação (B.10) pode ser escrita como:

$$
\Phi=L \int_{A_{d}} \int_{A_{f}} \frac{\cos \theta_{d} \cos \theta_{f}}{r_{f d}^{2}} d A_{f} d A_{d}
$$

No caso da radiância transferida entre superfícies circulares em que o mesmo eixo óptico transpassa o centro das duas superfícies, como está mostrado na figura (B.3a), é possível calcular a solução exata da integral mostrada na equação (B.11):

$$
\begin{aligned}
\Phi & =L \int_{A_{d}} \int_{A_{f}} \frac{d A_{f} d A_{d}}{r_{f d}^{2}} \\
\Phi & =\frac{2 L\left(\pi R_{d} R_{f}\right)^{2}}{R_{d}^{2}+R_{f}^{2}+r_{f d}^{2}+\left[\left(R_{d}^{2}+R_{f}^{2}+r_{f d}^{2}\right)^{2}-4 R_{d}^{2} R_{f}^{2}\right]^{1 / 2}}
\end{aligned}
$$

onde $R_{f}$ e $R_{d}$ são o raio da fonte e raio do detector, respectivamente.

Esse resultado pode ser aproximado para um caso onde as somas dos quadrados dos raios e da distância é maior que o produto dos raios, ou seja, $\left(R_{d}^{2}+R_{f}^{2}+r_{f d}^{2}\right) \gg 2 R_{f} R_{d}$, então:

$$
\Phi \cong \frac{L\left(\pi R_{d} R_{f}\right)^{2}}{R_{d}^{2}+R_{f}^{2}+r_{f d}^{2}}
$$

Essa é uma boa aproximação para o caso onde a distância entre o detector e a fonte é muito maior que as dimensões de suas superfícies, então pode ser escrita de uma forma mais simplificada:

$$
\Phi \cong \frac{L\left(\pi R_{d} R_{f}\right)^{2}}{r_{f d}^{2}}=\frac{L A_{d} A_{f}}{r_{f d}^{2}}
$$




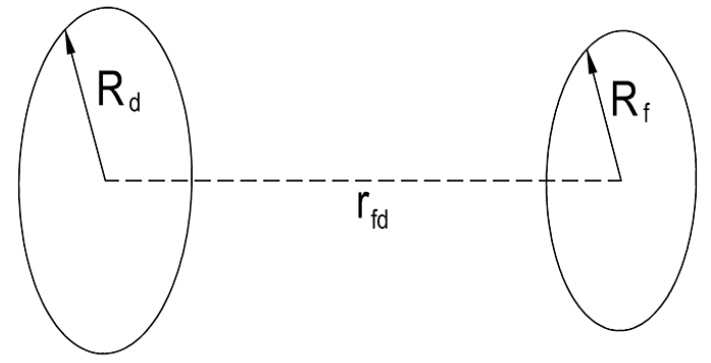

(a)

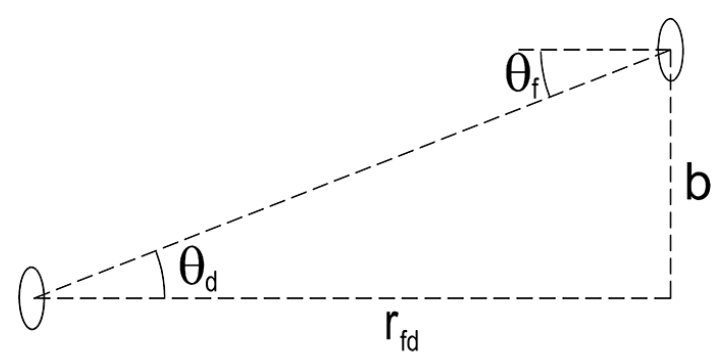

(b)

Figura B.3: Representação da transferência de potência radiante entre duas superfícies circulares, em (a) normais e centradas no mesmo eixo e, em (b), normais porém com um deslocamento $b$ entre seus eixos.

Um caso de interesse é quando as superfícies do detector e da fonte são paralelas, porém seus eixos são deslocados de uma distância $b$, como é mostrado na figura (B.3b). Nesse sistema de irradiância fora de eixo, como as superfícies são paralelas, os ângulos $\theta_{d}$ e $\theta_{f}$ são iguais e podem ser escritos como:

$$
\theta_{f}=\theta_{d}=\theta=\arctan \left(\frac{b}{r_{f d}}\right)
$$

Em um caso onde as dimensões das superfícies emissora e detectora são muito pequenas comparadas à distância entre elas, é possível aplicar a equação (B.14) e, em um sistema de irradiância fora de eixo, as áreas projetadas são:

$$
\begin{aligned}
& A_{\text {fproj }}=A_{f} \cos \theta \\
& A_{\text {dproj }}=A_{d} \cos \theta
\end{aligned}
$$

e a distância entre as duas superfícies fica maior:

$$
s_{f d}=\frac{r_{f d}}{\cos \theta}
$$

Utilizando o mesmo raciocínio empregado no desenvolvimento da equação (B.14), é possível concluir que, para o sistema em questão:

$$
\Phi \cong \frac{L A_{d} A_{f}}{r_{f d}^{2}} \cos ^{4} \theta
$$


A equação (B.16) é conhecida como Lei do cosseno à quarta. Como a energia radiante se conserva em um sistema óptico sem perdas, essa aproximação também pode ser usada para sistemas de irradiância fora de eixo onde a fonte grande emita sobre um pequeno detector. Para calcular isso basta somar sobre todas as infinitesimais regiões da fonte.

\section{B.3 Correção geométrica para o bolômetro}

Uma característica que os sistemas ópticos em geral possuem é a sua capacidade de transmitir o fluxo radiativo. Essa característica deve ser definida de tal forma que independa das propriedades da fonte radiativa, ou seja, para um sistema óptico sem perdas, essa capacidade de transmitir o fluxo radiativo deve depender apenas da geometria do sistema [59].

Tratando-se de um sistema sem perdas, contendo apenas os elementos fonte e detector, a potência radiante total transmitida pelo sistema é dado pela equação (B.10) e, assumindo que a superfície emissora seja uma fonte Lambertiana de radiância $L$, a potência total será dada pela equação (B.11):

$$
\Phi=L \int_{A_{d}} \int_{A_{f}} \frac{\cos \theta_{d} \cos \theta_{f}}{r_{f d}^{2}} d A_{f} d A_{d}
$$

Que também pode ser escrita como:

$$
\Phi=L g
$$

onde $g$, chamado de étendue ou fator geométrico do sistema, é definido como:

$$
g=\int_{A_{d}} \int_{A_{f}} \frac{\cos \theta_{d} \cos \theta_{f}}{r_{f d}^{2}} d A_{f} d A_{d}
$$

Esta é uma grandeza puramente geométrica e é uma medida da capacidade do sistema de coletar a potência radiante proveniente da fonte radiativa. A potência total transmitida pelo sistema pode ser calculada multiplicando a radiância $L$ da fonte pelo étendue $g$, como apresentado na equação B.18.

O que se deseja medir através do sistema óptico é a radiância da fonte, que é o objeto de estudo. Para medidas absolutas e relativas da radiância é necessário, então, considerar o fator geométrico de correção, pois alguns sinais podem ser mais atenuados do que outros.

O bolômetro instalado no tokamak TCABR possui três câmaras distintas, cada uma 
com uma fenda e 8 detectores posicionados linearmente a uma distância $d$ da fenda. O sistema óptico que descreve a transferência de potência radiante entre a fenda e um detector é um sistema fora de eixo. A potência radiante transferida por um sistema assim é dada pela equação (B.16), que agora pode ser escrita em função do fator geométrico:

$$
\Phi=L g=L \frac{A_{d} A_{f}}{r_{f d}^{2}} \cos ^{4} \theta
$$

então:

$$
g=\frac{A_{d} A_{f}}{r_{f d}^{2}} \cos ^{4} \theta
$$

Esse é o mesmo caso do sistema de tomografia de raios $\mathrm{X}$ mole utilizado no tokamak RTP [60] e também no sistema de tomografia de emissão H-alpha no tokamak TCABR [61]. Existem casos, entretanto, onde o array de detectores é circular, o que mantém sempre a mesma distância $d$ entre o detector e a fenda e $g \propto \cos \theta$ e não a $\cos ^{4} \theta$, o que reduz o efeito geométrico de atenuação para os sensores mais externos da câmara. Esse é o caso da câmara de tomografia de raios X duros do tokamak TORE SUPRA [62].

A figura (B.4) mostra um esquema das grandezas utilizadas para calcular o fator geométrico expresso na equação (B.21).

Para um elemento de área do detector $\left(x_{d}, y_{d}\right)$ e um elemento de área da fenda $\left(x_{f}, y_{f}\right)$, de acordo com a figura (B.4), o termo $\cos ^{4} \varphi^{\prime}$ pode ser escrito como função de $x$ e $d$, onde $x$ é a distância do eixo de simetria até o centro do detector e $d$ a distância do centro da fenda até o centro do array de detectores.

$$
\cos ^{4} \varphi^{\prime}=\frac{d^{4}}{\left[\left(x+x_{d}-x_{f}\right)^{2}+\left(y_{d}-y_{f}\right)^{2}+d^{2}\right]^{2}}
$$

Abrindo o termo no denominador e colocando $1 /\left(x^{2}+d^{2}\right)^{2}$ em evidência:

$$
\cos ^{4} \varphi^{\prime}=\frac{d^{4}}{\left(x^{2}+d^{2}\right)^{2}} \cdot \frac{1}{\left[1+\frac{2 x\left(x_{d}-x_{f}\right)+\left(x_{d}-x_{f}\right)^{2}+\left(y_{d}-y_{f}\right)^{2}}{x^{2}+d^{2}}\right]^{2}}
$$




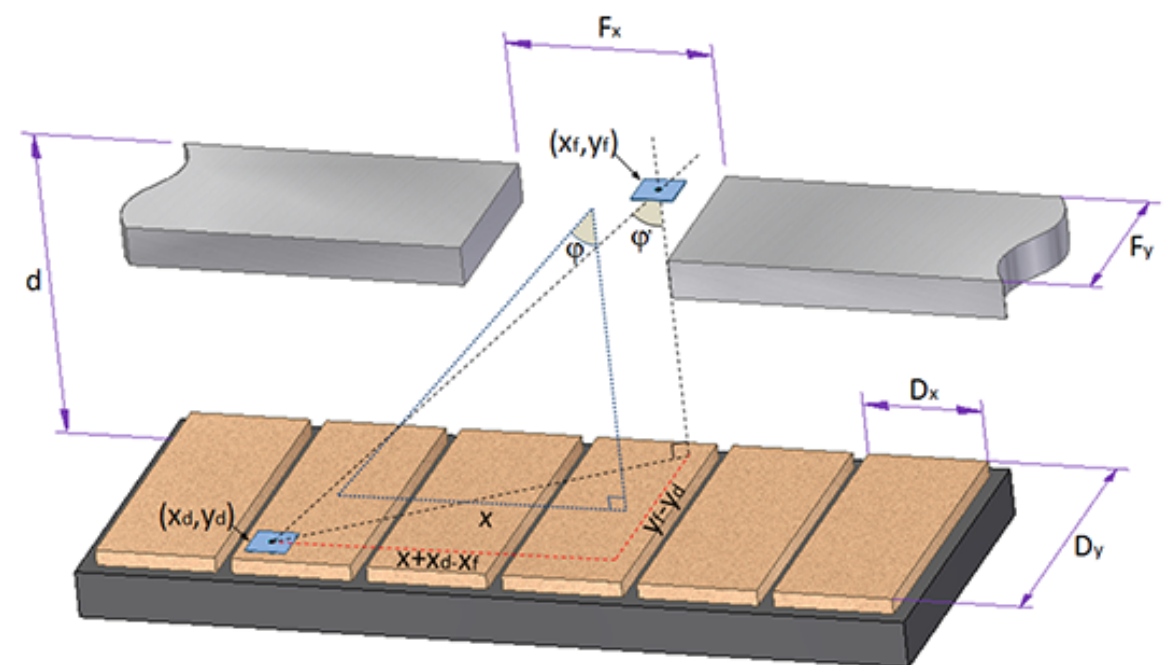

Figura B.4: Representação da fenda, de área $A_{f}=F_{x} \times F_{y}$, e do array de fotodiodos. Cada fotodiodo possui área $A_{d}=D_{x} \times D_{y}$. O ângulo $\theta$ é definido do centro de um detector com relação ao eixo central e $x$ é a distância de cada detector até esse mesmo eixo.

O primeiro termo $\frac{d^{4}}{\left(x^{2}+d^{2}\right)^{2}}=\cos ^{4} \varphi$, e como $d^{2}+x^{2} \gg x x_{d}$, o segundo termo pode ser expandido em uma série de Maclaurin,

$$
\frac{1}{(1+\tau)^{2}}=1-2 \tau+3 \tau^{2}-4 \tau^{3}+\ldots
$$

portanto:

$$
\begin{aligned}
\cos ^{4} \varphi^{\prime}= & \cos ^{4} \varphi\left[1-2\left(\frac{2 x\left(x_{d}-x_{f}\right)+\left(x_{d}-x_{f}\right)^{2}+\left(y_{d}-y_{f}\right)^{2}}{x^{2}+d^{2}}\right)+\right. \\
& \left.+3\left(\frac{2 x\left(x_{d}-x_{f}\right)+\left(x_{d}-x_{f}\right)^{2}+\left(y_{d}-y_{f}\right)^{2}}{x^{2}+d^{2}}\right)^{2}-\ldots\right]
\end{aligned}
$$

A contribuição média $\left\langle\cos ^{4} \varphi^{\prime}\right\rangle$ é dada pela integral sobre as áreas do detector e da fenda, normalizado pelas mesmas:

$$
\left\langle\cos ^{4} \varphi^{\prime}\right\rangle=\int_{-\frac{D_{x}}{2}}^{\frac{D_{x}}{2}} \int_{-\frac{D_{y}}{2}}^{\frac{D_{y}}{2}} \int_{-\frac{F_{x}}{2}}^{\frac{F_{x}}{2}} \int_{-\frac{F_{y}}{2}}^{\frac{F_{y}}{2}} \frac{\cos ^{4} \varphi^{\prime}}{D_{x} D_{y} F_{x} F_{y}} d x_{d} d x_{f} d y_{d} d y_{f}
$$

Através da contribuição média para cada detector, obtida pela substituição da equação (B.23) na (B.24) e posterior integração, se obtém um valor para o fator de correção geométrica. O fator geométrico, obtido até quarta ordem de $\left(\frac{D_{x}, D_{y}, F_{x}, F_{y}}{d}\right)$, é: 


$$
\begin{gathered}
g=\frac{A_{f} A_{d}\left\langle\cos ^{4} \varphi^{\prime}\right\rangle}{4 \pi d^{2}} \\
g=\frac{A_{f} A_{d} \cos ^{4} \varphi}{4 \pi d^{2}}\left[1-\frac{D_{x}^{2}+D_{y}^{2}+F_{x}^{2}+F_{y}^{2}}{6 d^{2}} \cos ^{2} \theta+\left(D_{x}^{2}+F_{x}^{2}\right)\left(\frac{\sin ^{2} \theta \cos ^{2} \theta}{d^{2}}\right)+\right. \\
+\frac{\cos ^{4} \theta}{d^{4}}\left(\frac{3}{80}\left(D_{x}^{4}+D_{y}^{4}+F_{x}^{4}+F_{y}^{4}\right)+\frac{1}{8}\left(D_{x}^{2} F_{x}^{2}+D_{y}^{2} F_{y}^{2}\right)+\right. \\
\left.+\frac{1}{24}\left(D_{x}^{2} D_{y}^{2}+D_{x}^{2} F_{y}^{2}+F_{x}^{2} D_{y}^{2}+F_{x}^{2} F_{y}^{2}\right)\right)-\frac{3 \cos ^{4} \theta \sin ^{2} \theta}{d^{4}} \times \\
\left.\times\left(\frac{D_{x}^{4}+F_{x}^{4}}{5}+\frac{\left(7 D_{x}^{2} F_{x}^{2}+D_{x}^{2} D_{y}^{2}+F_{x}^{2} D_{y}^{2}+F_{x}^{2} F_{y}^{2}+D_{x}^{2} F_{y}^{2}\right)}{9}\right)\right]
\end{gathered}
$$




\section{Referências Bibliográficas}

[1] SMITH, C. L. The need for fusion. Fusion Engineering and Design, v. 74, n. 1, p. 3-8, 2005.

[2] DE SENE, E. e MOREIRA, J. C. Geografia. São Paulo: Editora Scipione, $1^{a}$ ed., 1998.

[3] BORTOLETO, E. M. A implantação de grandes hidrelétricas: desenvolvimento, discurso e impactos. Geografares, v. 2, p. 53-62, 2001. Disponível em: http: //periodicos.ufes.br/geografares/article/view/1140/853 (Acessado em: 15 jul. 2013).

[4] RÜHL, C. BP Statistical Review of World Energy: June 2012. Disponível em: http://bp.com/statisticalreview. (Acessado em: 01 abr. 2013).

[5] World Nuclear Association. Safety of Plants. Disponível em: http://www . world-nuclear.org/. (Acessado em: 11 jun. 2013). .

[6] ITER. Disponível em: http://www.iter.org/sci/fusionfuels. (Acessado em: 11 jun. 2013). .

[7] JET Team. Fusion energy production from a deuterium-tritium plasma in the JET tokamak. Nuclear Fusion, v. 32, n. 2, p. 187-203, 1992.

[8] CAP, F. F. Handbook on Plasma Instabilities, volume 1. Academic Press, 1976.

[9] LAWSON, J. D. Some criteria for a power producing thermonuclear reactor. Proc. Phys. Soc. B, v. 70, n. 6, p. 6-10, 1957.

[10] ROSEnBluth, M. N., RUThERFORD, P. H. Fusion: Tearing Modes in Tokamaks, volume 1. Parte A, Nova Iorque: Academic Press, 1981.

[11] NASCIMENTO, I. C. et al. Preliminary results from the TCABR tokamak. Em 1999 IAEA Technical Committee Meeting on Research Using Small Fusion Devices, Outubro de 1999.

[12] Laboratório Associado de Plasma - INPE. Disponível em: http://www.plasma. inpe.br/LAP_Portal/LAP_Sitio/Texto/Toroide_Esferico.htm. (Acessado em: 05 abr. 2013). .

[13] CHEN, F. F. Introduction to plasma physics and controlled fusion. Springer, $3^{a}$ ed., 1984.

[14] WILSON, H. R. Neoclassical Tearing Modes. Transactions of fusion science and technology, v. 49, p. 155-163, 2006.

[15] CLASSEN, I. G. J. Imaging and Control of Magnetic Islands in Tokamaks. Tese (Doutorado em Física), Technische Universiteit Eindhoven, 2007.

[16] WESSON, J. Tokamaks. Claredon Press, Oxford, 2004. 
[17] La Haye, R. J. Neoclassical tearing modes and their control. Physics of Plasmas, v. 13, n. 5, p. 055501:1-18, 2006.

[18] S. V. Mirnov, I. B. Semenov. Investigation of the instabilities of the plasma string in the Tokamak-3 system by means of a correlation method. Soviet Atomic Energy, v. 30, n. 1, p. 22-29, 1971.

[19] BATEMAN, G. MHD Instabilities. Massachusetts: MIT Press, $1^{a}$ ed., 1978.

[20] BISKAMP, D. Magnetic reconnection in plasmas. Reino Unido: Cambridge University Press, $1^{a}$ ed., 2000.

[21] STRAUSS, H. R., MONTICELlO D. A.,ROSENBLUTH, M. N. Nonlinear helical pertubations of a tokamak. The Physics of Fluids, v. 20, n. 3, p. 390-395, 1977.

[22] KADOMTSEV, B. B. Tokamak Plasma: A Complex Physical System. GrãBretanha: IOP Publishing Ltd, $1^{a}$ ed., 1992.

[23] HUTCHINSON, I. H. Principles of plasma diagnostics. Cambridge University Press, $2^{a}$ ed., 2005.

[24] HARLEY, T. R. et al. TFTR Mirnov coils analisys with toroidal effects as plasma startup. Nuclear Fusion, v. 29, n. 5, p. 771-785, 1989.

[25] OLSCHEWSKI, E. A. S. Construção e utilização de um limitador ergódico magnético no tokamak TCABR. Tese (Doutorado em Física), Universidade de São Paulo, 2004.

[26] VAN MILLIGEN, B. P. et al. Gradients of electron temperature and density across $\mathrm{m}=2$ magnetic islands in RTP. Nuclear Fusion, v. 33, n. 8, p. 1119-1132, 1993.

[27] GILL, R. D. Plasma physics and nuclear fusion research. Londres: Academic Press, $1^{a}$ ed., 1981.

[28] VON GOELER, S., STODIEK, W., SAUTHOFF, N. Studies of Internal Disruptions and $m=1$ Oscillations in Tokamak Discharges with Soft-X-Ray Techniques. Nuclear Fusion, v. 33, n. 20, p. 1201-1203, 1974.

[29] KADOMTSEV, B. B. Disruptive instability in tokamaks. Sov. J. Plasma Phys, v. 1, n. 5, p. 389-390, 1975.

[30] SPITZER, L. e HÄRM, R. Transport Phenomena in a Completely Ionized Gas. Physical Review, v. 89, n. 5, p. 977-981, 1953.

[31] ROSEnBluth, M. N., DAGAZIN, R. Y., RUTHERFORD, P. H. Nonlinear properties of the internal $m=1$ kink instability in the cylindrical tokamak. Phys. Fluids, v. 16, n. 11, p. 1894-1903, 1973.

[32] MANHEIMER, W. M., LASHMORE-DAVIES, C. MHD instabilities in simple plasma configuration. Naval Research Laboratory, 1984.

[33] MANHEIMER, W. M., LASHMORE-DAVIES, C. MHD and microinstabilities in confined plasma. Nova Yorque: Adam Higler, $1^{a}$ ed., 1989. 
[34] SYKES, A. e WESSON, J. A. Relaxation Instability in tokamaks. Physical Review letters, v. 37, n. 3, p. 140-143, 1976.

[35] JONES, R. C. The General Theory of Bolometer Performance. J. Opt. Soc. Am., v. 43, n. 1, p. $1-14,1953$.

[36] RIEKE, G. H. Detection of light. Cambridge: Cambridge University Press, $1^{a}$ ed., 1994.

[37] RUNYAN, M. C. et al. ACBAR: The Arcminute Cosmology Bolometer Array Receiver. ApJS, v. 149, n. 2, p. 265-287, 2003.

[38] SZE, S. M. Physics of semiconductor devices. Nova Iorque: John Wiley \& Sons, $2^{a}$ ed., 1981.

[39] GRAEME, J. G. Photodiode Amplifiers. Nova Iorque: McGraw-Hill, $1^{a}$ ed., 1996.

[40] BELLINTANI, V. Jr. Bolômetro metálico para medida da potência irradiada no Tokamak TCABR. Dissertação (Mestrado em Física), Universidade de São Paulo, 1999.

[41] BELLINTANI, V. Jr. Diagnóstico Bolométrico no TCABR. Tese (Doutorado em Física), Universidade de São Paulo, 2005.

[42] Opto Diode Corporation. AXUV/SXUV/UVG: Salient Applications. Disponível em: http://www.ird-inc.com/brochure/IRD2011.pdf. (Acessado em: 01 fev. 2013). .

[43] NASCIMENTO, I. C. et al. Suppression and excitation of MHD activity with an electrically polarized electrode at the TCABR tokamak plasma edge. Nuclear Fusion, v. 47, n. 11, p. 1570-1576, 2007.

[44] BOIVIN, R. L. et al. High resolution bolometry on the Alcator C-Mod tokamak. Review of Scientific Instruments, v. 70, n. 1, p. 260-264, 1999.

[45] BOYLESTAD, R. L. ; NASHELSKY, L. Electronic Devices and Circuit Theodry. Nova Jersey: Prentice Hall, $6^{a}$ ed., 1996.

[46] FAGUNDES, A. N. ; de SÁ, W. P. ; COELHO, P. M. S. A. TCABR acquisition system. Fusion Engineering and Design, v. 48, n. 1, p. 213-218, 2000.

[47] de SÁ, W. P. Tokamak TCABR: Acquisition system, data analysis, and remote participation using MDSplus. Fusion Engineering and Design, v. 87, n. 12, p. 2199-2202, 2012.

[48] DREVAL, M. et al. Determination of radial location of rotating magnetic islands by use of poloidal soft x-ray detector arrays in the STOR-M tokamak. Review of Scientific Instruments, v. 82, n. 5, 2011.

[49] KORNEV, V. A. et al. Electron Density Modulation in Magnetic Islands in the TUMAN-3M Tokamak. Plasma Physics Reports, v. 31, n. 10, p. 803-808, 2005. 
[50] SAVRUKHIN, P. V. et al. Toroidal cartography of the high-m magnetic islands in tokamak plasma. Review of Scientific Instruments, v. 70, n. 1, p. 591-594, 1999.

[51] PORCELLI, F. et al. Modelling of macroscopic magnetic islands in tokamaks. Nuclear Fusion, v. 41, n. 9, p. 1207-1218, 2001.

[52] FONSECA, A. M. M. et al. Not completely flattened radial profile of the electron temperature in the vicinity of magnetic island in Tokamak Chauffage Alvén Brésilien. Physics of Plasmas, v. 12, n. 5, 2005.

[53] SHAFRANOV, V. D. Equilibrium of a toroidal pinch in a magnetic field. Soviet Atomic Energy, v. 13, n. 6, p. 524-529, 1963.

[54] SEVERO, J. H. F. et al. Plasma rotation measurement in small tokamak using an optical spectrometer and a single photomultiplier as detector. Review of Scientific Instruments, v. 78, n. 4, 2007.

[55] FONSECA, A. M. M. Emissão eletrociclotrônica no tokamak TCABR: Um estudo experimental. Tese (Doutorado em Física), Universidade de São Paulo, 2005.

[56] WOLF, E. Coherence and radiometry. J. Opt. Soc. Am., v. 68, n. 1, p. 6-17, 1987.

[57] KUNZE, H. J. Introduction to Plasma Spectroscopy. Berlin: Springer-Verlag, $1^{a}$ ed., 2009.

[58] BASS, M. Handbook of Optics, volume 2. Nova Yorque: McGraw-Hill INC, $2^{a}$ ed., 1995.

[59] BOYD, R. W. Radiometry and the detection of optical radiation. Nova Iorque: John Wiley \& Sons, $2^{a}$ ed., 1983.

[60] TANZI, C. P. Emission of soft X-ray and microwave radiation from tokamaks plasmas. Tese (Doutorado em Física), Rijksuniversiteit Utrecht, 1996.

[61] USURIAGA, O. C. N. Tomografia de emissão H-alpha no tokamak TCABR. Tese (Doutorado em Física), Universidade de São Paulo, 2006.

[62] PEYSSON, Y. ; IMBEAUX, F. . Tomography of the fast electron bremsstrahlung emission during lower hybrid current drive on tore supra. Review of Scientific Instruments, v. 70, n. 10, p. 3987-4007, 1999. 